\section{4}

\title{
Modulation of macrophage inflammatory function through selective inhibition of the epigenetic reader protein SP140
}

Mohammed Ghiboub ${ }^{1,3,5}$, Jan Koster ${ }^{2}$, Peter D. Craggs ${ }^{4}$, Andrew Y.F. Li Yim ${ }^{3,6}$, Anthony Shillings ${ }^{4}$, Sue Hutchinson $^{4}$, Ryan P. Bingham ${ }^{4}$, Kelly Gatfield ${ }^{4}$, Ishtu L. Hageman ${ }^{1}$, Gang Yao ${ }^{7}$, Heather P. O'Keefe ${ }^{7}$, Aaron Coffin ${ }^{8}$, Amish Patel ${ }^{9}$, Lisa A. Sloan ${ }^{4}$, Darren J. Mitchell ${ }^{4}$, Laurent Lunven ${ }^{4}$, Robert J. Watson ${ }^{4}$, Christopher E. Blunt ${ }^{4}$, Lee A. Harrison ${ }^{4}$, Gordon Bruton ${ }^{4}$, Umesh Kumar ${ }^{3}$, Natalie Hamer ${ }^{3}$, John R. Spaull $^{4}$, Danny A. Zwijnenburg ${ }^{2}$, Olaf Welting ${ }^{1}$, Theodorus B.M. Hakvoort ${ }^{1}$, Johan van Limbergen ${ }^{1,5}$, Peter Henneman $^{6}$, Rab K. Prinjha ${ }^{3}$, Menno PJ. de Winther ${ }^{10,11}$, Nicola R. Harker ${ }^{3}$ II, David F. Tough ${ }^{12} \mathbb{I}^{\bigotimes}$, Wouter J. de Jonge ${ }^{1,13} q^{\square}$

${ }^{1}$ Tytgat Institute for Liver and Intestinal Research, Amsterdam Gastroenterology \& Metabolism, Amsterdam University Medical Centers, University of Amsterdam, the Netherlands.

${ }^{2}$ Department of Oncogenomics, Amsterdam University Medical Centers, University of Amsterdam and Cancer Center Amsterdam, Amsterdam, Netherlands.

${ }^{3}$ Immuno-Epigenetics, Adaptive Immunity Research Unit, GlaxoSmithKline, Medicines Research Centre, Stevenage, United Kingdom.

${ }^{4}$ Medicine Design, Medicinal Science and Technology, GlaxoSmithKline, Stevenage, United Kingdom.

${ }^{5}$ Department of Pediatrics, Division of Pediatric Gastroenterology \& Nutrition, Emma Children's Hospital, Amsterdam University Medical Centers, University of Amsterdam, the Netherlands.

${ }^{6}$ Department of Clinical Genetics, Genome Diagnostics Laboratory, Amsterdam Reproduction \&

Development, Amsterdam University Medical Centers, University of Amsterdam, the Netherlands.

${ }^{7}$ GlaxoSmithKline, Cambridge, Massachusetts, USA.

${ }^{8}$ Constellation Pharmaceuticals, Cambridge, Massachusetts, USA.

${ }^{9}$ WuXi AppTec, Cambridge, Massachusetts, USA.

${ }^{10}$ Department of Medical Biochemistry, Amsterdam University Medical Centers, University of Amsterdam, Amsterdam, Netherlands.

${ }^{11}$ Institute for Cardiovascular Prevention (IPEK), Munich, Germany.

${ }^{12}$ Adaptive Immunity Research Unit, GlaxoSmithKline, Medicines Research Centre, Stevenage, United Kingdom.

${ }^{13}$ Department of Surgery, University of Bonn, Bonn, Germany.

II Shared senior authorship.

${ }^{\circledR}$ Corresponding authors: w.j.dejonge@amsterdamumc.nl; david.f.tough@gsk.com. 


\section{Abstract}

Speckled $140 \mathrm{KDa}$ (SP140) is a nuclear body protein, mainly expressed in immune cells, which contains a SAND domain. Single nucleotide polymorphisms and epigenetic modifications in the SP140 locus have been linked to autoimmune and inflammatory diseases including Crohn's disease (CD). However, little is known about the cellular function of SP140; this is due in part to the fact that, unlike for other many other epigenetic proteins, no small molecule inhibitors have been available to investigate the biological role of SP140. We report the discovery of the first small molecule SP140 inhibitor (GSK761) and utilize this to elucidate SP140 function in innate immune cells. We show that SP140 is highly expressed in CD68 ${ }^{+}$CD mucosal macrophages and in in vitro-generated inflammatory macrophages. SP140 inhibition through GSK761 reduced monocyte differentiation into inflammatory macrophages and lipopolysaccharide (LPS)induced inflammatory activation, whilst inducing the generation of $\mathrm{CD}_{206}{ }^{+}$regulatory macrophages that mark anti-TNF remission induction in CD patients. ChIP-seq analyses revealed that SP140 preferentially occupies transcriptional start sites (TSS) in inflammatory macrophages, with enrichment at gene loci encoding pro-inflammatory cytokines/chemokines and inflammatory pathways. GSK761 specifically reduced SP140 binding and thereby expression of SP140-dependent downstream inflammatory genes. Notably, in CD14+ macrophages isolated from CD intestinal-mucosa, GSK761 inhibited the spontaneous expression of cytokines, including TNF. Together, this study identifies SP140 as a druggable epigenetic reader and therapeutic target for $\mathrm{CD}$.

\section{Introduction}

Although various therapeutic strategies provide benefit in Crohn's disease (CD), the unmet need remains high with only approximately $30 \%$ of patients maintaining long term remission ${ }^{1,2,3,4}$. Intestinal macrophages, which arise mainly from blood-derived monocytes, play a central role in maintaining gut homeostasis in health, but are also implicated as key contributors to $\mathrm{CD}^{5,6}$. These opposing activities are linked to the capacity of macrophages to take on different functional properties in response to environmental stimuli. Epigenetic processes play an important role in the regulation of macrophage differentiation and gene expression, mediated by DNA methylation and histone post-translational modification $^{7,8}$. As such, epigenetic mechanisms mediated through the activity of specific histone acetylases and deacetylases activity are implicated in CD pathogenesis ${ }^{9,10,11}$. $S P 140$ and $\mathrm{CD}^{16}$ while rare $S P 140$-associated variants have been identified in pediatric CD patients ${ }^{17}$. 
68 Further, we identified two differentially hyper-methylated positions at the SP140 locus in blood cells of

69 CD patients ${ }^{18}$, suggesting aberrant regulation of its expression. Although little is known about how SP140

70 may be functionally linked to CD, a recent study reported that SP140 knockdown in in vitro-generated

71 inflammatory macrophages results a decrease in levels of pro-inflammatory cytokines ${ }^{10}$. Lower expression

72 of SP140 in intestinal biopsies was correlated with an improved response to anti-TNF therapy in CD

73 patients ${ }^{10}$. Conversely, in biopsies from those who showed resistance to anti-TNF therapy, SP140 was

74 highly expressed ${ }^{10}$. Together, these previous findings suggest a role for SP140 in CD pathogenesis.

75 SP140 protein harbors both a bromodomain (Brd) and a PHD finger ${ }^{10,15}$. Since Brd and PHD domains are

76 capable of binding to histones, this suggests that SP140 might function as an epigenetic reader. Readers

77 are recruited to chromatin possessing specific epigenetic 'marks' and regulate gene expression through

78 mechanisms that modulate DNA accessibility to transcription factors (TFs) and the transcriptional

79 machinery ${ }^{19}$. Brds are tractable to small molecule antagonists, with selective inhibitors of several Brd-

80 containing proteins (BCPs) reported ${ }^{20}$. Such compounds have helped elucidate the function of their BCP

81 targets; for instance, multiple inhibitors targeting BRD2, BRD3 and BRD4 have been used to demonstrate

82 the role of these proteins in selectively regulating gene expression in the context of cancer and

83 inflammation ${ }^{9,21,22}$. To date, no inhibitors targeting SP140 have been reported.

84 Here, we describe the discovery of the first specific SP140 inhibitor and utilize this compound to

85 investigate the functional relevance of SP140 in CD pathogenesis, focusing on its role in macrophages.

86 We show that SP140 functions as an epigenetic reader in controlling the generation of an inflammatory

87 macrophage phenotype, and in regulating the expression of pro-inflammatory and CD-associated genes.

88 We show that GSK761 inhibits SP140 binding to an array of inflammatory genes and demonstrate its

89 efficacy in CD colon macrophages ex vivo, presenting evidence for SP140 as a target for regulating

90 inflammation in CD. In addition, this study suggests that SP140 inhibition may also serve to support anti-

91 TNF therapy in non-responder CD patients.

\section{Results}

Elevated SP140 expression in inflammatory diseases and mucosal macrophages of CD patients.

SP140 gene expression in a variety of cells and tissues was analyzed using an in-house GSK microarray 
and S1). Notably, an increase in $\mathrm{CD}^{+} 8^{+} \mathrm{SP} 140^{+}$but not $\mathrm{CD}^{+} 8^{+} \mathrm{SP} 140^{-}$macrophages was observed in $\mathrm{CD}$ inflamed colonic mucosa compared to normal control mucosa (Fig. 1e,f). Elevated SP140 expression was also found in other inflammatory conditions including in WBC of systemic lupus erythematosus and rheumatoid arthritis patients (Fig. 1b), and in inflamed tissues of appendicitis, sarcoidosis, psoriatic arthritis, rheumatoid arthritis, Hashimoto's thyroiditis and Sjogren's syndrome patients (Fig. S1). High expression of SP140 was also observed in chronic lymphocytic leukemia (Fig. 1b).

Next, we analyzed data set from a publicly available single-cell RNA-sequencing experiment ${ }^{23}$ of analysis identified 22 cluster blocks (Fig. 2a). Based on the expression of CD14, CD16 (FCGR3A), CD64 (FCGR1A), CD68, CD163 and CD206 (MRC1), we identified cluster 6 as containing monocytes, macrophages and dendritic cells (Fig. 2b,c), representing mononuclear phagocytes. Inflamed ileal biopsies contained more cells in cluster 6 as compared to uninflamed biopsies (Fig. S2). Interestingly, within cluster 6 the number of SP140-expressing cells was higher in inflamed ileal biopsies as well (Fig. 2d). In addition, the percentage of SP140 expressing cells in cluster 6 was higher in inflamed compared with uninflamed tissue, which coincides with an increased number of CD68-, CD64-CD14- and CD16expressing cells (Fig. 2e).

SP140 mediates inflammatory M1 macrophage function. Given the high SP140 expression in CD mucosal macrophages, we investigated whether SP140 is associated with inflammatory activation. Human $\mathrm{CD} 14^{+}$monocytes or THP-1 cells were differentiated into macrophages and then polarized into M1 and M2 phenotypes using IFN- $\gamma$ and IL-4 respectively or left without treatment (M0) (Fig. 3a). The polarization was verified by measuring gene expression of CD64 and CCL5 (markers of M1 macrophages) and CD206 and CCL22 (markers of M2 macrophages) (Fig. S3a,b). SP140 mRNA was expressed at significantly higher levels in M1 compared to M0 or M2 macrophages derived from primary monocytes (Fig. 3b) or from THP-1 cells (Fig. S3c). Protein staining showed increased numbers of SP140 proteincontaining speckles in the nucleus of M1 compared to M2 macrophages derived from both human monocytes (Fig. 3c) and THP-1 cells (Fig. S3d). LPS induced an increase in SP140 gene expression in M0 and M1 macrophages, along with enhanced CCL5 and decreased CCL22 gene expression (Fig. S3e). The expression levels of 13 other BCPs (SP140L, SP100, SP110, BRD2, BRD3, BRD4, BRD9, BRDT, BAZ2A, $B A Z 2 B, P C A F, E P 300$ and $C R E B B P$ ) showed no increase in M1 compared to M0 macrophages (Fig. 
To investigate SP140 function, we initially used siRNA-mediated knock-down to reduce SP140 expression in M1 macrophages, achieving approximately $75 \%$ reduction in mRNA (Fig. 3e) and a clear decrease in the number of SP140 protein-containing speckles (Fig. 3f). Knockdown seemed specific to SP140, as expression of related family members SP110 (Fig. S4b) and SP100 was not affected (Fig. S4b,c). After knockdown, cells were simulated with LPS or kept unstimulated (Fig. 3d). SP140 silencing led to a decrease in LPS-induced IL-6 and TNF mRNA and protein levels (Fig. 3g). After transcriptional profiling, principal component analysis (PCA) revealed that the variance was most associated with SP140 siRNA treatment in LPS-stimulated M1 macrophages (Fig. 3h). Downregulation of some key CDassociated genes, notably $C X C L 9, C E A C A M 1$ and $J A K 2$, was apparent amongst $S P 140$-siRNA-treated unstimulated macrophages, and IL2RA, TRIM69 and ADAM9 amongst SP140-siRNA LPS-stimulated macrophages (Fig. 3i). SP140 silencing affected common inflammatory pathways, such as TNF-signaling via NFKB, IFN- $\gamma$ response, inflammatory response (Fig. 3j) and cytokine-signaling (Fig. 3k).

The development of a selective inhibitor of SP140 (GSK761). To identify selective SP140 binding compounds, we utilized encoded library technology to screen the GSK proprietary collection of DNAlinked small molecule libraries ${ }^{29,30}$. Affinity selection utilizing a recombinant protein construct spanning the PHD and Brd domains of SP140 was carried out, leading to identification of an enriched building block combination in DNA Encoded Library 68 (DEL68) (Fig. 4a). Representative compounds of the identified three-cycle benzimidazole chemical series were synthesized, which yielded the small molecule, GSK761 (Fig. 4b). To quantify the interaction between GSK761 and SP140 (aa 687-867), the dissociation constant $\left(K_{\mathrm{d}}\right)$ was determined using a fluorescence polarization (FP) binding approach. A fluorophoreconjugated version of GSK761, GSK064 (Fig. 4c), was prepared and subsequently used to determine a $K_{\mathrm{d}}$ value of $41.07 \pm 1.42 \mathrm{nM}$ for the interaction with SP140 (aa 687-867) (Fig. 4d). To further validate this interaction, competition studies were carried out using GSK761 in a FP-binding assay configured using GSK064 and SP140 (aa 687-867). Competitive displacement of GSK064 from SP140 (aa 687-867) by GSK761 was observed, subsequently leading to the determination of an $\mathrm{IC}_{50}$ value of $77.79 \pm 8.27 \mathrm{nM}$ (Fig. 4e). Prior to utilizing GSK761 for cell-based binding studies to endogenous SP140, the cell penetration capacity of the compound was assessed using mass spectrometry and the methodology described by ${ }^{28}$. Concentration measurements showed that GSK761 had a $\mathrm{p} \Delta \mathrm{C}_{\text {total }}$ value of $1.45 \pm 0.21$ (data not shown), indicating that GSK761 permeates human cells and accumulates intracellularly by an order of magnitude, when compared to GSK761 free in solution. 
Western Blotting (Fig. 4f). Endogenous SP140 is observed as a doublet containing the four largest isoforms (predicted $86-96 \mathrm{KDa})^{10}$ while Halo-tagged SP140 exhibits a single band. The specificity of GSK761 for SP140 was profiled using the BROMOscan® Assay, in which DNA tagged BCPs were incubated with an increasing concentration of GSK761 or DMSO. Binding is assessed by measuring the amount of bromodomain captured in GSK761 vs DMSO samples by using an ultra-sensitive qPCR. There was evidence of low affinity interaction between GSK761 and several tested BCPs, with binding detected at concentrations $>21000 \mathrm{nM}$. However, no binding was detected at concentrations $\leq 21000 \mathrm{nM}$ indicating a high degree of specificity of GSK761 for SP140 (Supplemental table 2). us to test whether SP140 is required for the polarization to inflammatory macrophage phenotype. We first tested whether GSK761 demonstrated any toxicity in macrophages to determine the appropriate dose range. At $\leq 0.12 \mu \mathrm{M}$, GSK761 showed no cytotoxicity (Fig. S5a,b). To investigate the effect of GSK761 on macrophage polarization to inflammatory phenotype, M0 macrophages were treated with either DMSO or GSK761 for 3 days in presence of IFN- $\gamma$ or IL-4 (during the polarization to M1 and M2 macrophages, respectively). GSK761 enhanced mRNA expression of the anti-inflammatory marker CD206 in both M1 and M2 macrophages and decreased the pro-inflammatory marker CD64 in M1 macrophages (Fig. 5a). FACS analysis showed that GSK761-treatment prior to IFN- $\gamma$ (M1) polarization reduced CD64 ${ }^{+}$cells and CD64 protein expression (Fig. 5b) and increased CD206 ${ }^{+}$cells and CD206 protein expression (Fig. 5c). Adding GSK761 to the cells during IFN- $\gamma$ (M1) polarization lowered TNF (M1 polarization marker) gene expression in these cells compared to the control (Fig. S5c). Altogether, these data suggest that SP140 inhibition during M1 polarization biased differentiation towards a regulatory M2 phenotype.

We next assessed the effect of SP140 inhibition on the response of M1 polarized macrophages to inflammatory stimuli. LPS-stimulated M1 macrophages pretreated with GSK761 showed a strong reduction in secretion of IL-6, TNF, IL-1 $\beta$ and IL-12 (Fig. 5e) at concentrations where cytotoxicity was not observed $(0.04$ and $0.12 \mu \mathrm{M})$. When employing RNA transcriptional profiling using a customized qPCR array, SP140 inhibition was found to reduce the expression of many other pro-inflammatory cytokines and chemokines including GM-CSF, CCL3, CCL5 and CCL1 (Fig. 5d). may be an effective approach for IBD. Unfortunately, due to poor in vivo pharmokinetics (data not shown), GSK761 was not suitable to evaluate the effects of SP140 inhibition in in vivo animal models of colitis. To evaluate the impact of SP140 inhibition in human CD, CD14 mucosal macrophages were isolated from CD anti-TNF refractory patients' colonic-mucosa and then cultured in vitro with either 
DMSO or GSK761 for 4h. Spontaneous gene expression of TNF, IL6 and IL10 was strongly decreased in GSK761-treated macrophages, demonstrating that GSK761 inhibited their immune reactivity (Fig. 5f). Previous studies have demonstrated that successful anti-TNF therapy is associated with an increase in $\mathrm{CD}_{206}{ }^{+}$regulatory macrophages ${ }^{31}$ and a decrease in pro-inflammatory cytokines ${ }^{10}$ and SP140 expression ${ }^{10}$ in CD mucosa. Thus, our data suggests that SP140 inhibition could be also beneficial in supporting the anti-TNF therapy.

SP140 preferentially interacts with transcription start sites (TSS) and enhancer regions. SP140 aa, while methylation at lysine residue 4 (K4) led to substantially ( 30-fold) reduced affinity (Fig. S6b). K9 acetylation also resulted in lower affinity binding (4-5-fold), while SP140 binding was unaffected by either acetylation or methylation of K14 (Fig. S6c). Similar binding affinity was observed for unmodified $\mathrm{H} 3_{1-21}$ vs H3 $3_{1-18}$, while reduced (4-5-fold) but still significant SP140 binding was measured for H3 $3_{1-9}$ (Fig. S6c). Taken together, these data suggest that the SP140 Brd-PHD module functions as a reader for unmodified histone $\mathrm{H} 3$, with binding focused around the $\mathrm{N}$-terminal 9 aa.

To evaluate whether native SP140 is also capable of binding to histones, we used immobilized histone H3 peptides with varying modifications to precipitate proteins from nuclear extracts of anti-CD3/CD28stimulated HuT78 T cells and probed via Western blotting for the presence of SP140. SP140 was efficiently pulled down by un-modified $\mathrm{H} 3_{1-21}$ (Fig. 6a). Notably, $\mathrm{H} 3_{1-21}$ peptides bearing certain methylation and acetylation marks (K4me3, K9me3, K9ac and K14ac) were also capable of capturing native SP140 (Fig. 6a), despite the lower measured affinity of some of these for recombinant SP140 BrdPHD (see above). To evaluate whether SP140 interacts with histone H3 in a cellular setting, we utilized a NanoBRET system (Fig. S6d). NanoBRET is a proximity-based assay that can detect protein interactions by measuring energy transfer from a bioluminescent protein donor NanoLuc $®$ (NL) to a fluorescent protein acceptor HaloTag ${ }^{\circledR}(\mathrm{HT})$. This energy transfer was observed in the nuclei of HEK293 cells transfected with SP140-NL and Histone3.3-HT DNA, indicating close proximity of the two proteins. 
231 expression (RNA-seq) in the context of LPS-stimulation. In DMSO-treated, LPS-stimulated macrophages,

232 epigenome roadmap scan analysis revealed that the majority of SP140 occupancy was at strong

233 transcription associated-regions, enhancers and TSS regions (Fig. 6c). However, this occupancy was

234 decreased when the cells were pretreated with GSK761 at 1h (Fig. S6f) and 4h (data not shown) post LPS-

235 stimulation. Heatmap rank ordering of SP140 occupancy in unstimulated and LPS-stimulated M1

236 macrophages showed a strong SP140 enrichment at the TSS (Fig. 6d). The top 20 enriched genes

237 belonged mostly to those involved in the innate immune response, including TNF, ICAM4, IRF1, LITAF,

238 TNFAIP2 and NFKBIA (Fig. 6d). However, the most SP140-enriched gene FLOT1 (Fig. 6d) has been

239 reported to be strongly involved in tumorigenesis ${ }^{33}$. We found SP140 also to occupy active enhancers, as

240 marked by H3K27Ac in human macrophages by overlapping the publicly available H3K27Ac ChIP-seq

241 data (GSE54972) with our SP140 ChIP-seq dataset at 1h of LPS-stimulation (Fig. S6e). ChIP-qPCR

242 showed a strong reduction of SP140 occupancy at the TNF-TSS in GSK761-treated M1 macrophages,

243 which was reduced to that of unstimulated cells (Fig. 6e), correlating with the previously observed

244 reduced expression of TNF in GSK761-treated macrophages.

245 Following LPS-stimulation, we observed a marked increase in binding at the TSS of the top 1000 genes

246 occupied by SP140, reaching its maximum at 4h (Fig. 6f). GSK761-treatment prior to LPS-stimulation

247 strongly reduced SP140 occupancy at the TSS (Fig. 6f) associated with an altered LPS-induced gene

248 expression (Fig. 6g). PCA of RNA-seq data revealed a large separation in global gene expression between

249 DMSO- and GSK761-treated macrophages at both time points post of LPS-stimulation (4h and 8h) (Fig.

$2506 \mathrm{~g})$.

251 Gene Ontology and Reactome enrichment analysis of SP140-bound genes showed enrichment of genes

252 which participate in the processes of cytokine response and immune response that were inhibited through

253 GSK761 pre-exposure (Fig. 6h and S6g). To elucidate the regulatory pathways enriched by SP140 and

254 affected by GSK761, we carried out hallmark pathway analysis for differentially SP140 bound-genes

255 (DBGs) (Fig. 6i) and DEGs (Fig. 6j) upon DMSO- or GSK761-treatment at each time point of LPS-

256 stimulation. In DMSO-treated M1 macrophages, we found that SP140 binding is predominantly enriched

257 at many pathways typically defined as inflammatory such as TNF-signaling via NFKB, and inflammatory

258 response (Fig. 6i). However, this enrichment was no longer seen in GSK761-treated macrophages (Fig.

259 6i). Similar pathways were observed for DEGs and were downregulated in GSK761-treated macrophages,

260 especially at 4h (Fig. 6j). In addition, we observed an up-regulation of MYC targets and oxidative

261 phosphorylation gene sets in GSK761-treated macrophages, whereas these normally are down-regulated

262 because of the induction of aerobic glycolysis upon LPS-stimulation of macrophages (Fig. S7a) ${ }^{34}$. These 
data suggest SP140 as a critical regulator of genes involved in the inflammatory response and that

GSK761 can inhibit this response through displacing SP140 binding to TSS and enhancer regions.

SP140 preferentially controls the expression of specific gene sets involved in the innate immune

response. We next investigated the functional significance of inhibiting SP140 binding for gene

expression. Heatmap (Top 100) and volcano plots of DEGs after 4h LPS-stimulation demonstrated a

strong effect of GSK761 on gene sets that are involved in innate immune response such as the TNFAIP2, TAF1, TNF, LTA, and IRF1 was reduced (Fig. 7e). By conducting a focused TNF-signaling enrichment analysis (Fig. S7b) and R2 TSS-plot analysis (Fig. S7c), we illustrated a new set of DBGs including TFs (TNFAIP3, CEBPB, ATF4, MAP3K8, MAP2K3 and JUNB), cytokines (IL1 $\beta, I L 23 A)$ and adhesion molecules (ICAM1). Most of these genes were DEGs (Fig. S7d).

We next verified the impact of global reduced SP140 binding on gene expression by integrating the DBGs and the DEGs. Interrogating the top 1000 DBGs (at 1h or 4h LPS) for their gene expression (at $4 \mathrm{~h}$ or $8 \mathrm{~h}$ LPS), implicated genes that are involved in TNF-signaling pathway (NFKBIA, SOD2, LITAF, SGK1, $P N R C 1, I R F 1$ and $R N F 19 B$ ) and cytokine-mediated signaling pathway (For example: IL1ORA, NFKBIA, IRF1, SOD2, CAMK2D, IRF2 and ISG15) which showed the strongest concordant differential binding and expression (Fig. 7f and S8).

In addition to SP140 binding to chromatin, we speculated that SP140 may also interact with other TFs proteins to regulate gene expression. To this end, we performed homer known motif enrichment analysis (HKMEA) at DMSO_1h LPS (Fig. 7g). We also conducted a homo de novo motif discovery to define new DNA sequence motifs that are recognized specifically by SP140 (Fig. 7g). Interestingly, HKMEA suggests that SP140 may bind the same DNA sequence motifs recognized by certain TFs defined as key proteins in TNF-signaling via NFKB (ATF3, FOSL2, FOSL1, NFKB-p65-rel, JUNB and JUN-AP1) and of cytokine-mediated signaling pathway (BATF, NFKB-p65-rel, JUNB, IRF8 and IRF3) (Fig. 7g).

291 LPS-stimulation strongly recruits SP140 to multiple human leukocyte antigen (HLA) genes, including $292 \quad H L A-A, H L A-B, H L A-C, H L A-F, H L A-D P A$ and $H L A-D P B$ (Fig. S7e), binding which was strongly 293 reduced by GSK761. This indicates a role of SP140 in regulating antigen presentation-associated genes. 294 Notably, the Brd-containing protein 2 (BRD2) gene was occupied by SP140, and GSK761 reduced this 
binding and lowered BRD2 gene expression (Fig. S7e and table 5). BRD2 has been reported to play a key role in inflammatory response in murine macrophages and in inducing insulin resistance ${ }^{35}$.

Finally, we noticed that SP140 occupancy on TSS of chemokine activity genes was dramatically reduced by GSK761, inducing a reduced global chemokine activity at mRNA level (Fig. 7h). R2 TSS-plots and R2 TSS-peak calling indicate a strong SP140 occupancy at several inflammatory macrophage-associated chemokines (CCL2, CCL3, CCL4, CCL5, CCL8, CXCL1, CXCL3, CXCL8 CXCL9, CXCL10 and CXCL11), chemokine ligands (CCLAL1, CCL3L1, CCL3L3, CCLAL2), chemokine receptors (CCR7), TFs (STAT1, JAK2, PIK3R5, RELA) and protein kinases (PRKCD, FGR and HCR) (Fig. S9a,b,c). This binding was reduced by GSK761, affecting expression of many genes involved in chemokine-signaling (Fig. S9d). However, SP140 binding was selective as it did not bind to the TSS of a range of other chemokines such as CXCL6, CXCL5, CCL11, and CCL7 (Fig. S9c).

\section{Discussion}

SP140 has been implicated in CD and other autoimmune diseases through genetic and epigenetic association studies ${ }^{16,36}$. Here, we describe the first small molecule inhibitor of SP140 protein, which has been used to investigate its function. The novel SP140-binding small molecule GSK761 was shown to compete with the N-terminal tail of histone H3 for interactions with the SP140 Brd-PHD module. In human macrophages, SP140 associated with the regulatory regions of immune-related/inflammatory genes in a stimulus-dependent manner. GSK761 inhibited SP140 binding to the TSS of many inflammatory genes, correlating with compound-induced decreased expression of these genes and reduced macrophage inflammatory function. The predominant SP140 expression in immune cells and in particular inflammatory macrophages, further identify SP140 as an epigenetic reader protein that contributes to inflammatory gene expression.

317 Inflammatory macrophages generated in vitro or in CD patients were shown to express high levels of 318 SP140, and SP140 silencing in macrophages reduced expression of a range of inflammatory genes. These 319 anti-inflammatory effects were extended using GSK761, which was able to inhibit spontaneous cytokine 320 expression from $\mathrm{CD}_{1} 4^{+}$macrophages isolated from $\mathrm{CD}$ anti-TNF refractory patients' colonic mucosa.

321 LPS-stimulation of macrophages was shown to cause SP140 recruitment to the TSS of a specific set of 322 inflammatory genes, which was prevented by GSK761, dampening the induced expression of those genes. 323 The strongest SP140 occupancy was at the TSS of a range of genes involved in TNF-signaling. TNF324 signaling plays an integral role in CD as evidenced by the efficacy of chimeric anti-TNF mAbs-therapy ${ }^{37}$. 325 Notably, anti-TNF therapy response rests on TNF neutralisation, but specifically in CD also on its potency 
macrophages to a more regulatory $\mathrm{CD} 206^{+} \mathrm{M} 2$-like phenotype ${ }^{31,39}$. This is for example evidenced by the clinical observation using etanercept (does not bind membrane bound TNF), which is not effective in CD, whilst infliximab is ${ }^{39}$. A reduced expression of SP140 in CD-biopsies was shown to be correlated with a better anti-TNF response ${ }^{10}$. In this study, we found that GSK761 increased CD206 expressing macrophages in in vitro. Furthermore, GSK761 reduced pro-inflammatory cytokine expression in CDmucosal macrophages of anti-TNF resistant patients. Thus, we anticipate that SP140 inhibition would be useful in enhancing anti-TNF remission-induction in CD patients. In this respect, SP140 was also shown by ChIP-seq analysis to bind and regulate expression of some key CD-associated genes such as $I L 23 A^{40}$, $T Y K 2^{41}, J A K 2^{41}, N O D 2^{42}$ and $C A R D 9^{43}$.

In IBD, epigenetic mechanisms control macrophage inflammatory activation and polarization ${ }^{44}$. These macrophages are central components of the inflamed mucosa and contribute to disease pathology by producing inflammatory cytokines, which promote the differentiation and activation of Th1 and Th17 cells ${ }^{45}$. In this study, SP140 is shown to be critical for both the polarization of inflammatory macrophages and in the response of polarised macrophages to inflammatory stimuli. In particular, the TFs STAT1 and STAT2 are crucial for inflammatory macrophages polarization ${ }^{5,46,47}$. We found high levels of SP140 binding associated with the STAT1 and STAT2 genes; GSK761 disrupted SP140 binding to these genes and reduced their expression, providing a probable mechanistic basis for the inhibitory effects of the compound on M1 polarisation. Notably, GSK761 inhibited macrophage-induced cytokines and costimulatory molecules required for inflammatory $\mathrm{T}$ cell activation including $I L 23 A^{40}, I L 12^{48}, I L 18^{49}$, $I L 1 \beta^{49}, C D 40^{50}$ and $C D 80^{51}$. Therefore, in addition to reducing the direct inflammatory function of macrophages, inhibition of SP140 may inhibit downstream activation/polarisation of responding T cells.

While the mechanism by which SP140 is targeted to gene regulatory regions remains to be determined, motif analysis indicated a strong overlap between the DNA sequences enriched for SP140 binding and the binding motifs of some key TFs involved in regulating the inflammatory response as well as the differentiation and polarization to inflammatory macrophages, such as NFkB-p50 52 , IRF $3^{53}$ and IRF8 ${ }^{54}$.

352 Thus, it is possible that SP140 is recruited to chromatin via binding to stimulation-induced TFs - either before or after the TFs bind to DNA. Conversely, SP140 may associate with other proteins recruited to 
In a previous study, SP140 was found to be enriched at the HOXA genes in macrophages, and SP140 binding at these locations was proposed to play a role in repression of these lineage-inappropriate genes ${ }^{10}$. However, SP140 binding to this region was minimal in our study in both unstimulated and LPS-stimulated macrophages. The reason for this discrepancy is unclear, but the use of different SP140 antibodies in the two studies is one possibility. The antibody used in our ChIP experiments was found to be the most SP140-specific amongst 5 antibodies that we tested. Importantly, the displacement of SP140 binding by GSK761 provides strong support for the specificity of the SP140 binding identified in our ChIP-seq study.

Analysis of the gene sets identified in our SP140 ChIP-seq study suggested a role for SP140 in immune defence against microbes (in accordance with ${ }^{55} \mathrm{and}^{56}$ ) and some other diseases, such as graft-versus-hostdisease, cancers and rheumatoid arthritis. The intestinal microbiota is thought to play a central role in the pathogenesis of CD, and subsequent investigations could consider the role of SP140 in this respect as a previous study linked SP140 SNPs to microbial dysbiosis in human intestinal microbiota ${ }^{57}$. In this study,

371 ChIP-seq analysis was mainly focused on investigating SP140 binding to coding genes. However, by including non-coding RNA molecules, we observed very strong SP140 binding to a limited set of microRNAs (miRNAs) mainly involved in tumorigenesis, such as MIR3687 ${ }^{58}$, MIR3648 ${ }^{59}$ and capable of binding and modulating transcription of some miRNAs involved in tumorogenesis ${ }^{61,62}$. SP140 binding in these locations is independent of the Brd-PHD region with which GSK761 interacts; binding of SP140 to DNA via the SAND domain is one possibility. While not the focus of this study, other potential links between SP140 and cancer were observed, including high expression of SP140 in chronic lymphocytic leukemia cells (although reduced expression in acute myelogenous leukemia), and high binding of SP140 to the FLOT1 gene, which has been implicated in tumorigenesis ${ }^{33}$

We conclude that SP140 is an epigenetic reader protein that regulates gene expression in macrophages in response to inflammatory stimuli, including those present in the CD intestinal mucosa of patients failing therapy. Targeting SP140 with a selective inhibitor was shown to displace SP140 from chromatin and decrease inflammatory gene expression in macrophages. This study suggests that SP140 inhibition could represent a promising approach for $\mathrm{CD}$, which might include in addition to remission induction, the potential for combination with anti-TNF therapy. 
391 University Medical Centers at the time of conducting this study. GSK has a patent EP2643462B1 related

392 to the therapeutic use of SP140 inhibitors.

393 Acknowledgment: We thank Charlotte J. Barrett, previous student trainee at GSK for the assistance with

394 a compound synthetic work. Funding: This project was funded by European Union's Horizon 2020

395 research and innovation program under Grant Agreement No. ITN-2014-EID-641665. Further grant

396 support is acknowledged from Dutch Ministry of Economical Affairs, LSH TKI, grants nr TKI-LSH

397 T2017, and European Crohn's and Colitis Organization (ECCO) Pioneer Grant, 2018.

398 Author Contributions. Conduction of the study, laboratory and writing of the manuscript: MG; study

399 design: MG, WJdJ, NRH and DFT; bioinformatics analyses; MG, JK, AYFLY and DAZ; supervision:

400 WJdJ, NRH, DFT, MPJV and PH; reviewing and editing: WJdJ, NRH, DFT, MPJV, JVL, TBMH, PH and

401 RKP; compound development: PDC, AS, SH, RPB, KG, LAS, DJM, GY, HPO, AC, AP, LL, RJW, CEB,

402 LAH and UK; laboratory analysis: OW, NH, JRS and ILH; technical support: GB. All authors have read

403 and agreed to the published version of the manuscript.

\section{Materials and methods}

The human biological samples were sourced ethically, and their research use was in accord with the terms of the informed consents under an IRB/EC approved protocol. Written informed consent was obtained from each donor, as approved by the UK East of England - Cambridgeshire and Hertfordshire Research Ethics Committee.

410 In-house GSK microarray profiler. Human gene expression data, along with accompanying sample 411 descriptions, was purchased from GeneLogic (GeneLogic Division, Ocimum Biosolutions, Inc.) in 2006, 412 and later organized by sample type. Gene expression data for each sample had been determined using 413 mRNA amplification protocols as recommended by Affymetrix (Affymetrix, Inc.) and subsequently 414 hybridized to the Affymetrix U133_plus2 chip. Purchased data was subject to reported quality control 415 measures including ratios for $A C T B$ and $G A P D H$, as well as maximal scale factors as reported by 416 Affymetrix MAS 5.0. Expression data was normalized using MAS5.0 with a target intensity of 150.

417 Immunohistochemistry. An anti-SP140 antibody produced in rabbit (HPA006162; Sigma Prestige 418 Antibody) was used to visualize SP140 protein in a Cambridge Bioscience 69571061 Normal Human 419 tissue microarray, a Cambridge Bioscience 4013301 Human Autoimmune Array, a Cambridge Bioscience 4204013101 Human Colitis Array and on in-house rheumatoid arthritis synovial samples. Anti-SP140 421 antibody was detected with a Leica polymer secondary antibody. Sections were de-waxed using 422 proprietary ER1, low pH 6 and ER2, high pH 8 buffers for 20 minutes at $98^{\circ} \mathrm{C}$. Sites of antibody binding 
were visualized with peroxidase and DAB. Staining was performed on a Leica Bondman immunostaining instrument, using protocol IHC F.

Tissue immunofluorescence of SP140 and CD68. Paraffin embedded tissue sections from inflamed and non-inflamed colon were obtained from patients with $\mathrm{CD}$ during surgical procedures, were first

427 deparaffinized and washed with TBS. For antigen retrieval, slides were treated at $96^{\circ} \mathrm{C}$ for 10 minutes in $4280.01 \mathrm{M}$ sodium citrate buffer $\mathrm{pH}$ 6.0. The tissue sections were blocked and permeabilized with PBT (PBS, $4290.1 \%$ Triton X-100 (Biorad), $1 \%$ w/v BSA (Sigma-Aldrich)) and incubated with primary antibodies for 2 430 hours (h) at room temperature (RT), to detect pan-macrophage marker CD68 (dilution 1:200) (M0876, 431 Dako) and SP140 (dilution 1:200) (ab171141; Abcam). After washing, slides were stained with the 432 following secondary antibodies: polyclonal goat anti-Mouse Alexa Fluor488 to detect CD68 protein 433 (Green color) (A-11029, Invitrogen) or polyclonal goat anti-Rabbit Alexa Fluor546 to detect SP140 434 protein (Orange color) (A-11035, Invitrogen). Slides were mounted in SlowfadeGold reagent containing 435 DAPI (4',6-diamidino-2-phenylindole, Thermo-Fisher) and imaged using a Leica DM6000B microscope equipped with LAS-X software (Leica Microsystems).

437 SP140 expression in ileal macrophages. Publicly available single-cell RNA-sequencing data from 11 438 involved (inflamed) and 11 paired uninvolved (uninflamed) ileal biopsies was downloaded from the 439 sequence read archive accession number SRP216273 ${ }^{23}$. Raw reads were aligned against GRCh38 using 440 Cellranger (v3.1.0). The resulting unique molecular identifier (UMI) count matrices were then imported 441 into the R statistical environment (v3.6.3) whereupon the samples were analyzed in an integrative fashion 442 using Seurat (v3.1.5) $)^{24,25}$. Clustering analyses were performed using the top 2000 most variable genes and 443 the top 15 principal components yielding 22 clusters whereupon they were visualized through UMAP 444 (arXiv:1802.03426). We identified the monocytes and macrophages containing cluster through the 445 expression of CD68, FCER1A (CD64), CD163, MRC1 (CD206), CD14 and FCGR3A (CD16A), after 446 which SP140 was visualized in the cluster representing monocytes/macrophages. Comparative cell count 447 analyses were performed using the Wald test as implemented in DESeq2 (v1.24.0). Comparative 448 percentage non-zero cells were performed using t-tests.

449 Isolation, differentiation and polarization of primary human monocytes and THP-1 cells. Peripheral 450 blood mononuclear cells (PBMCs) were obtained from whole blood of healthy donors (from Sanquin 451 Institute Amsterdam or from GSK Stevenage Blood Donation Unit) by Ficoll density gradient 452 (Invitrogen). $\mathrm{CD} 14^{+}$monocytes were positively selected from PBMCs using CD14 Microbeads according 453 to the manufacturer's instructions (Miltenyi Biotec). CD14 ${ }^{+}$cells were differentiated with $20 \mathrm{ng} / \mathrm{mL}$ of 454 macrophage colony-stimulating factor (M-CSF) (R\&D systems) for 3 days followed by 3 days of 
polarization into naïve macrophages (M0) (media only) ${ }^{26}$, classically activated (inflammatory) M1

macrophages (100 ng/mL IFN- $\gamma$; R\&D systems) ${ }^{26}$ or alternative activated (regulatory) M2 macrophages (40 ng/mL IL4;R\&D systems) ${ }^{26}$. Human monocytic cell line (THP-1) cells were differentiated with 100 $\mathrm{nM}$ phorbol myristate acetate (Sigma-Aldrich) for 3 days and then the same polarization protocol was performed. Cells were incubated in Isocove's Modified Dulbecco's Medium (Lonza) supplemented with $10 \%$ fetal bovine serum (FBS) (Lonza), $2 \mathrm{mM}$ 1-glutamine (Lonza), $100 \mathrm{U} / \mathrm{mL}$ penicillin (Lonza) and 100 $\mathrm{U} / \mathrm{mL}$ streptomycin (Lonza), at $37^{\circ} \mathrm{C}, 5 \% \mathrm{CO} 2$.

siRNA-mediated SP140 knockdown. Human M1 macrophages were generated in vitro from human primary $\mathrm{CD} 14^{+}$monocytes as described above. M1 macrophages were transfected with siGENOME human smartpool SP140 siRNA or non-targeting scrambled siRNA for 48h with DharmaFECT ${ }^{\text {TM }}$ transfection reagents according to manufacturer's protocol (Dharmacon). The cells were left unstimulated or stimulated with $100 \mathrm{ng} / \mathrm{mL}$ LPS (E. coli 0111:B4; Sigma) for 4h (for qPCR) or 24h (for Elisa). The supernatant was harvested for cytokine measurement and the cells were lysed (ISOLATE II RNA Lysis Buffer RLY- Bioline) for RNA extraction.

\section{RNA isolation and Reverse Transcriptase, Polymerase Chain Reaction (PCR) and Real-Time}

Quantitative PCR. Total RNA was extracted from macrophages using RNeasy Mini Kit (Qiagen)

472 following the manufacturer's instructions. The concentration of RNA was determined using

473 spectrophotometry (Nano-Drop ND-1000). Complementary DNA (cDNA) was synthesized with qScript

474 cDNA SuperMix (Quanta Biosciences). PCR amplification of SP140, SP100, SP110, SP140L, BRDT,

475 BRD2, BRD3, BRD4, BRD9, EP300, BAZ2A, BAZ2B, PCAF, CREBBP, TNF, IL6, IL10, IL8, CCL5,

476 CCL22, CD206 and CD64 was performed by Fast Start DNA Master ${ }^{\text {plus }}$ SYBR Green I kit on the Light

477 Cycler 480 (Roche, Applied Science). Relative RNA expression levels were normalized to the geometric mean of two reference genes RPL37A and ACTB. Primer sequences are listed in Supplementary table 1.

479 Immunofluorescence cell staining. Primary human monocyte derived macrophages were polarized to

480 M1 phenotype on coverslips. The cells were fixed with 4\% paraformaldehyde and then permeabilized in $4810.2 \%$ Triton (Biorad)/PBS. Blocking buffer 2\% BSA (Sigma-Aldrich) was added for 30 minutes. Rabbit 482 polyclonal anti-SP140 antibody (dilution 1:200) (ab171141; Abcam) or mouse polyclonal anti-SP100 483 antibody (dilution 1:200) (ab167605; Abcam) were added for 2h) followed by $2 \mathrm{~h}$ of secondary antibody, 484 Polyclonal goat anti-Rabbit, Alexa Fluor546 (A-11035, Invitrogen) (dilution of 1:1000) or goat anti485 mouse, Alexa Fluor546 (A-21123, Life Technologies) (dilution of 1:500), respectively. DAPI (Thermo486 Fisher) was used for nuclear detection. 
Microarray. RNA from human M1 macrophages transfected with SP140 siRNA or scrambled siRNA was extracted using a RNeasy mini-kit (Qiagen). $150 \mathrm{ng}$ total RNA was labelled using the cRNA labelling kit for Illumina BeadArrays (Ambion) and hybridized with Ref8v3 BeadArrays (Illumina). Arrays were scanned on a BeadArray 500GX scanner and data were normalized using quantile normalization with background subtraction (GenomeStudio software; Illumina). Genes with negative values were removed from analysis. Differentially expressed genes (DEGs) had a P-value $<0.05$ (analysis of variance). The data was analyzed in R (v3.6.3) and R2 Genomics Analysis and Visualization Platform-UMC (r2.amc.nl). Gene ontology overrepresentation analyses were performed in ShinyGO v0.6027. diluted in the presence of $3 \mathrm{nM}$ GSK064 in Assay Buffer (50 mM HEPES, pH 7.5, 150mM NaCl, $0.05 \%$ Pluronic F-127, $1 \mathrm{mM}$ DTT) in a total assay volume of $10 \mu$ l. Following incubation for 60 minutes, FP was measured on a Perkin Elmer Envision multi-mode plate reader, by exciting the Alexa647 fluorophore of GSK064 at a wavelength of $620 \mathrm{~nm}$ and then measuring emission at $688 \mathrm{~nm}$ in both parallel and perpendicular planes. The FP measurement, expressed as milliP (mP), was then calculated using the following equation;

$$
m P=\frac{(\text { parallel fluorescence intensity })-(\text { perpendicular fluorescence intensity })}{(\text { parallel fluorescence intensity })+(\text { perpendicular fluorescence intensity })}
$$

These data were then used to calculate an apparent $K_{\mathrm{d}}$ value by application of the following Langmuir-Hill equation; $A B=\left(A_{0}+B\right) /\left(K_{\mathrm{d}}+B\right)$ where $\mathrm{AB}$ is the concentration of the bound complex, $\mathrm{A}_{0}$ is the total amount of one binding molecule added, B is the free concentration of the second binding molecule and $K_{d}$ is the dissociation complex. $\mathrm{IC}_{50}$ determination, GSK761 was serially diluted in DMSO (1\% final assay concentration) and tested in the presence of $50 \mathrm{nM} \mathrm{SP140} \mathrm{and} 3 \mathrm{nM}$ GSK064 in the same assay buffer and volume as above. Reactions were incubated for 60 minutes, and $\mathrm{IC}_{50}$ values calculated using a four-

511 parameter logistic equation; $y=x /\left[1+\left(\frac{I}{I C_{50}}\right)^{n \mathrm{H}}+D\right]$ where $y$ is the $\mathrm{mP}$ signal in the presence of the

512 inhibitor at concentration $\mathrm{I}, x$ is the $\mathrm{mP}$ signal without the inhibitor, $\mathrm{IC}_{50}$ is the concentration of the 513 inhibitor that gives $50 \%$ inhibition, $n H$ is the Hill coefficient and $D$ is the assay background. 
516 house reagent) for 96h. Nuclear extract from HuT78 cells (endogenous SP140) was prepared following

517 manufacturer's protocol (Active Motif nuclear extract and co-IP kit). Protein concentration was

518 determined by Bradford Assay (Pierce). Nuclear extracts were incubated with GSK675 (biotinylated

519 GSK761) prebound to streptavidin Dynabeads (Thermo Fisher). Dynabeads were incubated with 2X SDS

520 reducing buffer (Invitrogen) and the eluted proteins resolved on a 4-12\% Bis-Tris SDS-PAGE (Invitrogen)

521 with MagicMark (Invitrogen) and SeeBlue 2 (Invitrogen) protein ladders. The gel was subjected to

522 Western blotting (Invitrogen) and incubated with Rabbit anti-SP140 antibody (HPA-006162; Sigma)

523 followed by anti-rabbit IgG HRP (A4914; Sigma). The Western blot was developed with Super Signal

524 West femto kit (Thermo Fisher) and imaged on Carestream chemilluminescence imager (Kodak). A

525 chimeric gene encoding Halo-SP140 was synthesized using overlapping oligonucleotides and cloned in an

526 expression vector pCDNA3.1. HEK293 cells were transfected with expression vector using Lipofectamine

527 and incubated for $24 \mathrm{~h}$. The transfected cells were labelled with HaloTag TMR ligand following

528 manufacturer's protocol (HaloTag® TMR Ligand Promega). Nuclear extract from transfected HEK293

529 cells (Halo-SP140) was prepared and SP140 immunoprecipitation was carried out as described above.

530 Eluted proteins were resolved on a 4-12\% Bis-Tris SDS-PAGE gel (Invitrogen) with SeeBlue 2

531 (Invitrogen) protein ladder. Halo-SP140 was visualised using Versa Doc scanner and 520LP UV

532 Transilluminator.

533 BROMOscan ${ }^{\circledR}$ Bromodomain Profiling. BROMOscan ${ }^{\circledR}$ bromodomain profiling was provided by

534 Eurofins DiscoverX Corp (Fremont, CA, USA, http://www.discoverx.com). Determination of the $\mathrm{K}_{d}$

535 between test compounds and DNA tagged bromodomains was achieved through binding competition

536 against a proprietary reference immobilized ligand.

537 Cell penetration assessment assay of GSK761. Intracellular GSK761 compound concentration was

538 measured by RapidFire Mass Spectrometry utilizing the methodology described by ${ }^{28}$.

539 Cell viability and cytotoxicity assays. M1 macrophages were generated in vitro from human primary

$540 \mathrm{CD} 14^{+}$monocytes as described above. M1 macrophages were plated into opaque-walled 96-well plate at

$54110 \times 10^{5}$ cells per well and incubated with a concentration gradient of GSK761 $(0.04-1.11 \mu \mathrm{M})$ for $1 \mathrm{~h}$

542 (0.1\% DMSO was used as control). The cells were left unstimulated or stimulated with $100 \mathrm{ng} / \mathrm{mL}$ LPS

543 for $24 \mathrm{~h}$. Cell viability was assessed using CellTiter-Glo® Luminescent Cell Viability Assay kit (Promega)

544 according to the manufacturer's protocol. This assay quantifies ATP, an indicator of metabolically active

545 cells. An equal volume of freshly prepared CellTiter-Glo® reagent was added to each well the plate was

546 shaken for 10 minutes at RT and luminescent signals were recorded using a plate reader (SpectraMax 
547 M5). The index of cellular viability was calculated as the fold change of luminescence with respect to

548 untreated control cells.

549 Cell viability was also determined using Muse® Count \& Viability Kit (Luminex corp) according to the

550 manufacturer's protocol and measured on the Guava® Muse® Cell Analyzer (Luminex corp).

551 Histone $\mathbf{H 3}$ peptide displacement. Various H3 peptides (Anaspec library (https://www.anaspec.com/))

552 were serially diluted in DMSO (1\% final assay concentration) and tested in the presence of $10 \mathrm{nM}$

553 GSK306 (FAM-labelled version of GSK761) and $80 \mathrm{nM}$ 6HisFLAGTEVSP140 (687-867) (2x apparent

$554 K_{d}$ for this ligand) in $50 \mathrm{mM}$ HEPES (Sigma-Aldrich), pH 7.5, $50 \mathrm{mM} \mathrm{NaCl}$ (Sigma-Aldrich), $1 \mathrm{mM}$

555 CHAPS (Sigma-Aldrich), $1 \mathrm{mM}$ DTT (Sigma-Aldrich) in a total volume of $10 \mu 1$. Reactions were

556 incubated for 30 minutes and FP was measured on a Perkin Elmer Envision multi-mode plate reader

557 (PerkinElmer), by exciting the FAM fluorophore of GSK306 at a wavelength of $485 \mathrm{~nm}$ and then

558 measuring emission at $535 \mathrm{~nm}$ in both parallel and perpendicular planes. The FP measurement, expressed

559 as milliP (mP), was then calculated as described previously, and normalised to free- and bound- ligand

560 controls to determine $\%$ response. $\mathrm{IC}_{50}$ values were calculated using the described four-parameter logistic

561 equation.

562 SP140/Histone Nano-bioluminescence resonance energy transfer ${ }^{\text {TM }}$ (NanoBRET ${ }^{\mathrm{M} M}$ ) Assay Testing.

563 The NanoBRET ${ }^{\text {TM }}$ System is a proximity-based assay that can detect protein interactions by measuring

564 energy transfer from a bioluminescent protein donor NanoLuc $®$ (NL) to a fluorescent protein acceptor

565 HaloTag® (HT). Briefly, SP140-NL and Hitone3.3-HT DNA was transfected into HEK293 cells using the

566 following ratios: 1:1, 1:10 and 1:100, respectively. Signal window was determined by relative NL/HT-

567 fused protein expression. Minus HT controls were used as the baseline in this experiment for each

568 condition. The data is presented as NanoBRET response (mBU) which is dependent on the presence of the

569 HT Ligand, and by microscopic imaging of NL/HT-fused protein signal. For more information about

570 NanoBRET assay protocol: (https://www.promega.com/-/media/files/resources/protocols/technical-

571 manuals/101/nanobret-proteinprotein-interaction-system-protocol.pdf?la=en)

572 Flow cytometry (FACS). Primary human CD14+ monocytes were positively selected from PBMCs using

573 CD14 Microbeads according to the manufacturer's instructions (Miltenyi Biotec) and differentiated for 3

574 days with $20 \mathrm{ng} / \mathrm{mL}$ M-CSF. The monocytes were then washed with PBS and treated with $0.1 \%$ DMSO or

$5750.04 \mu \mathrm{M}$ GSK761. After $1 \mathrm{~h}, 100 \mathrm{ng} / \mathrm{mL}$ IFN- $\gamma$ (R\&D systems) was added to the cells to generate M1

576 macrophages. After 3 days of incubation, the cells were harvested and subsequently permeabilized using

$5771 \%$ Saponin (Sigma-Aldrich) for 10 minutes on ice. Cells were then stained using the conjugated 
578 antibodies; PerCP-Cy5 mouse anti-human CD64 (dilution 1:50) (305023, Biolegend) and PE mouse anti579 human CD206 (dilution 1:20) (2205525, Sony Biotechnology). The analysis was performed by flow

580 cytometry (FACS) using the LSRFortessa and FACSCalibur (both BD Biosciences). FlowJo (BD

581 LSRFortessa ${ }^{\mathrm{TM}}$ cell analyzer) was used for data analysis.

582 Cytokine analysis. Cytokine expression in the supernatant of DMSO- or GSK761-treated M1

583 macrophages (LPS-stimulated or unstimulated) were measured using electro-chemiluminescence assays

584 (Meso Scale Discovery [MSD])-Human ProInflammatory 7-Plex Tissue Culture Kit (IFN- $\gamma$, IL-1 $\beta$, IL-6,

585 IL-8, IL-10, IL-12p70, TNF) according to manufacturer's protocols and analyzed on an MSD 1250 Sector

586 Imager 2400 (Mesoscale). Supernatant IL-6, IL-8 and TNF from SP140 siRNA or scrambled-treated M1

587 macrophages (LPS-stimulated or unstimulated) were determined by Sandwich Enzyme-Linked

588 Immunosorbent Assay (ELISA; R\&D systems) according to manufacturer's protocol.

589 Customized qPCR-Array. Human M1 macrophages were generated in vitro from human primary CD14 590 monocytes as described above (from 5 independent donors). M1 macrophages were treated either with

$5910.1 \%$ DMSO or $0.04 \mu$ M GSK761 for $1 \mathrm{~h}$. The cells where then washed with PBS and stimulated with LPS

592 for 4h. Total RNA was isolated using RNeasy Mini Kit (Qiagen) and treated with DNaseI (Qiagen)

593 according to the manufacturer's instructions. RNA was reverse transcribed using the First Strand

594 Synthesis Kit (Qiagen) and loaded onto a customized $\mathrm{RT}^{2}$ profiler array for selected 89 genes according to

595 the manufacturer's instructions (Qiagen) and run on QuantStudio 7 Flex (software v1.0). Qiagen's online

596 GeneGlobe Data Analysis Center (https://geneglobe.qiagen.com/us/analyze/) was used to determine the

597 DEGs. The data was presented as scatter plot. All data were normalized to the geometric mean of two

598 reference genes (RPL37A and ACTB). The list of genes included in this experiment were selected from

599 DEG in SP140 silenced M1 macrophages in ${ }^{10}$ and from our MSD, qPCR and microarray datasets of

600 SP140 silenced M1 macrophages.

601 Genome wide expression profiling (RNA-sequencing (RNA-seq)). M1 macrophages were generated in

602 vitro from human primary $\mathrm{CD} 14^{+}$monocytes as described above (from 3 independent donors). M1

603 macrophages were incubated for $1 \mathrm{~h}$ with either $0.1 \%$ DMSO or $0.04 \mu \mathrm{M}$ GSK761. M1 macrophages were

604 then kept unstimulated or stimulated with $100 \mathrm{ng} / \mathrm{mL}$ LPS (E. coli 0111:B4; Sigma) for 4h or 8h. Total

605 RNA was isolated from macrophages using the RNAeasy mini kit (Qiagen) and transcribed into cDNA by

606 qScript cDNA SuperMix (Quanta Biosciences) according to manufacturer's instructions. Sequencing of

607 the cDNA was performed on the Illumina HiSeq4000 to a depth of 35M reads at the Amsterdam UMC

608 Core Facility Genomics. Quality control of the reads was performed with FastQC (v0.11.8) and

609 summarization through MultiQC (v1.0). Raw reads were aligned to the human genome (GRCh38) using 
STAR (v2.7.0) and annotated using the Ensembl v95 annotation. Post-alignment processing was

611 performed through SAMtools (v1.9), after which reads were counted using the featureCounts application

612 in the Subread package (v1.6.3). Differential expression (DE) analysis was performed using DESeq2

613 (v1.24.0) in the R statistical environment (v3.6.3), in R2 Genomics Analysis and Visualization Platform-

614 UMC (r2.amc.nl) and ShinyGO v0.6027.

615 Chromatin immunoprecipitation (ChIP). M1 macrophages were generated in vitro from human primary

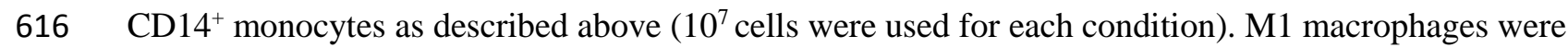
617 either incubated for $1 \mathrm{~h}$ with $0.1 \%$ DMSO or with $0.04 \mu \mathrm{M}$ GSK761 and left unstimulated or simulated 618 with $100 \mathrm{ng} / \mathrm{mL}$ LPS for $1 \mathrm{~h}$ or $4 \mathrm{~h}$. The cells were cross-linked with $1 \%$ formaldehyde for 10 minutes at 619 RT and quenched with 2.5 M glycine (Diagenode) for 5 minutes at RT. The ChIP assay was performed 620 using the iDeal ChIP kit for Transcription Factors (Diagenode) and sonication was performed using the 621 Picoruptor $^{\mathrm{TM}}$ (Diagenode) according to the manufacturer's protocols. Chromatin shearing was verified by 622 migration on a 1\% agarose gel (E-Gel, Thermo-Fisher) and visualised using E-Gel imager (Thermo623 Fisher). Immunoprecipitation was performed with a polyclonal SP140 antibody (H00011262-M07, 624 Abnova). DNA was purified using IPure kit (Diagenode) according to the manufacturer's protocol. For validation, quantitative real-time ChIP-qPCR was performed on DNA isolated from input (unprecipitated) chromatin and SP140 ChIP DNA with primer pairs specific for the TSS of TNF and IL6 genes. For detailed PCR primer sequences, please see supplemental table 1. Quantitative PCR was performed using SYBR Green (Applied Biosystems) and StepOnePLus (Applied Biosystems). Results were quantitated using the delta-delta $\mathrm{CT}(\Delta \Delta \mathrm{CT})$ method. Libraries of input DNA and ChIP DNA were prepared from gel-purified >300-base pair DNA.

Global profiling of chromatin binding sites. The DNA was used to generate sequencing libraries according to the manufacturer's procedure (Life Technologies). The DNA was end polished and dA tailed, and adaptors with barcodes were ligated. The fragments were amplified (eight cycles) and quantified with 634 a Bioanalyzer (Agilent). Libraries were sequenced using the HiSeq PE cluster kit v4 (Illumina) with the 635 HiSeq 2500 platform (Illumina), resulting in 125-bp reads. FastQ files were adapter clipped and quality 636 trimmed using BBDukF (java -cp BBTools.jar jgi.BBDukF -Xmx1g in=fastqbef.fastq.gz out=fastq.fastq 637 minlen=25 qtrim=rl trimq=10 ktrim=r k=25 mink=11 hdist=1 ref=adapters.fa). Subsequently the reads 638 were mapped to NCBI37/HG19 using Bowtie (bowtie2 -p 8 -x hg19 fastq.fastq > sample.sam) and sorted 639 and converted into bam files using samtools. Peaks were called using MACS2, with the reads being 640 extended to 200bp (callpeak --tempdir/data/tmp -g hs -B -t sample.bam -c control.bam -f BAM -n result/ -nomodel --extsize 149) and duplicates removed. BDG files were binned in 25bp regions and loaded in the 
643 from the MACS2 analyses were extended by 250 bases and subsequently analyzed on a repeat masked

644 hg19 genome with HOMER to identify over represented sequences (both known as well as de novo). The

645 data was uploaded and analyzed in R2 Genomics Analysis and Visualization Platform-UMC (r2.amc.nl).

646 SP140 inhibition in isolated human mucosal macrophages. Colon tissues were obtained during surgery

647 procedures from patients with CD. The mucosa was stripped and dissociated in GentleMACS tubes in

648 digestion medium (DM; complete medium (RPMI 1640 with PGA/L-glutamine/10\% FCS) with $1 \mathrm{mg} / \mathrm{mL}$

649 Collagenase D (Roche), $1 \mathrm{mg} / \mathrm{mL}$ soybean Trypsin inhibitor (Sigma), $50 \mu \mathrm{g} / \mathrm{mL}$ DNase I (Roche)), and

650 then mechanically dissociate on GentleMACS using program B01. The mucosa was then incubated in DM

651 for $1 \mathrm{~h}$ at $37^{\circ} \mathrm{C}$ while shaking. During digestion the dissociation was repeated two times. The tissue

652 suspension was passed through a cell strainer (200-300 um) and centrifuged at $1500 \mathrm{rpm}$ for 10 minutes.

653 The dissociated cells were resuspended in cold MACS Buffer and macrophages were isolated using CD14

654 MicroBeads according to the manufacturer's instructions (MiltenyiBiotec). The macrophages were

655 incubated with either $0.1 \%$ DMSO or $0.04 \mu \mathrm{M}$ GSK761 for 4h. RNA was extracted as described above

656 and gene expression of IL6, TNF, IL10 and CD64 was measured by qPCR. All data were normalized to

657 the reference gene $A C T B$.

659 Statistics analysis. Statistical analysis was performed with GraphPad Prism v8.0.2.263 (GraphPad

660 Software Inc.). For group analysis, data were subjected to one-way ANOVA or Student's t-test. The two-

661 tailed level of significance was set at $\mathrm{p} \leq 0.05(*), 0.01(* *), 0.001(* * *)$ or $0.0001(* * * *)$ for group

662 differences. Data is shown as mean \pm SEM. The figures were prepared using Inkscape 0.92.4.

663 Data Availability. Processed microarray data is publicly available and can be explored at r2.amc.nl under 664 the data set name 'Exp SP140 siRNA in M1 macrophages - deJonge - 12 - custom - ilmnht12v4'. The

665 summary statistics for microarray data can be found in supplemental tables 3 and 4. Raw data of RNA-seq

666 and ChIP-seq are publicly available and have been deposited in European Genome-phenome Archive

667 (https://ega-archive.org/studies/EGAS00001004460). The counts and the summary statistics for RNA-seq

668 data can be found in supplemental table 5, 6 and 7. The normalized read count for ChIP-seq data can be

669 found in supplemental tables 8, 9, 10,11, 12 and 13.

$670 \quad$ Figure legends

671 Figure 1: SP140 is highly associated with inflammatory diseases and mucosal CD68 ${ }^{+}$macrophages of 672 CD patients.

673 (a) SP140 gene expression in human tissues and cell types. (b) SP140 gene expression in white blood cells 674 of normal healthy controls (N), Crohn's disease (CD), ulcerative colitis (CD), systemic lupus 
675 erythematosus (SLE), chronic lymphocytic leukemia (CCL), acute myeloid leukemia (AML) and

676 rheumatoid arthritis (RA) patients. (c) SP140 gene expression in human colon tissue obtained from N,

677 inflamed and non-inflamed CD and UC colonic tissues. Data was collected from in-house GSK

678 microarray profiler. (d) Immunohistochemistry of SP140 protein in colon tissue obtained from N and

679 inflamed CD tissue, scale bar: $50 \mu \mathrm{m}$. (e) Immunofluorescence staining of DAPI (blue), CD68 (green) and

680 SP140 (red) in N or inflamed CD colon tissue, scale bar: $100 \mu \mathrm{m}$. (f) Mucosal cell count per visual field of

681 total $\mathrm{CD} 68^{+}$macrophages, SP140 ${ }^{+} \mathrm{CD} 68^{+}$macrophages and SP140- CD68 ${ }^{+}$macrophages in $\mathrm{N}$ and inflamed

$682 \mathrm{CD}$ tissue $(\mathrm{n}=3)$. Statistical significance is indicated as follows: $* P<0.05, * * P<0.01, * * * * P<0.0001$.

Figure 2. The percentage of $S P 140$ expressing macrophages in cluster 6 is higher in inflamed tissue compared with uninflamed CD-ileal biopsies.

686 Publicly available single-cell RNA-sequencing was used to investigate SP140 expression in ileal

687 macrophages in inflamed $(n=11)$ and uninflamed $(n=11)$ biopsies of CD patients. (a) Clustering analyses

688 of all cells were performed using the top 2000 most variable genes and the top 15 principal components

689 yielding 22. (b) Visual illustration of the actual counts of cells expressing different

690 monocytes/macrophages markers. Darker blue represents more reads per cell. (d) The percentage

691 (represented by the hue) of cells that are non-zero for the indicated macrophage marker genes (c). UMAP

692 of cluster 6 only with blue dots representing SP140 expression per cell. (e) Comparative analyses of the

693 percent non-zero cells when comparing inflamed with uninflamed, where the percentage was calculated

694 relative to cluster 6 only.

Figure 3: SP140 knock-down reduces the activity of the inflammatory macrophages.

697 (a) Polarization protocol of human $\mathrm{CD} 14^{+}$monocytes to M0, M1 and M2 macrophage phenotypes.

698 Freshly isolated CD14+ monocytes were differentiated for 3 days using $20 \mathrm{ng} / \mathrm{mL}$ M-CSF. The cells were then washed with PBS and polarized for 3 days to M0, M1 and M2 macrophages using media only, 100 $\mathrm{ng} / \mathrm{mL}$ IFN- $\gamma$ or 40ng/mL IL-4, respectively. (b) Relative gene expression (qPCR) of SP140 in M0, M1 and M2 macrophages, n=6. (c) Immunofluorescence staining of SP140 speckles in M1 and M2 macrophages imaged by microscopy (left) or nuclear bodies count (right). (d) SP140 silencing protocol; M1 macrophages were incubated with either scrambled control siRNA or SP140 siRNA for 48h. The cells were then washed with PBS and stimulated with $100 \mathrm{ng} / \mathrm{mL}$ LPS for 4h (for qPCR) and 24h (for Elisa) or kept without LPS-stimulation. (e) The efficiency of SP140 silencing was assessed by measuring relative gene expression (qPCR) of $S P 140(\mathrm{n}=6)$ and (f) immunofluorescence staining of SP140 speckles nuclear bodies (left) and nuclear bodies count (right). (g) Relative gene expression (qPCR) (top) $n=6$, and protein levels (ELISA) (bottom) n=3, of TNF, IL-6 and IL-8. (h) PCA of microarray dataset; PC1 represents most 
variance associated with the data (LPS-stimulation) and PC2 represents second most variance (siRNA), $\mathrm{n}=3$. (i) Heatmap of top 50 DEGs at 0h LPS or $4 \mathrm{~h}$ of $100 \mathrm{ng} / \mathrm{mL}$ LPS (non-annotated genes were not included). (j) Hallmark pathways analysis at 0h (top) and 4h of $100 \mathrm{ng} / \mathrm{mL}$ LPS (bottom). (k) Reactome pathway analysis carried out using ShinyGO v0.60 in unstimulated M1 macrophages (bottom) or 4h of $100 \mathrm{ng} / \mathrm{mL}$ LPS-stimulated M1 macrophages (bottom). In all assays, statistical significance is indicated as follows: $* P<0.05, * * P<0.01, * * * P<0.001, * * * * P<0.0001$. investigating its affinity and selectivity.

(a) Three-cycle benzimidazole library (left) and cube view of the SP140 selection output (right). Each individual dot in the cube represents a DEL68 molecule, while the size of the dot corresponds to the total copy number (2-24) identified for that library molecule. The dots are colored by the BB3s that compose the library molecules. Library members with a single copy were removed to simplify visualization revealing a prominent line defined by a specific BB1\&BB3 combination. (d) Biochemical characterization of the interaction between (b) GSK761 and recombinant SP140 in a FP binding assay using (c) GSK064, generated by fluorescent labelling of GSK761. The mean binding affinity for this interaction was a $K_{\mathrm{d}}=$ $41.07 \pm 1.42 \mathrm{nM}(\mathrm{n}=5)$.

(e) A FP binding assay was configured using recombinant SP140 and GSK064, which was used to determine the potency of GSK761.Displacement of GSK064 from SP140 by GSK761 (circles) was achieved and determined to have a mean $\mathrm{IC}_{50}$ of $77.79 \pm 8.27 \mathrm{nM}(\mathrm{n}=3)$. No effect on GSK064 motion was observed in the presence of varying concentrations of GSK761 (triangles). The data presented in (d) and (e) are representative data form a single experimental replicate, affinities and

Figure 5: GSK761 biases differentiation towards an CD206 expressing macrophages and reduces pro-inflammatory cytokine expression in $\mathrm{CD}^{+} 4^{+}$macrophages isolated from $\mathrm{CD}$ anti-TNF refractory patients' colonic-mucosa.

Human primary CD14+ monocytes were differentiated with $20 \mathrm{ng} / \mathrm{mL}$ M-CSF for 3 days. The cells where then washed with PBS and treated with 0.1\% DMSO or $0.04 \mu \mathrm{M}$ GSK761 for 1 h prior to 3 days polarization to M1 and M2 macrophages phenotypes with $100 \mathrm{ng} / \mathrm{mL}$ INF- $\gamma$ or $40 \mathrm{ng} / \mathrm{mL}$ IL-4, 
and (b,c) FACS analysis was performed in IFN- $\gamma(\mathrm{M} 1)$ polarized macrophages to assess: (b) the frequency

of $\mathrm{CD}^{+} 4^{+}$macrophages (left) and CD64 protein expression intensity (right) and (c) the frequency of CD206 ${ }^{+}$macrophages (left) and CD206 protein expression intensity, n=3. For FACS data, the count was normalized to mode. (d) M1 polarized macrophages were pretreated for $1 \mathrm{~h}$ with $1 \%$ DMSO or with 0.04 $\mu$ M GSK761. The cells were then stimulated for $4 \mathrm{~h}$ with $100 \mathrm{ng} / \mathrm{mL}$ LPS and Customized RT ${ }^{2}$ Profiler PCR Arrays was performed, the scatter plot illustrates the differentially expressed genes (2-fold change), $\mathrm{n}=4$ to 5. (e) M1 polarized macrophages were pretreated for $1 \mathrm{~h}$ with $1 \%$ DMSO or with an increasing concentration of GSK761 $(0.01,0.04,0.12,0.37 .1 .11 \mu \mathrm{M})$. The cells were then stimulated for $24 \mathrm{~h}$ with $100 \mathrm{ng} / \mathrm{mL}$ LPS. Protein levels of TNF, IL-6, IL-1 $\beta$, IL-10, IL-8 and IL-12p70 were measured in the supernatant using ProInflammatory 7-Plex MSD kit, $\mathrm{n}=4$ to 7. The $\mathrm{Y}$ axis indicates the fold change in cytokine protein expression relative to DMSO control. (f) $\mathrm{CD} 14^{+}$cells were isolated from inflamed CD mucosa. The cells were then incubated ex vivo for $4 \mathrm{~h}$ with either $0.1 \%$ DMSO or $0.04 \mu \mathrm{M}$ GSK761. Relative gene expression of TNF, IL6, IL10 and CD64 were measured using qPCR, $\mathrm{n}=2$. The $\mathrm{Y}$ axis indicates the fold change in mRNA level relative to DMSO control. Statistical significance is indicated as follows: $* P<0.05, * * P<0.01, * * * P<0.001, * * * * P<0.0001$.

Figure 6: LPS-stimulation enhances SP140 protein recruitment to chromatin; GSK761 reduces this recruitment and dampens inflammatory pathways in inflammatory macrophages.

(a) Nuclear extracts from $\alpha \mathrm{CD} 3 / \alpha \mathrm{CD} 28$ stimulated HuT78 cells were incubated with unmodified or modified (acetylated and methylated) histone H3 peptides. SP140 was then pulled-down and its interaction with $\mathrm{H} 3$ peptides was visualized. (b) ChIP-qPCR of SP140 occupancy at TSS of TNF and IL6 in M1 macrophages stimulated with $100 \mathrm{ng} / \mathrm{mL}$ LPS for 4h or without LPS-stimulation, $\mathrm{n}=3$ donors (DN). (c) Epigenome roadmap scan illustrating proportions of SP140 genome-wide occupancy after SP140 LPS-stimulated (left) or on 4h LPS-stimulated (right) M1 macrophages rank-ordered from high to low occupancy centered on TSS. Top 20 genes with high SP140 occupancy were listed. (e) ChIP-qPCR of SP140 occupancy at TSS of TNF in M1 macrophages pretreated with 0.1\% DMSO or $0.04 \mu \mathrm{M}$ GSK761 for $1 \mathrm{~h}$ and then stimulated with $100 \mathrm{ng} / \mathrm{mL}$ LPS for 1 or $4 \mathrm{~h}$ or kept unstimulated (0h LPS). (f) Metagene created from normalized genome-wide average reads for SP140 centered on TSS. (g) PCA of RNA-seq comparing 0.1\% DMSO to $0.04 \mu \mathrm{M}$ GSK761 treated M1 macrophages after 4h of LPS-stimulation (left) or after 8h of LPS-stimulation (right). (h) SP140 ChIP-seq gene ontology analysis of the most enriched molecular function and biological process after 1h of LPS-stimulation, comparing 0.1\% DMSO with 0.04 $\mu$ M GSK761 treated M1 macrophages. (i,j) Hallmarks pathway enrichment analysis at (i) 0,1 and 4h of $100 \mathrm{ng} / \mathrm{mL}$ LPS-stimulation for ChIP-seq and at (j) 0, 4 and 8h of $100 \mathrm{ng} / \mathrm{mL}$ LPS-stimulation for RNA- 
seq. (j) The direction and color of the arrow indicates the direction and size of the enrichment score, the size of the arrow is proportional to the $-\log _{10}(p$-value), and non-transparent arrows represent significantly affected pathways.

Figure 7: SP140 preferentially controls the expression of specific gene sets involved in the innate immune response.

(a) Heatmap of the top 100 DEGs and (b) volcano plots of the all genes comparing $0.1 \%$ DMSO- with $0.04 \mu \mathrm{M}$ GSK761-treated M1 macrophages after 4h of $100 \mathrm{ng} / \mathrm{mL}$ LPS-stimulation. (c) R2 TSS-plot comparing a global DBGs after $1 \mathrm{~h}$ of $100 \mathrm{ng} / \mathrm{mL}$ LPS-stimulation of 0.1\% DMSO- and $0.04 \mu \mathrm{M}$ GSK761treated M1 macrophages. (d) SP140 ChIP-seq genome browser view of some of the most affected DBGs; TNF, TRAF1, IRF1 and TRAFAIP2. Y axis represents signal score of recovered sequences in $0.1 \%$ DMSO and $0.04 \mu \mathrm{M}$ GSK761 treated macrophages after 0, 1 and 4h of $100 \mathrm{ng} / \mathrm{mL}$ LPS-stimulation. (e) RNAsequencing derived gene expression of some of the most DBGs. (f) Comparative analyses of the top 1000 DBGs (signal) with their gene expression (Wald statistic). Gene expression at $4 \mathrm{~h}$ and ChIP at $1 \mathrm{~h}$ (left) and gene expression at $4 \mathrm{~h}$ and ChIP at $4 \mathrm{~h}$ (right), Y axis represents the SP140 differential binding signal (BD).

(g) Homer Known Motif Enrichment using TF motifs and their respective p-value scoring (top) and Homer de novo Motif results with best match TFs (bottom) in 0.1\% DMSO treated M1 macrophages after $1 \mathrm{~h}$ of $100 \mathrm{ng} / \mathrm{mL}$ LPS-stimulation. (h) An enrichment analysis targeted chemokine activity for SP140 ChIP-seq (top) and RNA-seq (bottom) comparing 0.1\% DMSO- with $0.04 \mu \mathrm{M}$ GSK761 treated-M1 macrophages at 0,1 and $4 \mathrm{~h}$ of $100 \mathrm{ng} / \mathrm{mL}$ LPS-stimulation.

\section{Supplementary figure legends}

Supplementary figure 1: SP140 expression is associated with inflammatory diseases.

Immunohistochemistry of SP140 in ulcerative colitis (colon), appendicitis (appendix), sarcoidosis (lung), psoriatic arthritis (synovium), rheumatoid arthritis (synovium), Hashimoto's thyroiditis (thyroid) and Sjogren's syndrome (cervical cyst). SP140 is illustrated by peroxide staining.

\section{Supplementary figure 2: CD-ileal inflamed tissue has consistently more cells than uninflamed tissue} in cluster 6.

805 Publicly available single-cell RNA-sequencing was used to investigate SP140 expression in ileal macrophages in inflamed $(n=11)$ and uninflamed $(n=11)$ biopsies of CD patients. Comparative analyses of the cell counts per cluster when comparing inflamed with uninflamed. Graphs are ranked by p-values, which were calculated through the Wald test as implemented in DESeq2. 
Supplementary figure 3: Inflammatory stimulus induces SP140 expression.

811 (a,b) Relative gene expression of CD64, CCL5, CD206 and CCL22 in M0, M1 and M2 macrophages

812 derived from (a) human primary $\mathrm{CD} 14^{+}$monocytes or (b) from THP-1 cells, $\mathrm{n}=4$. (c) Relative gene

813 expression of SP140 in M0, M1 and M2 macrophages derived from THP-1 cells, $\mathrm{n}=5$. (d)

814 Immunofluorescence staining of SP140 in M1 and M2 macrophages derived from THP-1 cells. DAPI

815 staining nucleus in blue and SP140 speckles in red. (e) Relative gene expression of SP140, CCL5 and

$816 C D 206$ after $24 \mathrm{~h}$ of $100 \mathrm{ng} / \mathrm{mL}$ LPS-stimulated or unstimulated M0, M1 and M2 macrophages derived

817 from human primary CD14+ monocytes, $n=4$. Relative gene expression was measured by qPCR. Statistical

818 significance is indicated as follows: $* P<0.05$, *** $P<0.01, * * * P<0.001$, **** $P<0.0001$.

819 Supplementary figure 4: The association between SP140 and inflammatory macrophages is not a 820 common phenomenon amongst BCPs.

821 (a) Relative gene expression (qPCR) of 12 BCPs; SP100, SP110, SP140L, BRD2, BRD3, BRD4, BRD9,

$822 P C A F, E P 300, C R B B P, B A Z 2 A$ and $B A Z 2 B$ in M0, M1 and M2 macrophages derived from human

823 primary $\mathrm{CD} 14^{+}$monocytes, $\mathrm{n}=4$ to 8 . (b) Relative gene expression of SP110 and SP100 in M1

824 macrophages, transfected with siRNA against SP140 (grey bars) or a scrambled control siRNA (black

825 bars), and then stimulated or not with LPS (100 ng/mL for 4h). (c) Immunofluorescence staining of SP140

826 in M1 macrophages, transfected with siRNA against SP140 or a scrambled control siRNA, and then

827 stimulated with LPS (100 ng/mL for 24h). SP140 speckles (red dots) were imaged and SP140 nuclear

828 bodies were counted. DAPI (blue) was used to stain the nucleus.

Supplementary figure 5: GSK761 lowers the expression of the M1 macrophage polarization marker TNF.

(a) ATP luminescence measurement within M1 macrophages treated with an increasing concentration of GSK761 $(0.01,0.04,0.12,0.37 .1 .11 \mu \mathrm{M})$ or $1 \%$ DMSO in presence or absence of $100 \mathrm{ng} / \mathrm{mL}$ of LPS for 24h, $\mathrm{n}=6$, statistical significance is indicated as follows: $* P<0.05, * * P<0.01$. The $\mathrm{Y}$ axis indicates the fold change in detected ATP luminescence (relative to unstimulated DMSO control ). (b) M1 macrophages were pretreated with $0.1 \%$ DMSO or with GSK761 $(0.04 \mu \mathrm{M}, 0.12 \mu \mathrm{M}$ or $0.37 \mu \mathrm{M})$, and then stimulated with $100 \mathrm{ng} / \mathrm{mL}$ for $24 \mathrm{~h}$. The cells were stained with Muse ${ }^{\circledR}$ Count \& Viability Reagent, and then analyzed on the Muse ${ }^{\circledR}$ Cell Analyzer. The data shown as viability vs nucleated cells and presented as \% viability. (c) Primary human $\mathrm{CD} 14^{+}$monocytes were differentiated with $20 \mathrm{ng} / \mathrm{mL}$ M-CSF for 3 days. The cells were then washed with PBS and treated with 0.1\% DMSO or $0.04 \mu \mathrm{M}$ GSK761 for 1h prior to 3 days polarization to M1 phenotype with $100 \mathrm{ng} / \mathrm{mL}$ INF- $\gamma$ (DMSO and GSK761 were not 
842 washed and kept in the culture during the 3 days of polarization). TNF gene expression was measured by

$843 \mathrm{qPCR}, \mathrm{n}=3$.

844

845 Supplementary figure 6: SP140 protein binds to histone H3.

846 (a) IC50 $(0.36+/-0.03 \mu \mathrm{M})$ for the displacement of GSK761 from SP140 by H3 peptide (1-21,

847 ARTKQTARKSTGGKAPRKQLA). (b) IC50 for the displacement of GSK761 by H3 peptide (circles)

848 compared to IC50s for H3 peptide tri-methylated at position K4 (1-21, H3K4(3Me)) (Squares) and H3

849 peptide tri-methylated at position K14 (1-21, H3K14(3Me)) $(10+/-1$ and $0.28+0.03 \mu \mathrm{M}$, respectively).

850 (c) IC50s for the displacement of a range of modified H3 and truncated peptides. Open circles;

851 Biotinylated H3 peptide $(1-21$, IC50 = 0.51 $\mu \mathrm{M})$, open squares; Biotinylated H3K9(Ac) $(1-21$, IC50 =

$8522.22 \mu \mathrm{M})$, open triangles up; Biotinylated H3K4(3Me)K9(Ac) $(1-21$, IC50 = $11.32 \mu \mathrm{M})$, open triangles

853 down; Biotinylated H3K4(3Me) (1-21, IC50 = $17.66 \mu \mathrm{M})$, open diamonds; biotinylated H3K14(Ac) (1-21,

$854 \mathrm{IC} 50=0.43 \mu \mathrm{M})$, open octagon; H3K4(3Me) $(1-10$, IC50 = 12.47 $\mu \mathrm{M})$, plus symbol; H3K4(3Me) $(1-21$,

855 IC50 = 6.10 $\mu \mathrm{M})$, star symbol; biotinylated H3(+YCK $)(1-18+$ YCK, IC50 = $0.27 \mu \mathrm{M})$, solid circle;

856 H3K4(Ac)K14(3Me) $(1-21$, IC50 = $13.10 \mu \mathrm{M})$, solid square; H3K4(3Me)K14(Ac) $(1-21$ IC50 = $9.99 \mu \mathrm{M}$

857 and solid triangle up; biotinylated H3 (1-9 IC50 = $2.83 \mu \mathrm{M})$. (b) Peptides tested and data not shown (due

858 to no fit); Biotinylated H3K14(Ac) (9-20), Biotinylated H3 (15-40) and Biotinylated H3 (5-24). (d)

859 SP140-NL and Histone3.3-HT DNA was transfected into HEK293 cells. NL/HT-fused protein green

860 signal was imaged by microscopy (left) and NanoBRET response (mBU) was measured (right). (e) SP140

861 enrichment at H3K27 ac after $0 \mathrm{~h}, 1 \mathrm{~h}$ and $4 \mathrm{~h}$ of $100 \mathrm{ng} / \mathrm{mL}$ LPS-stimulation of M1 macrophages. (f)

862 Roadmap comparing the DMSO versus GSK761 on the peaks that were called in both instances (In $1 \mathrm{~h}$

863 LPS-stimulated M1 macrophages). If the peaks in both conditions are overlapping, then we call them

864 unaffected (a peak is found under both conditions) (right). If there was a peak in DMSO, but in the

865 presence of GSK761, SP140 binding is reduced or absent, then this is described as 'SP140 reduced'

866 (middle). Finally, if there was no peak called in DMSO samples, but a peak appears in the GSK761

867 condition, then SP140 binding is described as 'SP140 appears' (left). For the circles: All has been

868 compared to the epigenome roadmap data for 1 particular tissue (primary monocytes from peripheral

869 blood). This provides an annotation for every 200bp region in the genome and states its association in 15

870 different categories. The narrow outer circle reflects the proportion of the annotated genome in that

871 particular tissue (primary monocytes from peripheral blood). The thicker inner circle reflects the

872 proportions of the annotated genome where SP140 binding is seen (basepair with the highest signal in a

873 peak) for the peaks as termed above. The numbers inside the circles reflect the number of SP140 enriched

874 genes. (g) Reactome pathway analysis of SP140 DBGs in unstimulated, 1h LPS- and 4h LPS-stimulated

875 M1 macrophages comparing 0.1\% DMSO and $0.04 \mu \mathrm{M}$ GSK761. 
Supplementary figure 7: GSK761 prevents SP140 enrichment at gene set involved in TNF-signaling and antigen presentation.

(a) A complete data set of hallmark pathway analysis for global DEGs in LPS-unstimulated or stimulated (4 or 8h) M1 macrophages (pretreated with $0.1 \%$ DMSO or $0.04 \mu \mathrm{M}$ GSK761). The direction and color of the arrow indicates the direction and size of the enrichment score, the size of the arrow is proportional to the $-\log _{10}(p$-value), and non-transparent arrows represents significantly affected pathways,n=3. (b) An enrichment pathway analysis targeting TNF-signaling for SP140 ChIP-seq (top) and RNA-seq (bottom) comparing 0.1\% DMSO- with $0.04 \mu \mathrm{M}$ GSK761 treated-M1 macrophages at 0,1 and $4 \mathrm{~h}$ of $100 \mathrm{ng} / \mathrm{mL}$ LPS-stimulation. (c) R2 TSS-plot targeting TNF-signaling pathway genes, comparing 0.1\% DMSO with $0.04 \mu \mathrm{M}$ GSK761 treated M1 macrophages after $1 \mathrm{~h}$ of $100 \mathrm{ng} / \mathrm{mL}$ LPS-stimulation. The indicated genes in the graph present the most DBGs. (d) Heatmap of most DEGs that are involved in TNF-signaling, comparing 0.1\% DMSO with $0.04 \mu \mathrm{M}$ GSK761 treated M1 macrophages after 4h of $100 \mathrm{ng} / \mathrm{mL}$ LPSstimulation.(e) SP140 ChIP-seq genome browser view of HLA-DMB, HLA-DMA, HLA-DQA, HLA-DPA1, $H L A-D P B 1, H L A-D P B 2, H L A-C, H L A-B, H L A-F, H L A-A$ and $B R D 2$. Y axis represents signal score of recovered sequences in $0.1 \%$ DMSO and $0.04 \mu \mathrm{M}$ GSK761 treated macrophages after 0,1 and $4 \mathrm{~h}$ of 100 $\mathrm{ng} / \mathrm{mL}$ LPS-stimulation.

\section{Supplementary figure 8: Genes that are involved in innate immune response showed the strongest} concordant differential SP140 binding and gene expression.

Comparative analyses of the top 1000 DBGs (signal) with their gene expression (Wald statistic). Gene expression at $8 \mathrm{~h}$ LPS and ChIP at $1 \mathrm{~h}$ LPS (top) and gene expression at $8 \mathrm{~h}$ LPS and ChIP at $4 \mathrm{~h}$ LPS (bottom). Y axis represents the SP140 differential binding signal (BD).

901 (a) R2 TSS-plot of chemokine-signaling genes, comparing 0.1\% DMSO with $0.04 \mu \mathrm{M}$ GSK761-treated 902 M1 macrophages after $1 \mathrm{~h}$ of $100 \mathrm{ng} / \mathrm{mL}$ LPS-stimulation. The indicated genes in the graph represent the most DBGs involved in chemokine activity/response. (b, c) SP140 ChIP-seq genome browser view of some of most SP140 differentially bound chemokines at different time points of LPS-stimulation in M1 macrophages.SP140-bound chemokines were highlighted. (d) Volcano plot of DEGs involved in chemokine signaling/genes after $1 \mathrm{~h}$ of $100 \mathrm{ng} / \mathrm{mL}$ LPS-stimulation.

\section{Supplementary table legends}

908 Supplemental table 1. Primer sequences used in the quantitative PCR analysis of the genes of interest. 
909 Supplemental table 2. GSK761 screen against human BCPs (Bromoscan assay) reveals no binding

910 at $K d$ of $\leq 30000 \mathrm{nM}$ (for most of tested BCPs) and at $K d$ of $\leq 21000 \mathrm{nM}$ for PBRM1(5), indicating a high

911 degree of specificity of GSK761 for SP140

912 Supplemental table 3: Summary statistics for microarray data (SP140 siRNA M1 macrophages vs

913 scrambled siRNA-M1 macrophages)

914 Supplemental table 4: Summary statistics for microarray data (SP140 siRNA-M1 macrophages

915 stimulated with 4h LPS (100 ng/mL) vs scrambled siRNA-M1 with 4h LPS (100 ng/mL))

916 Supplemental table 5: Counts and summary statistics for RNA-seq data (GSK761-pretreated M1

917 macrophages vs DMSO-pretreated M1 macrophages)

918 Supplemental table 6: Counts and summary statistics for RNA-seq data (GSK761-pretreated M1

919 macrophages stimulated with 4h LPS $(100 \mathrm{ng} / \mathrm{mL})$ vs DMSO-pretreated M1 macrophages stimulated with

920 4h LPS $(100 \mathrm{ng} / \mathrm{mL}))$

921 Supplemental table 7: Counts and summary statistics for RNA-seq data (GSK761-pretreated M1

922 macrophages stimulated with 8h LPS (100 ng/mL) vs DMSO-pretreated M1 macrophages stimulated with

923 8h LPS $(100 \mathrm{ng} / \mathrm{mL}))$

924 Supplemental table 8: The normalized read count for ChIP-seq (DMSO-pretreated M1 macrophages)

925 Supplemental table 9: The normalized read count for ChIP-seq (DMSO-pretreated M1 macrophages

926 stimulated with $1 \mathrm{~h}$ LPS $(100 \mathrm{ng} / \mathrm{mL}))$

927 Supplemental table 10: The normalized read count for ChIP-seq (DMSO-pretreated M1 macrophages

928 stimulated with 4h LPS (100 ng/mL))

929 Supplemental table 11: The normalized read count for ChIP-seq (GSK761-pretreated M1 macrophages)

930 Supplemental table 12: The normalized read count for ChIP-seq (GSK761-pretreated M1 macrophages

931 stimulated with $1 \mathrm{~h}$ LPS $(100 \mathrm{ng} / \mathrm{mL}))$

932 Supplemental table 13: The normalized read count for ChIP-seq (GSK761-pretreated M1 macrophages

933 stimulated with 4h LPS (100 ng/mL)) 


\section{References}

938

939

940

941

942

943

944

945

946

947

948

949

950

951

952

953

954

955

956

957

958

959

960

961

962

963

964

965

966

967

968

969

970

971

972

973

974

975

976

977

978

979

980

981

982

983

984

985

986

1. Rutgeerts, P. A critical assessment of new therapies in inflammatory bowel disease. Journal of Gastroenterology and Hepatology 17, S176-S185 (2002).

2. Papadakis, K.A. et al. Safety and efficacy of adalimumab (D2E7) in Crohn's disease patients with an attenuated response to infliximab. The American journal of gastroenterology 100, 75-79 (2005).

3. Feagan, B.G. et al. Treatment of active Crohn's disease with MLN0002, a humanized antibody to the alpha4beta7 integrin. Clinical gastroenterology and hepatology : the official clinical practice journal of the American Gastroenterological Association 6, 1370-1377 (2008).

4. Sandborn, W.J. et al. A randomized trial of Ustekinumab, a human interleukin-12/23 monoclonal antibody, in patients with moderate-to-severe Crohn's disease. Gastroenterology 135, 1130-1141 (2008).

5. Bain, C.C. \& Schridde, A. Origin, Differentiation, and Function of Intestinal Macrophages. Frontiers in immunology 9, 2733-2733 (2018).

6. Mahida, Y.R. The key role of macrophages in the immunopathogenesis of inflammatory bowel disease. Inflammatory bowel diseases 6, 21-33 (2000).

7. Chen, S., Yang, J., Wei, Y. \& Wei, X. Epigenetic regulation of macrophages: from homeostasis maintenance to host defense. Cellular \& molecular immunology (2019).

8. Schmidt, S.V. et al. The transcriptional regulator network of human inflammatory macrophages is defined by open chromatin. Cell research 26, 151-170 (2016).

9. Chan, C.H. et al. BET bromodomain inhibition suppresses transcriptional responses to cytokineJak-STAT signaling in a gene-specific manner in human monocytes. European journal of immunology 45, 287-297 (2015).

10. Mehta, S. et al. Maintenance of macrophage transcriptional programs and intestinal homeostasis by epigenetic reader SP140. Science immunology 2 (2017).

11. Ray, G. \& Longworth, M.S. Epigenetics, DNA Organization, and Inflammatory Bowel Disease. Inflammatory bowel diseases 25, 235-247 (2019).

12. Bloch, D.B., de la Monte, S.M., Guigaouri, P., Filippov, A. \& Bloch, K.D. Identification and characterization of a leukocyte-specific component of the nuclear body. The Journal of biological chemistry 271, 29198-29204 (1996).

13. Dent, A.L. et al. LYSP100-associated nuclear domains (LANDs): description of a new class of subnuclear structures and their relationship to PML nuclear bodies. Blood 88, 1423-1426 (1996).

14. Karaky, M. et al. SP140 regulates the expression of immune-related genes associated with multiple sclerosis and other autoimmune diseases by NF-kappaB inhibition. Human molecular genetics 27, 4012-4023 (2018). 
15. Zucchelli, C. et al. Sp140 is a multi-SUMO-1 target and its PHD finger promotes SUMOylation of the adjacent Bromodomain. Biochimica et biophysica acta. General subjects 1863, 456-465 (2019).

16. Franke, A. et al. Genome-wide meta-analysis increases to 71 the number of confirmed Crohn's disease susceptibility loci. Nat Genet 42, 1118-1125 (2010).

17. Christodoulou, K. et al. Next generation exome sequencing of paediatric inflammatory bowel disease patients identifies rare and novel variants in candidate genes. Gut 62, 977-984 (2013).

18. Li Yim, A.Y.F. et al. Peripheral blood methylation profiling of female Crohn's disease patients. Clinical Epigenetics 8, 65 (2016).

19. Li, J., Zhao, G. \& Gao, X. Development of neurodevelopmental disorders: a regulatory mechanism involving bromodomain-containing proteins. Journal of Neurodevelopmental Disorders 5, 4 (2013).

20. Dawson, M.A. et al. Inhibition of BET recruitment to chromatin as an effective treatment for MLL-fusion leukaemia. Nature 478, 529-533 (2011).

21. Mertz, J.A. et al. Targeting MYC dependence in cancer by inhibiting BET bromodomains. Proc Natl Acad Sci U S A 108, 16669-16674 (2011).

22. Copsel, S.N. et al. BET Bromodomain Inhibitors Which Permit Treg Function Enable a Combinatorial Strategy to Suppress GVHD in Pre-clinical Allogeneic HSCT. Frontiers in immunology 9, 3104 (2018).

23. Martin, J.C. et al. Single-Cell Analysis of Crohn's Disease Lesions Identifies a Pathogenic Cellular Module Associated with Resistance to Anti-TNF Therapy. Cell 178, 1493-1508.e1420 (2019).

24. Butler, A., Hoffman, P., Smibert, P., Papalexi, E. \& Satija, R. Integrating single-cell transcriptomic data across different conditions, technologies, and species. Nature Biotechnology 36, 411-420 (2018).

25. Stuart, T. et al. Comprehensive Integration of Single-Cell Data. Cell 177, 1888-1902.e1821 (2019).

26. van der Mark, V.A. et al. Phospholipid flippases attenuate LPS-induced TLR4 signaling by mediating endocytic retrieval of Toll-like receptor 4. Cellular and Molecular Life Sciences 74, 715-730 (2017).

27. Ge, S.X., Jung, D. \& Yao, R. ShinyGO: a graphical gene-set enrichment tool for animals and plants. Bioinformatics (2019).

28. Gordon, L.J. et al. Direct Measurement of Intracellular Compound Concentration by RapidFire Mass Spectrometry Offers Insights into Cell Permeability. Journal of biomolecular screening 21, 156-164 (2016). 
29. Wellaway, C.R. et al. Discovery of a Bromodomain and Extraterminal Inhibitor with a Low Predicted Human Dose through Synergistic Use of Encoded Library Technology and Fragment Screening. Journal of Medicinal Chemistry 63, 714-746 (2020).

30. Kazmierski, W.M. et al. DNA-Encoded Library Technology-Based Discovery, Lead Optimization, and Prodrug Strategy toward Structurally Unique Indoleamine 2,3-Dioxygenase-1 (IDO1) Inhibitors. Journal of Medicinal Chemistry (2020).

31. Koelink, P.J. et al. Anti-TNF therapy in IBD exerts its therapeutic effect through macrophage IL10 signalling. Gut (2019).

32. Filippakopoulos, P. et al. Histone recognition and large-scale structural analysis of the human bromodomain family. Cell 149, 214-231 (2012).

33. Zhao, L. et al. Flotillin1 promotes EMT of human small cell lung cancer via TGF- $\beta$ signaling pathway. Cancer Biol Med 15, 400-414 (2018).

34. Netea, M.G. et al. Trained immunity: A program of innate immune memory in health and disease. Science 352, aaf1098-aaf1098 (2016).

35. Belkina, A.C., Nikolajczyk, B.S. \& Denis, G.V. BET protein function is required for inflammation: Brd2 genetic disruption and BET inhibitor JQ1 impair mouse macrophage inflammatory responses. Journal of immunology (Baltimore, Md. : 1950) 190, 3670-3678 (2013).

36. Beecham, A.H. et al. Analysis of immune-related loci identifies 48 new susceptibility variants for multiple sclerosis. Nat Genet 45, 1353-1360 (2013).

37. Bradford, E.M. et al. Epithelial TNF Receptor Signaling Promotes Mucosal Repair in Inflammatory Bowel Disease. Journal of immunology (Baltimore, Md. : 1950) 199, 1886-1897 (2017).

38. Bloemendaal, F.M. et al. TNF-anti-TNF Immune Complexes Inhibit IL-12/IL-23 Secretion by Inflammatory Macrophages via an Fc-dependent Mechanism. Journal of Crohn's \& colitis 12, 1122-1130 (2018).

39. Vos, A.C. et al. Anti-tumor necrosis factor-alpha antibodies induce regulatory macrophages in an Fc region-dependent manner. Gastroenterology 140, 221-230 (2011).

40. Neurath, M.F. IL-23: a master regulator in Crohn disease. Nature Medicine 13, 26-27 (2007).

41. De Vries, L.C.S., Wildenberg, M.E., De Jonge, W.J. \& D’Haens, G.R. The Future of Janus Kinase Inhibitors in Inflammatory Bowel Disease. Journal of Crohn's and Colitis 11, 885-893 (2017).

42. Bonen, D.K. et al. Crohn's disease-associated NOD2 variants share a signaling defect in response to lipopolysaccharide and peptidoglycan. Gastroenterology 124, 140-146 (2003).

43. Leshchiner, E.S. et al. Small-molecule inhibitors directly target CARD9 and mimic its protective variant in inflammatory bowel disease. Proceedings of the National Academy of Sciences 114, 11392-11397 (2017). 
44. Patel, U. et al. Macrophage polarization in response to epigenetic modifiers during infection and inflammation. Drug Discov Today 22, 186-193 (2017).

45. Steinbach, E.C. \& Plevy, S.E. The role of macrophages and dendritic cells in the initiation of inflammation in IBD. Inflammatory bowel diseases 20, 166-175 (2014).

46. Stark, G.R., Kerr, I.M., Williams, B.R., Silverman, R.H. \& Schreiber, R.D. How cells respond to interferons. Annual review of biochemistry 67, 227-264 (1998).

47. Darnell, J.E., Jr., Kerr, I.M. \& Stark, G.R. Jak-STAT pathways and transcriptional activation in response to IFNs and other extracellular signaling proteins. Science (New York, N.Y.) 264, 14151421 (1994).

48. Grohmann, U. et al. Positive regulatory role of IL-12 in macrophages and modulation by IFNgamma. Journal of immunology (Baltimore, Md. : 1950) 167, 221-227 (2001).

49. Nakanishi, K. Unique Action of Interleukin-18 on T Cells and Other Immune Cells. Front Immunol 9, 763-763 (2018).

50. Danese, S., Sans, M. \& Fiocchi, C. The CD40/CD40L costimulatory pathway in inflammatory bowel disease. Gut 53, 1035-1043 (2004).

51. Rugtveit, J., Bakka, A. \& Brandtzaeg, P. Differential distribution of B7.1 (CD80) and B7.2 (CD86) costimulatory molecules on mucosal macrophage subsets in human inflammatory bowel disease (IBD). Clin Exp Immunol 110, 104-113 (1997).

52. Genard, G., Lucas, S. \& Michiels, C. Reprogramming of Tumor-Associated Macrophages with Anticancer Therapies: Radiotherapy versus Chemo- and Immunotherapies. Frontiers in immunology 8, 828 (2017).

53. Gunthner, R. \& Anders, H.J. Interferon-regulatory factors determine macrophage phenotype polarization. Mediators of inflammation 2013, 731023 (2013).

54. Jia, Y. et al. IRF8 is the target of SIRT1 for the inflammation response in macrophages. Innate immunity 23, 188-195 (2017).

55. Madani, N. et al. Implication of the lymphocyte-specific nuclear body protein Sp140 in an innate response to human immunodeficiency virus type 1. Journal of virology 76, 11133-11138 (2002).

56. Regad, T. \& Chelbi-Alix, M.K. Role and fate of PML nuclear bodies in response to interferon and viral infections. Oncogene 20, 7274-7286 (2001).

57. Ruhlemann, M.C. et al. Application of the distance-based F test in an mGWAS investigating beta diversity of intestinal microbiota identifies variants in SLC9A8 (NHE8) and 3 other loci. Gut microbes 9, 68-75 (2018).

58. Hagio, K. et al. High miR-3687 Expression Affects Migratory and Invasive Ability of Oesophageal Carcinoma. Anticancer research 39, 557-565 (2019).

59. Xing, R. miR-3648 Promotes Prostate Cancer Cell Proliferation by Inhibiting Adenomatous Polyposis Coli 2. Journal of nanoscience and nanotechnology 19, 7526-7531 (2019). 
60. Tian, W. et al. MALAT1-miR663a negative feedback loop in colon cancer cell functions through direct miRNA-lncRNA binding. Cell Death \& Disease 9, 857 (2018).

61. Mensah, A.A. et al. Bromodomain and extra-terminal domain inhibition modulates the expression of pathologically relevant microRNAs in diffuse large B-cell lymphoma. Haematologica 103, 2049-2058 (2018).

62. Mio, C. et al. BET bromodomain inhibitor JQ1 modulates microRNA expression in thyroid cancer cells. Oncology reports 39, 582-588 (2018). 


\section{Figure 2}

a

CD14

bioRxiy preprint doi: https://doi.org/10.1101/2020.08.10.239475; this version possted August 20, 2020. The copyrightholder for this preprint 24 (which was not certified by peer review) is the author/funder, who has granted bioRxiv aticense to display the preprint in perpetuity. If is made

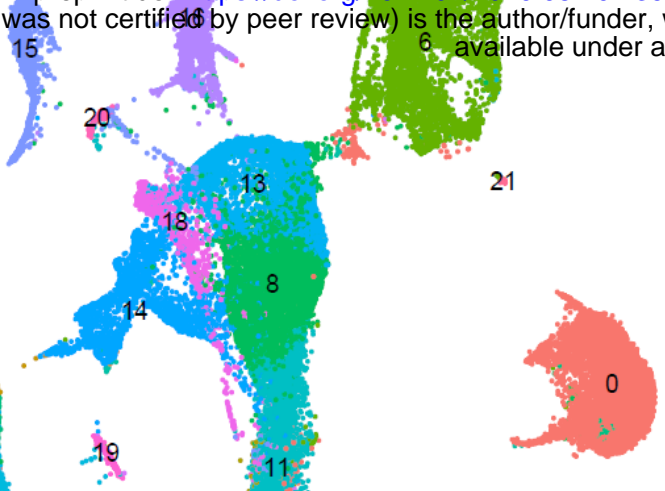

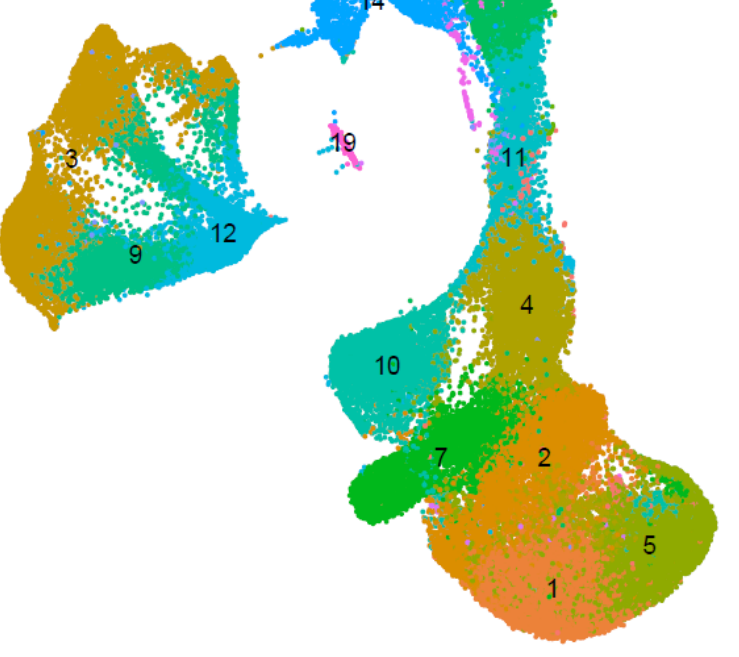

d

\section{SP140 in cluster 6}

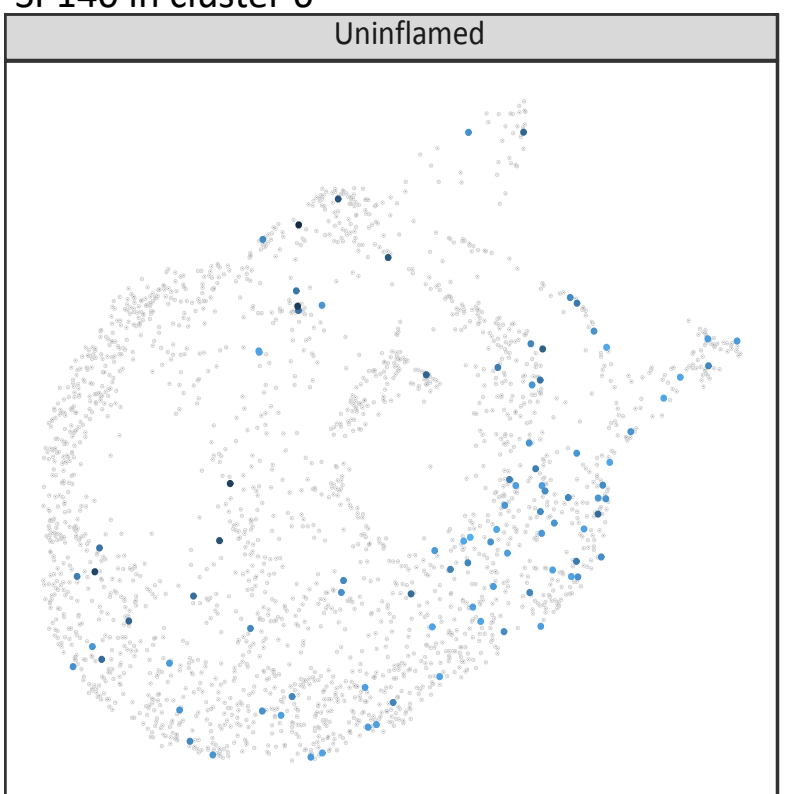

e

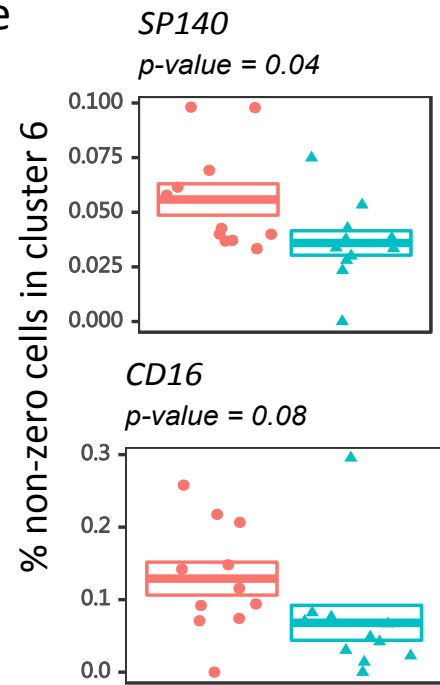

CD68

$p$-value $=0.37$

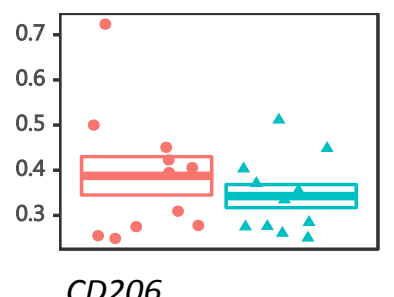

$p$-value $=0.71$

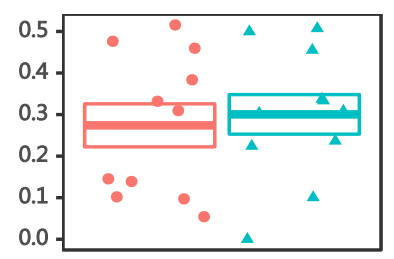

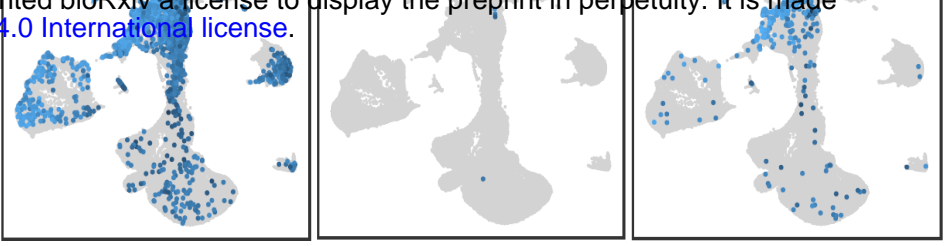

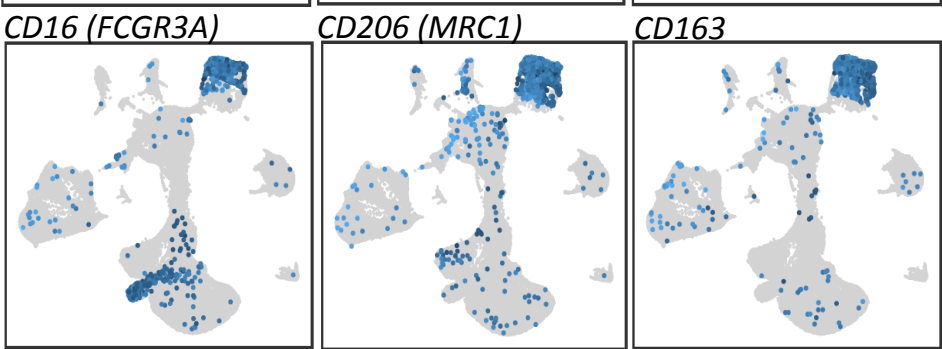

C

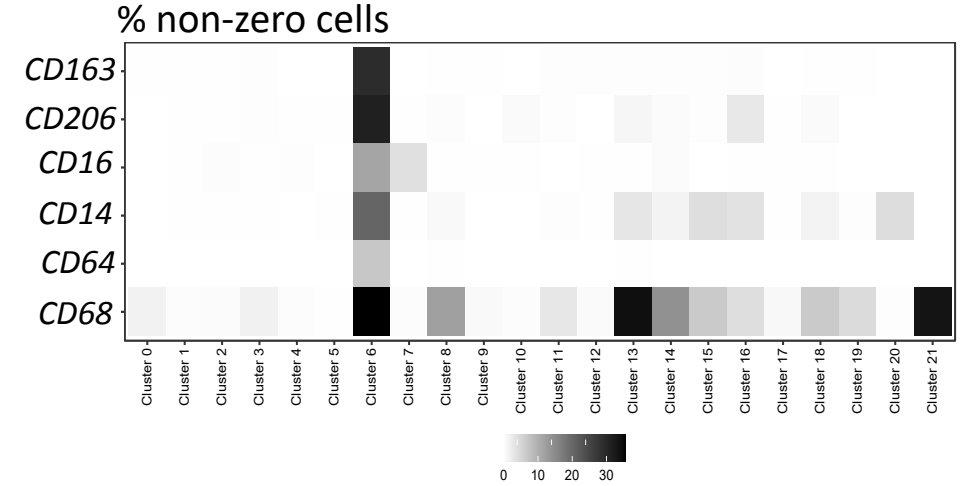

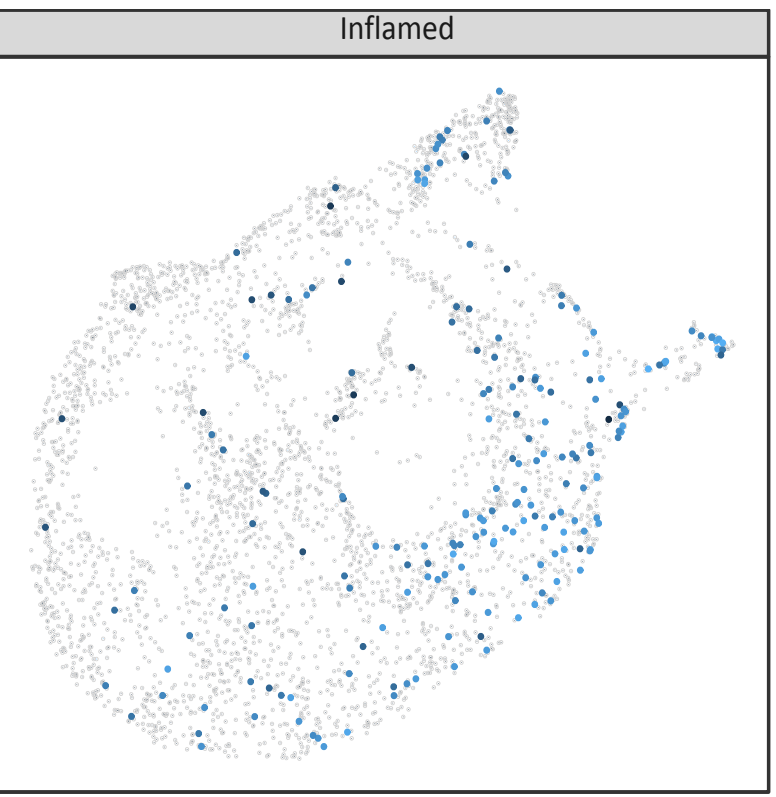

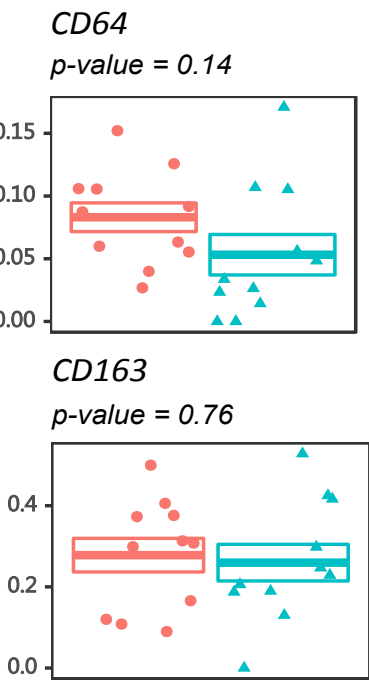

\section{CD14}

$p$-value $=0.17$

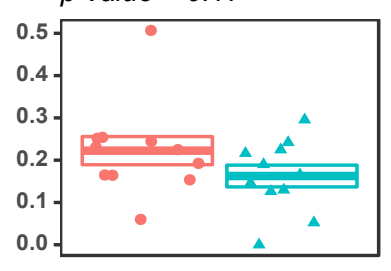

Phenotype

- Inflamed

๑ Uninflamed 


$$
\text { BB2 }
$$
DE L68 (which was preprint doi: https; Hodoi.org/10.9101/2020.08.10.239475; this version posted August 20, 2020. The copyright polder for this preprintth

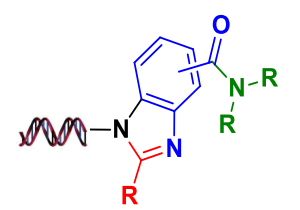

BB1: 2 scaffolds

BB2: 1456 aldehydes (1 blank) BB3: 3157 amines ( 2 blanks)

Library size: $9.19 \mathrm{M}$

d

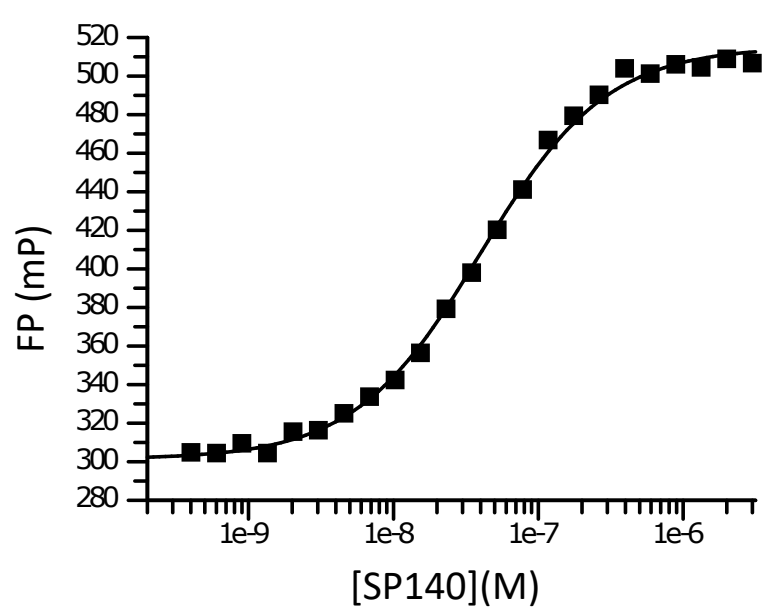

e

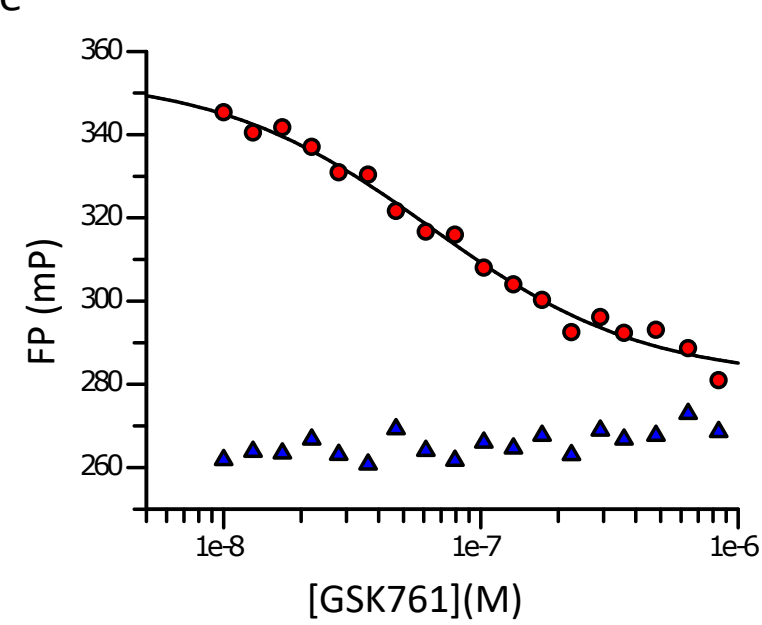

$\mathrm{f}$

Pull down of endogenous SP140 (Western blot)

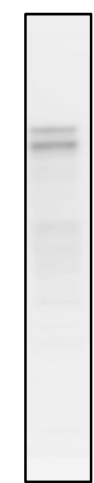

Pull down of transfected HaloSP140 (Halo visualisation)
C<smiles>CC(C)(C)OCCc1cccc(NC(=O)c2ccc(-c3nc4ccc(C(=O)Nc5cccc(CCOC(C)(C)C)c5)cc4n3CCO)cc2)c1</smiles>

$\mathrm{HO}$

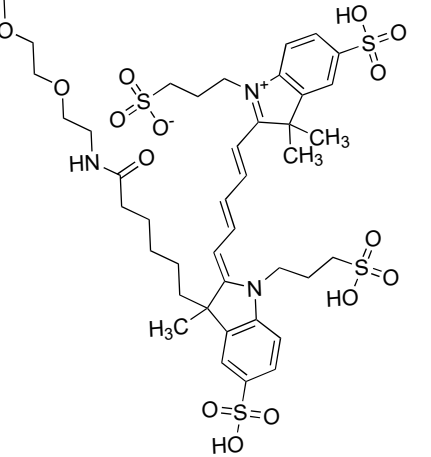

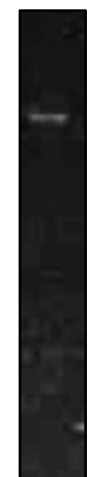


Figure 5

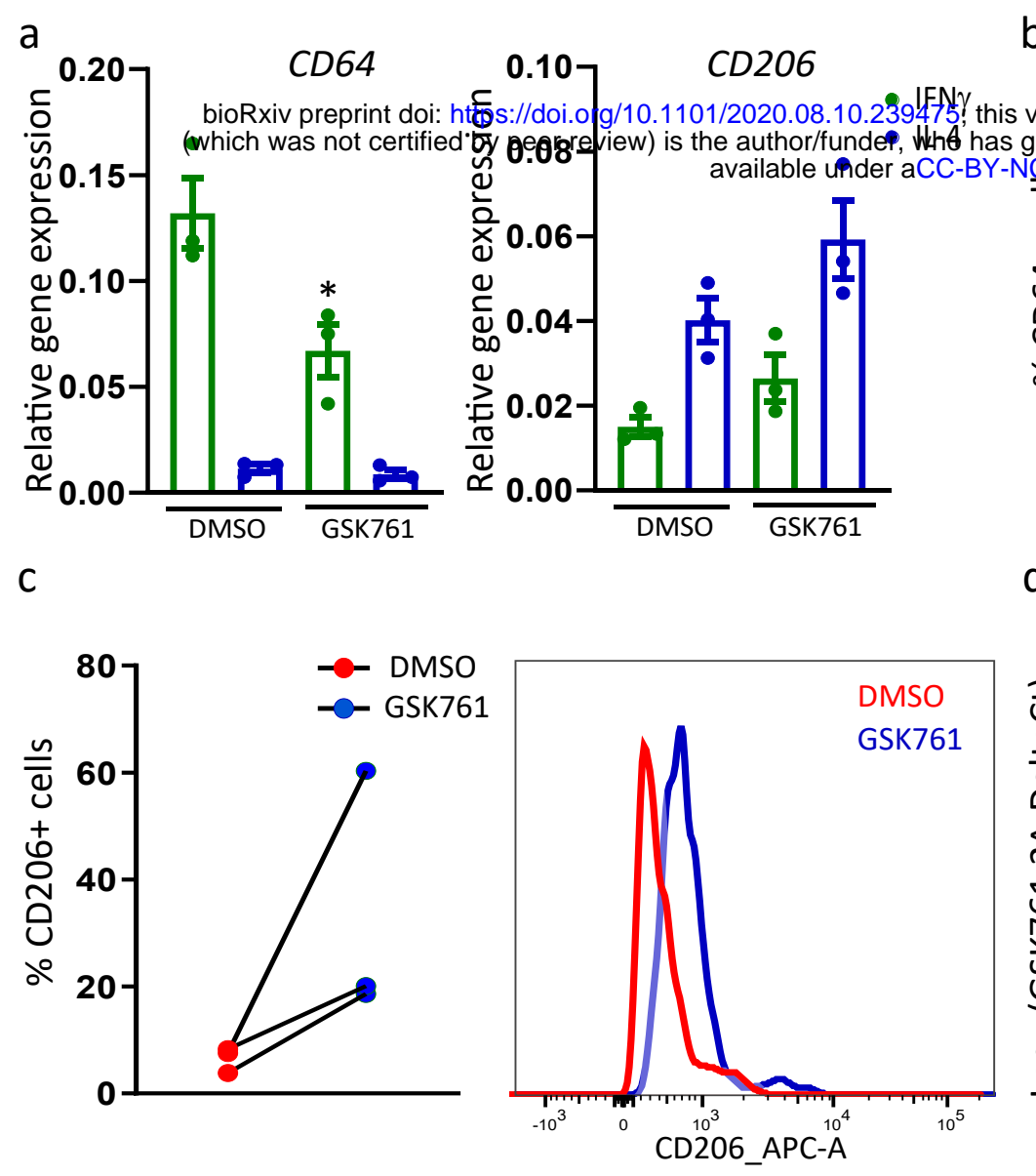

$\mathrm{b}_{100} \rightarrow$ DMSO

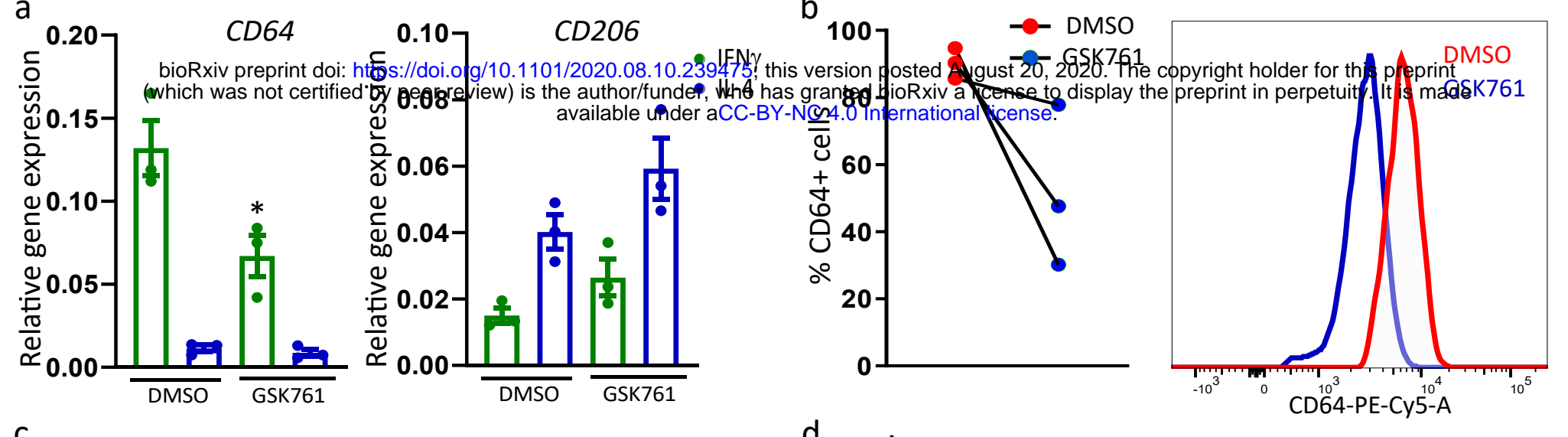

e
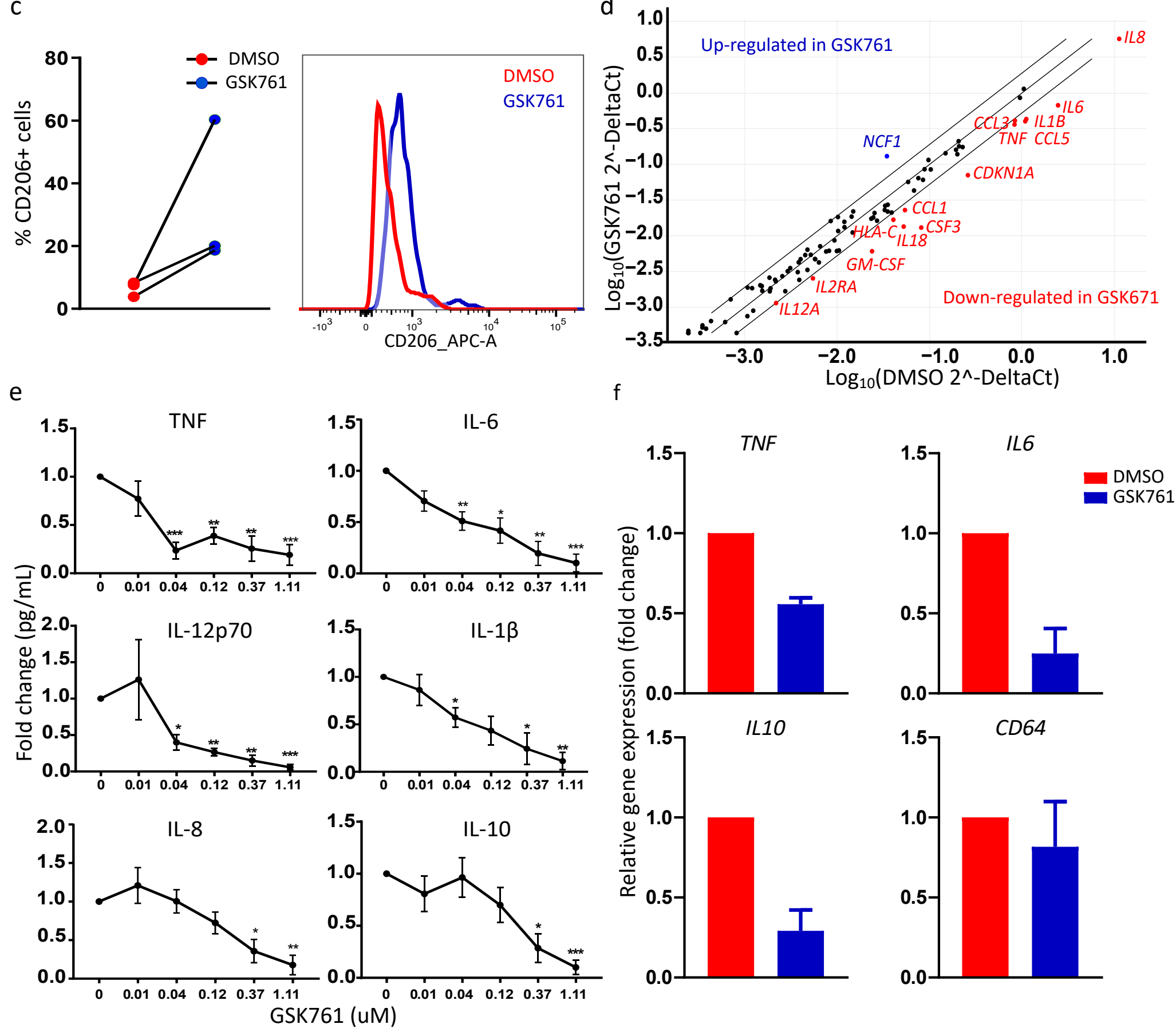
Figure 7

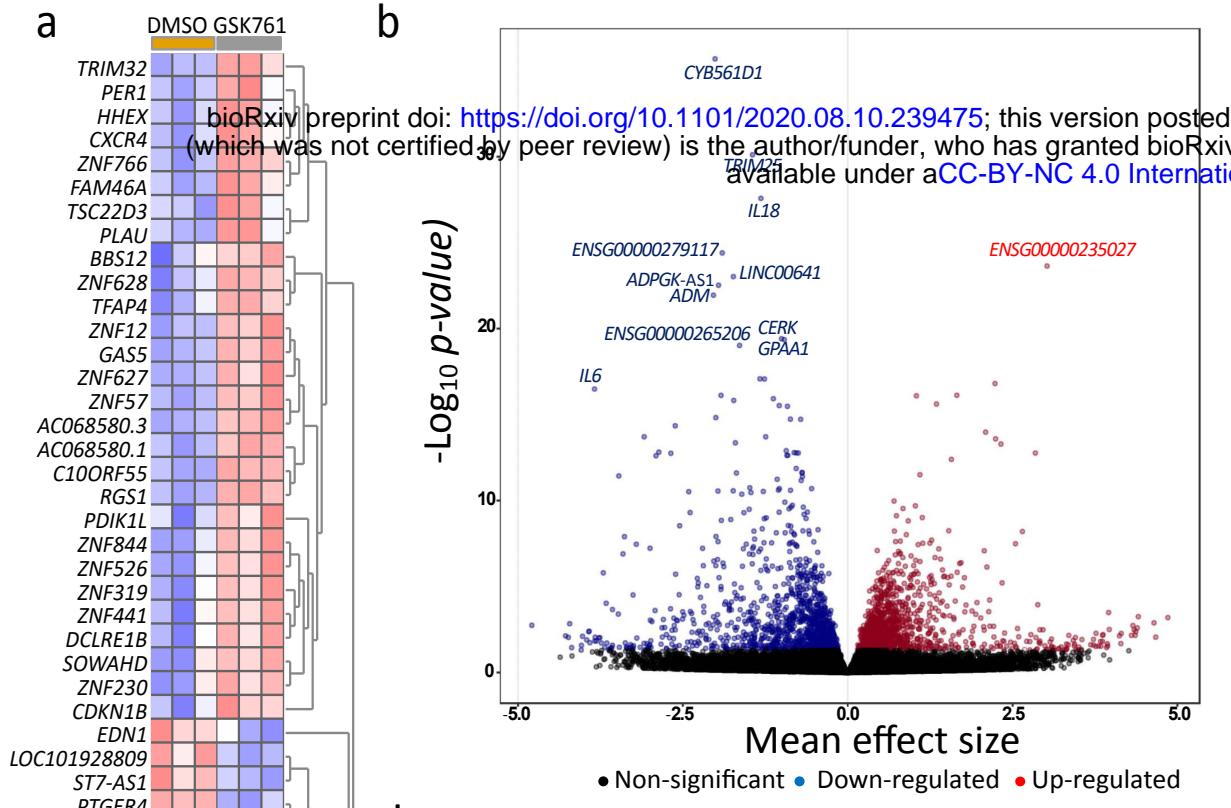

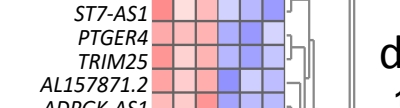

AL157871.
ADPGK-AS
OSR
AC092723.
NT5DC

MIR29B2CHG

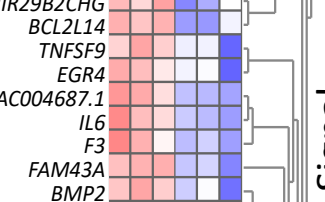

$\begin{array}{r}\text { IL6 } \\ F 3 \\ \hline\end{array}$

$B M P 2$

CXCL1
IL1B

KCNA3
PMAIP1

ZNF503
BTG2

BTG2
IER5

KCNJ2
TP53INP2

OASL
PTGS2

LINCO0515

DNAJB4

FAM65C
GPR132

TRAF1

AGER

PELI1
FSCN1

AP001972.5

AC018644.

LINC01465

CYB561D1

$A D M$
$C D K N 2 B$

CDKN2B
MEGF8

MEGF8
CLCF1

CLCF1
NCR3LG1

LINCO2605
IL23A

IL23A
CCDC200

MIR3945HG

MIR22HG

ZC3HAV1

BTBD19

IL18
E2F7

SLC25A34

AC124798.1

ACOD1

CCL5
GEM

GEM
AL031590.1
TNIP3

TNIP3
ESPL1

ESPL1
LOC101927686

TNFAIP6

CD300E
HIVEP1

ACO06449.6
CAMK1G

Expression_4h, ChIP_4h

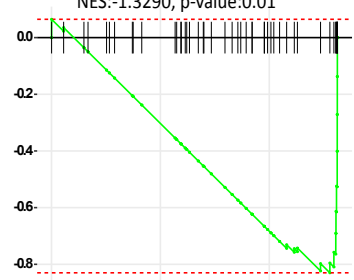

140
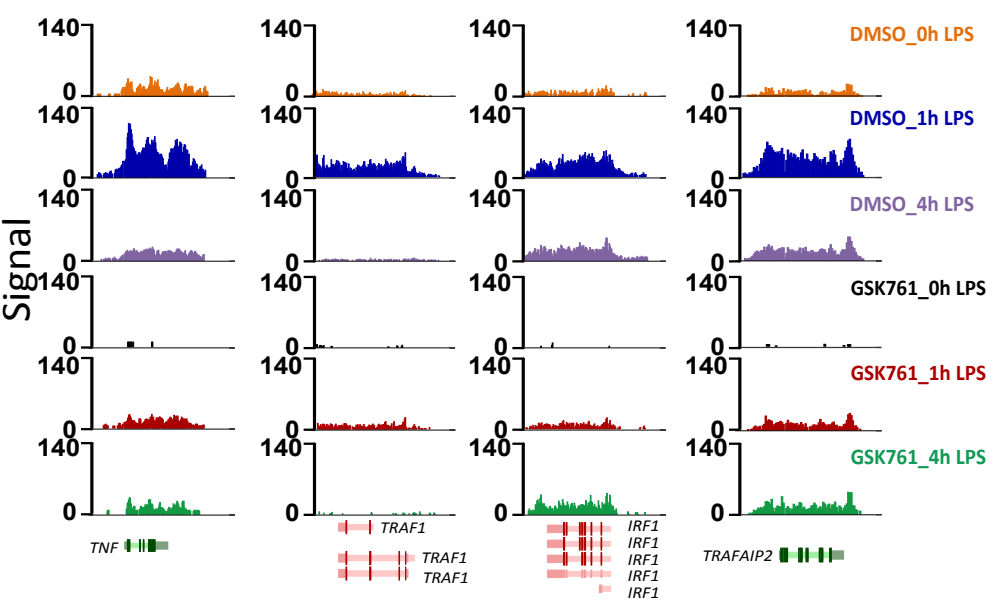

GSK761 vs DMSO

f GSK761 vs DMSO

Expression_4h, ChIP_1h

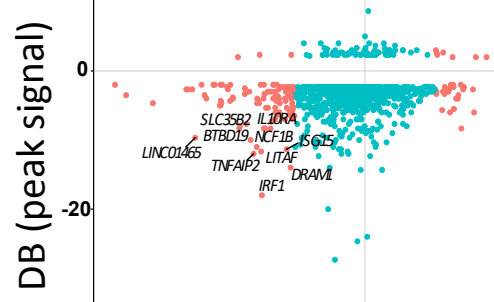

$-40$
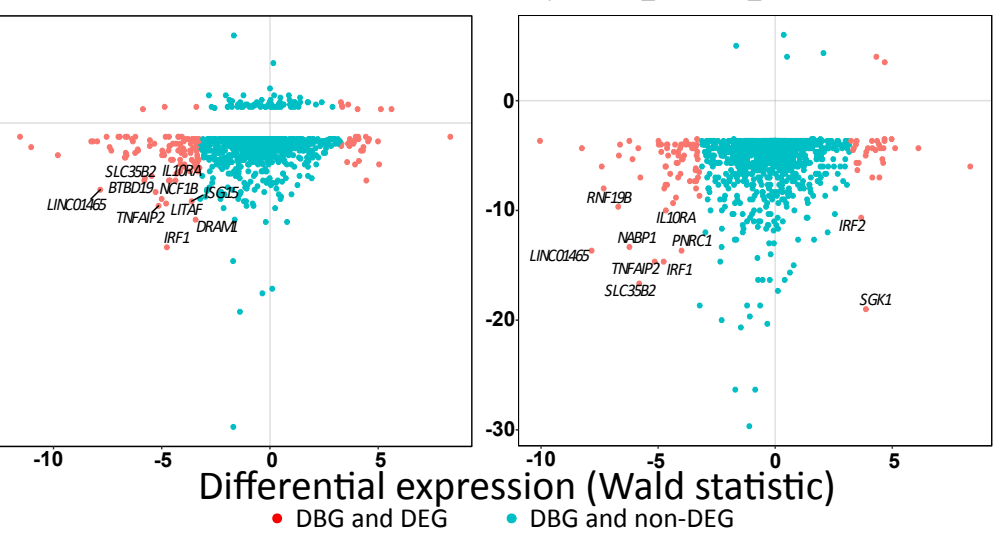

$\mathrm{H}$

GO: Chemokine activity (ChIP_Oh) GO: Chemokine activity (ChIP_1h) GO: Chemokine activity (ChIP_4h) NES:-1.3286, p-value:0.01

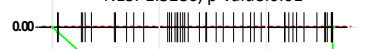
NES:-1.3290, p-value:0.01

NES:-1.2698, p-value: $3.43 E-3$
NES

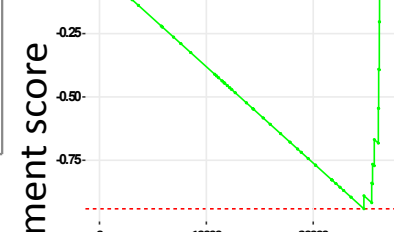

GO: Chemokine activity (RNA-seq_Oh NES:-1.8842, p-value:1.21E-3

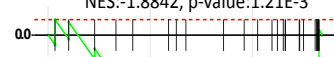

$10000 \quad 20000$

GO: Chemokine activity (RNA-seq_4h) NES:-2.1996, p-value:1.97E-4

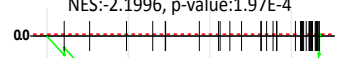

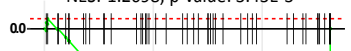

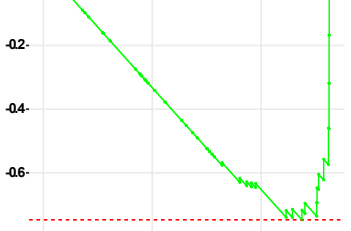

${ }^{\circ} \quad 10000 \quad 20000$ NES: 0.7486 , p-value: 0.8466

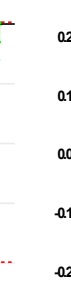

INFAIP2
Normalized read count_GSK761_1h LPS

e

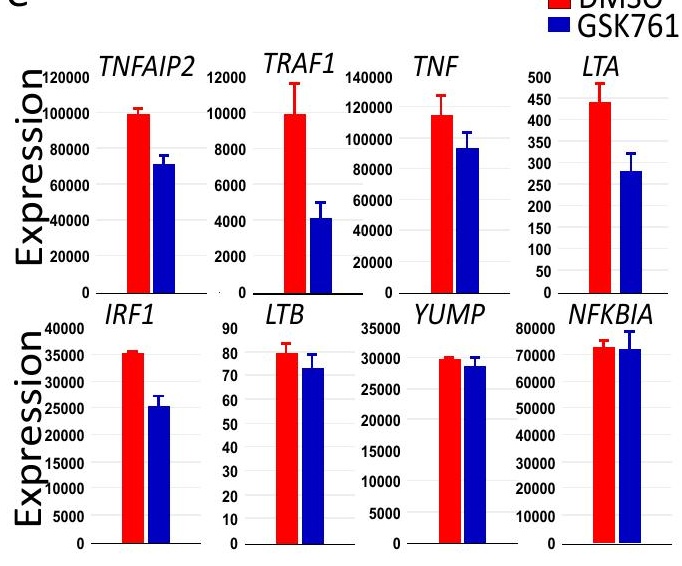

g Homer Known Motif Enrichment

\begin{tabular}{|c|c|c|}
\hline \multirow{2}{*}{\multicolumn{2}{|c|}{ 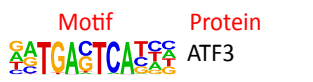 }} & \\
\hline & & \\
\hline 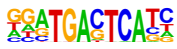 & FOSL2(FRA2) & $1 e-9$ \\
\hline ATGATCAT & BATF & $1 e-9$ \\
\hline 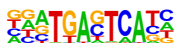 & FOSL1(FRA1) & \\
\hline GAAATICCC & NFkB-p65-Re & \\
\hline AAACTCAAACT & & \\
\hline TGACTCAT & Jun $B$ & \\
\hline GASTl & Jun-AP1 & $e-1$ \\
\hline & & \\
\hline & FOSL2 (FRA2) & \\
\hline
\end{tabular}

Homo de novo Motif

Motif P-value Best match

TCACCCTTIACA

everse opposite

1e-23 $\begin{gathered}\text { PH0158.1_Rhox11_2 } \\ \text { /Jaspar(0.620) }\end{gathered}$

TGTAAGGGTGA

CAGAAATCCCCA

TGGCCATTCTG

HIC2/MA0738.1

/Jaspar(0.675)

GGTCACTTGACC

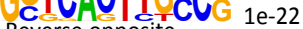

CGGCAAGTSACC
MITF/MA0620.2

/Jaspar(0.741) 


\section{Supplementary figure 1}

bioRxiv preprint doi: https://doi.org/10.1101/2020.08.10.239475; this version posted August 20, 2020. The copyright holder for this preprint

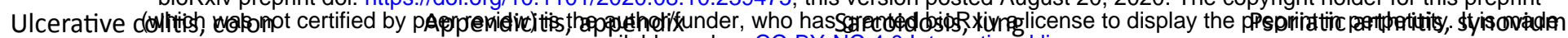
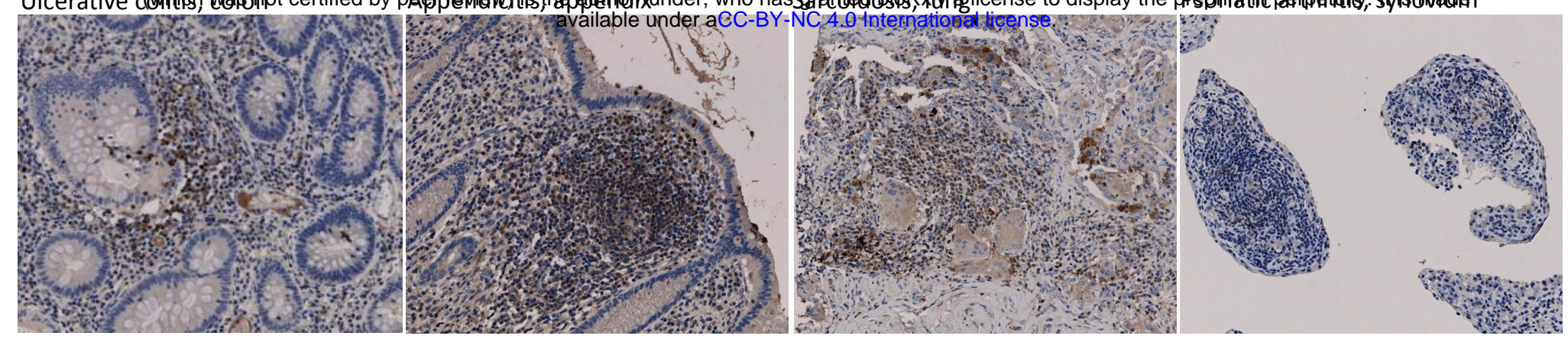

Rheumatoid arthritis, synovium

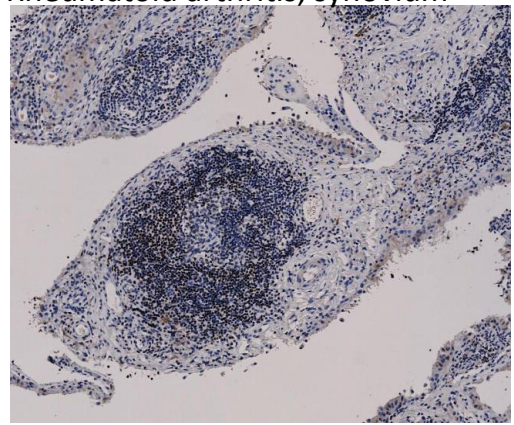

Hashimoto's thyroiditis, thyroid

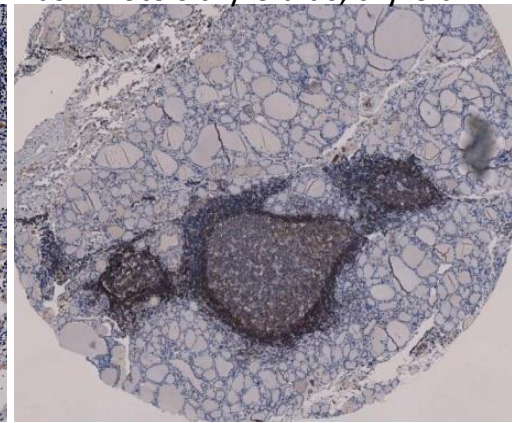

Sjogren's syndrome, cervical cyst

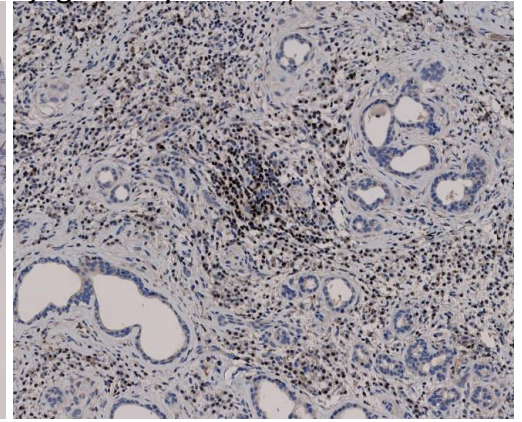




\section{Phenotype}

bioRxiv preprint doi: https://doi.org/10.1101/2020.08.10.239475; this version postephAflgustęe, 2020. The copyright holder for this preprint (which was not certified by peer review) is the author/funder, who has granted bioRxiv a ficense to display the preprint in perpetuity. It is made available under aCC-BY-NC 4.0 Interitionihiffensped

Cluster 9

p-value $=5.09 \mathrm{e}-03$

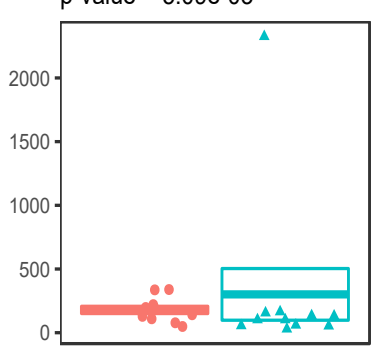

Cluster 13

$\mathrm{p}$-value $=7.42 \mathrm{e}-02$

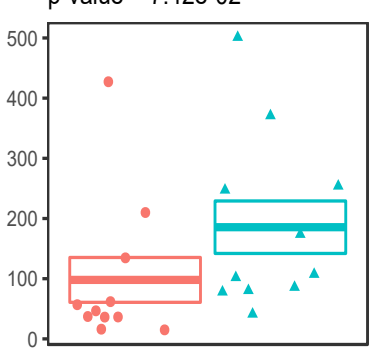

\section{Cluster 17}

$\mathrm{p}$-value $=1.31 \mathrm{e}-01$

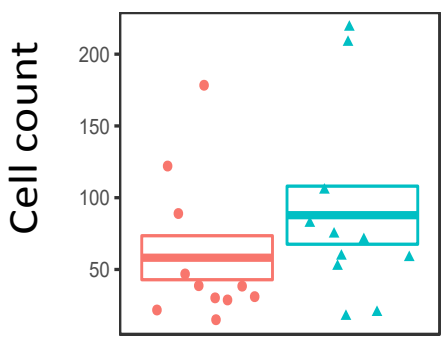

Cluster 12

$p$-value $=5.81 \mathrm{e}-01$

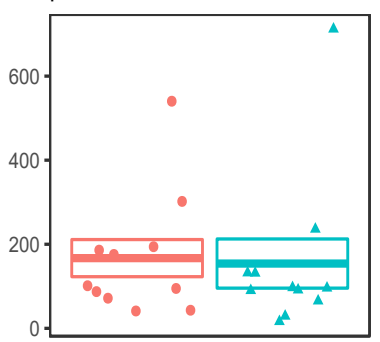

Cluster 19

$\mathrm{p}$-value $=9.24 \mathrm{e}-01$

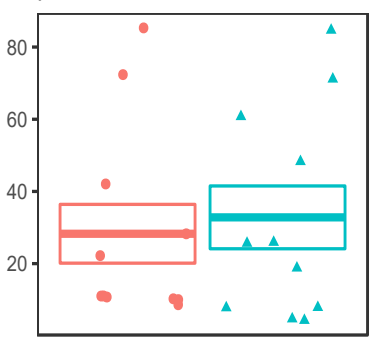

Cluster 21

$\mathrm{p}$-value $=7.24 \mathrm{e}-03$

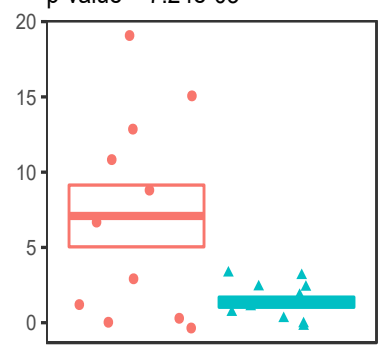

Cluster 10

$\mathrm{p}$-value $=7.64 \mathrm{e}-02$

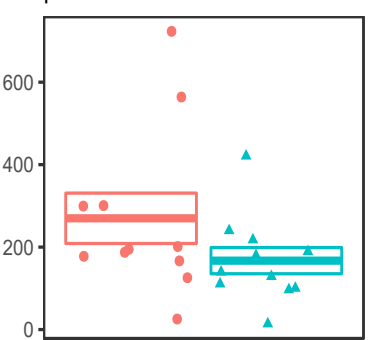

Cluster 0

$\mathrm{p}$-value $=2.14 \mathrm{e}-01$

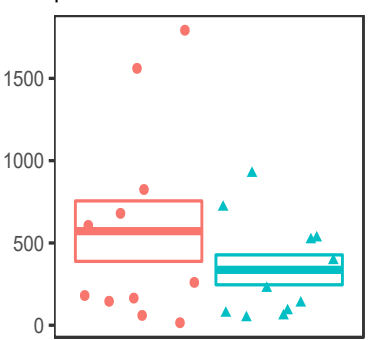

Cluster 7

$p$-value $=6.43 \mathrm{e}-01$

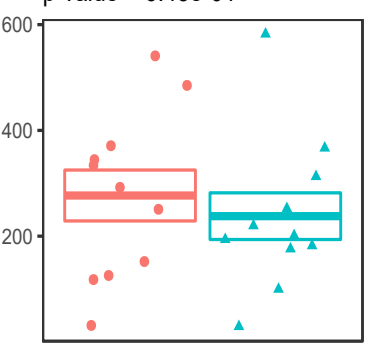

Cluster 20

$p$-value $=9.69 \mathrm{e}-01$

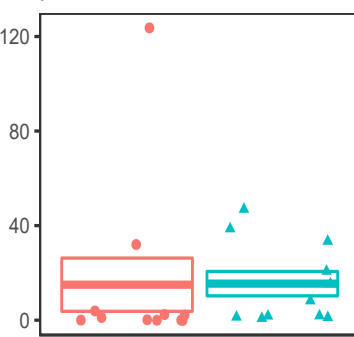

Cluster 8

$p$-value $=3.02 \mathrm{e}-02$

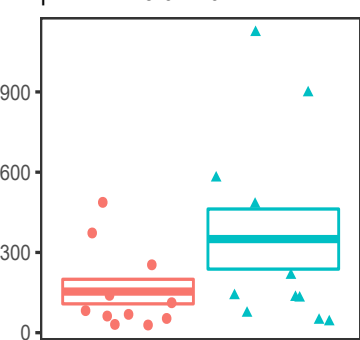

Cluster 15

$\mathrm{p}$-value $=8.63 \mathrm{e}-02$

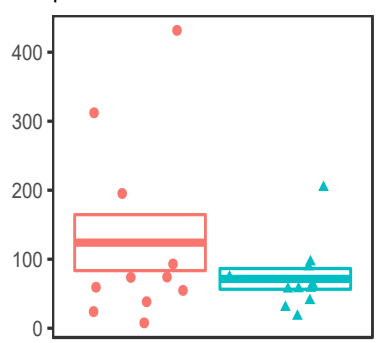

\section{Cluster 18}

$p$-value $=2.27 \mathrm{e}-01$

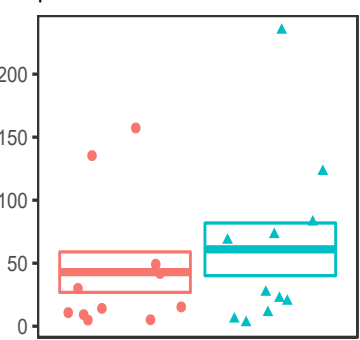

Cluster 3

$\mathrm{p}$-value $=6.88 \mathrm{e}-01$

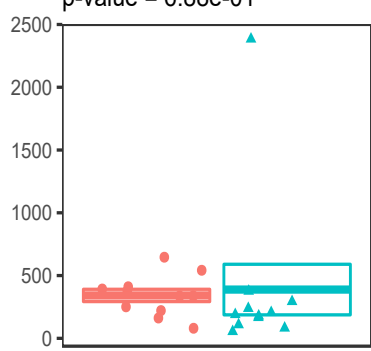

Cluster 6

$p$-value $=3.03 e-02$

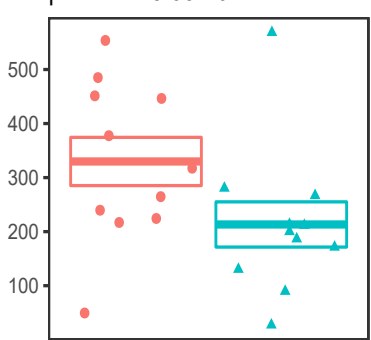

Cluster 14

$\mathrm{p}$-value $=1.17 \mathrm{e}-01$

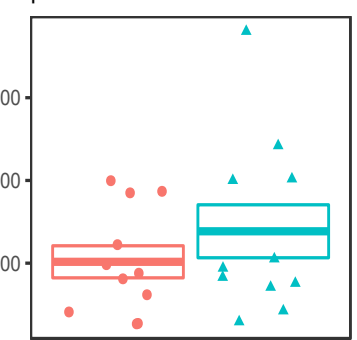

Cluster 2

$\mathrm{p}$-value $=5.11 \mathrm{e}-01$

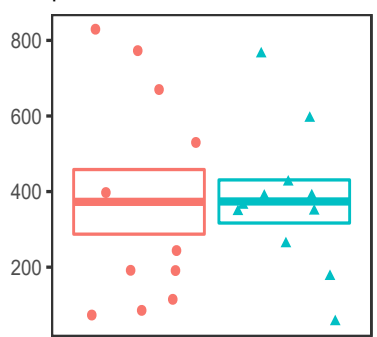

Cluster 4

$\mathrm{p}$-value $=8.27 \mathrm{e}-01$

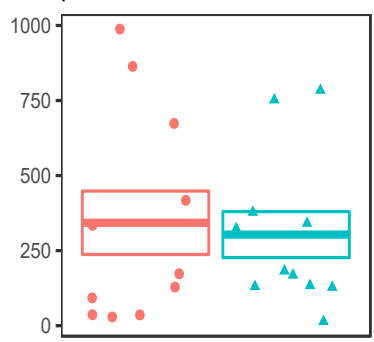

Cluster 11

$\mathrm{p}$-value $=6.64 \mathrm{e}-02$

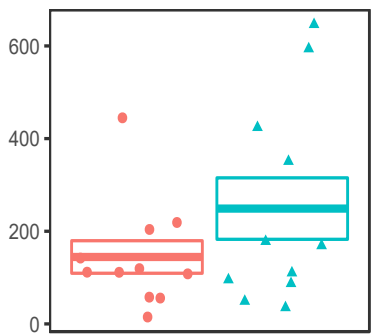

Cluster 1

$\mathrm{p}$-value $=1.28 \mathrm{e}-01$

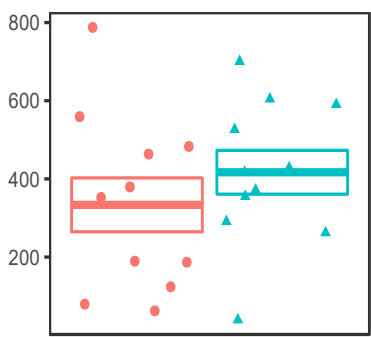

Cluster 16

$p$-value $=5.73 \mathrm{e}-01$

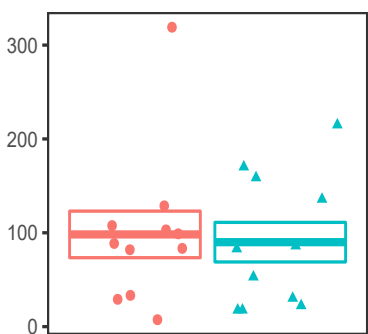

Cluster 5

$\mathrm{p}$-value $=8.38 \mathrm{e}-01$

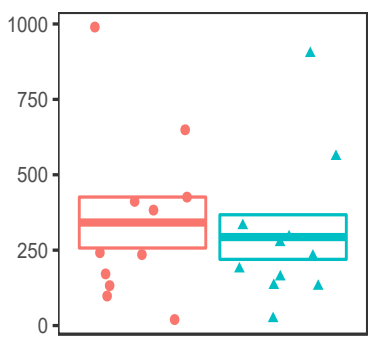




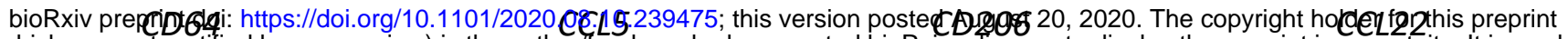
(which was not certified by peer review) is the authorffunder, who has granted bioRxiv a ticense to display the preprint in perpetuity. It is made

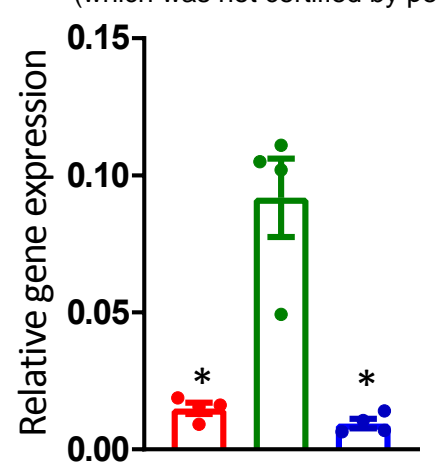

b

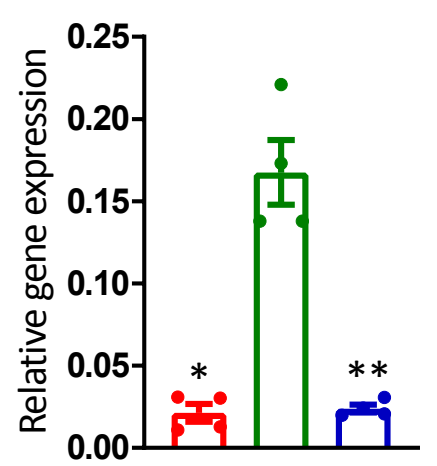

C

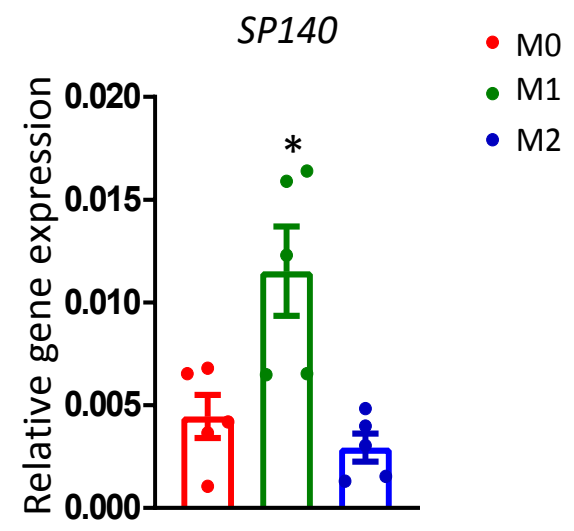

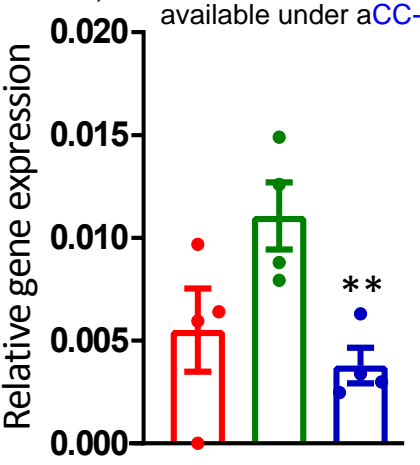

CCL5

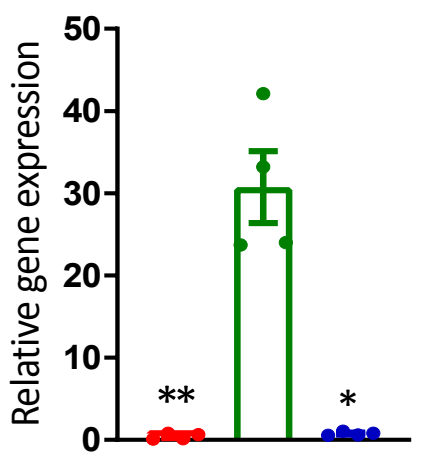

d

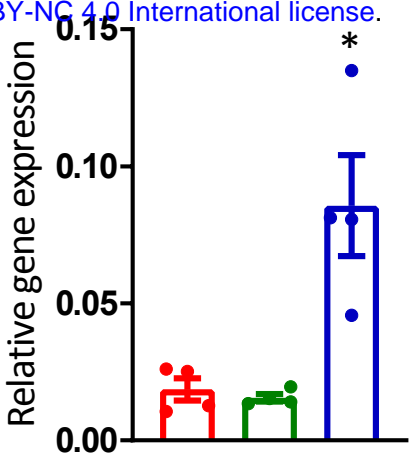

CD206
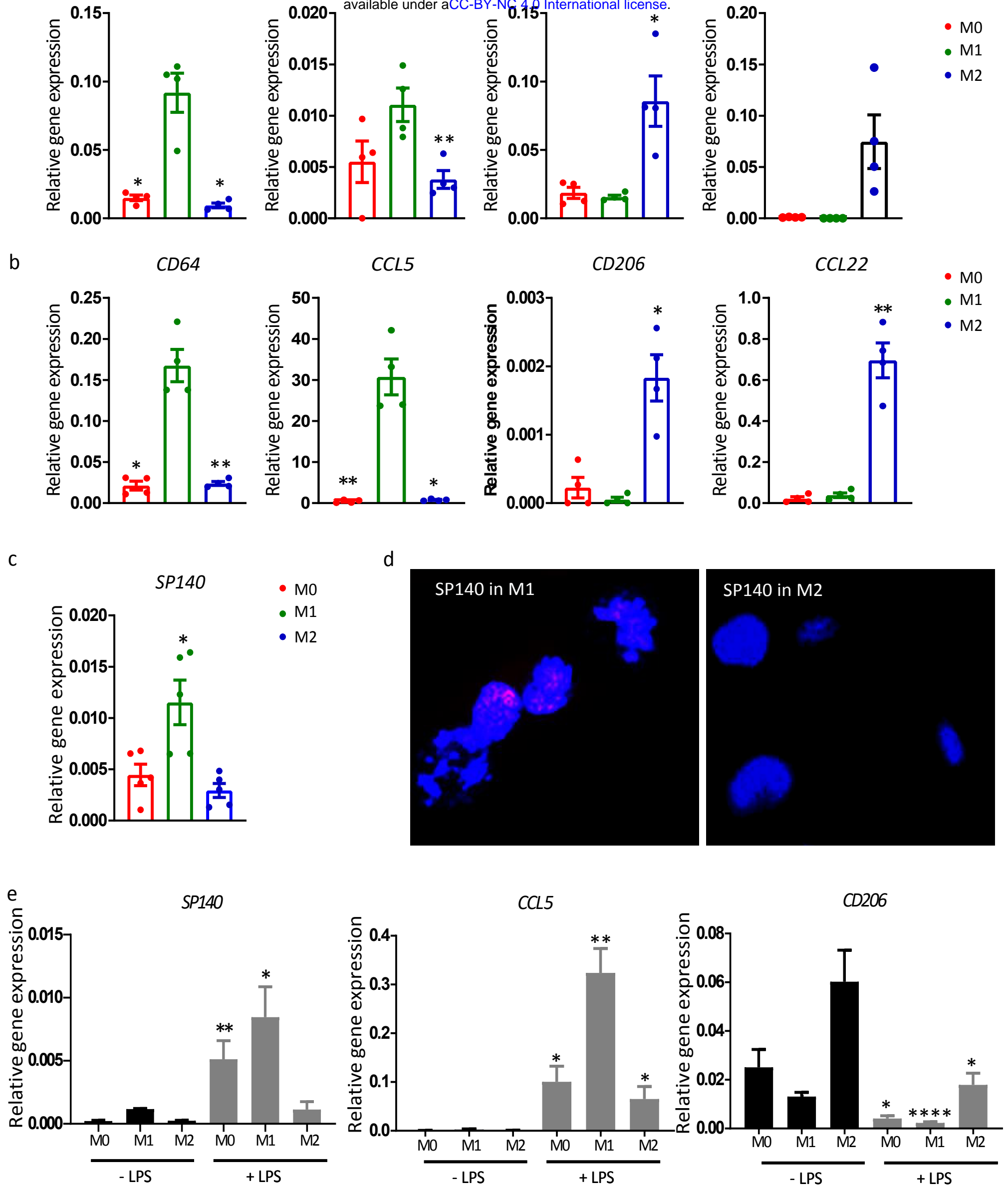
a

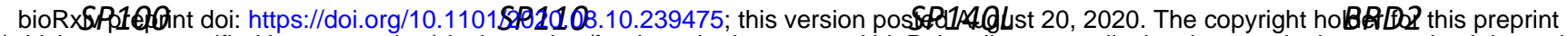
(which was not certified by peer review) is the author/funder, who has granted bioRxiv a license to display the preprint in perpetuity. It is made

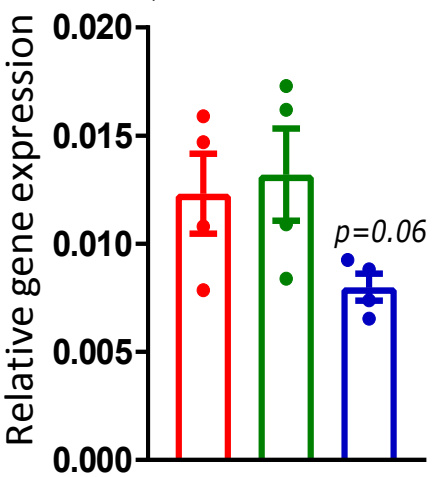

$B R D 3$

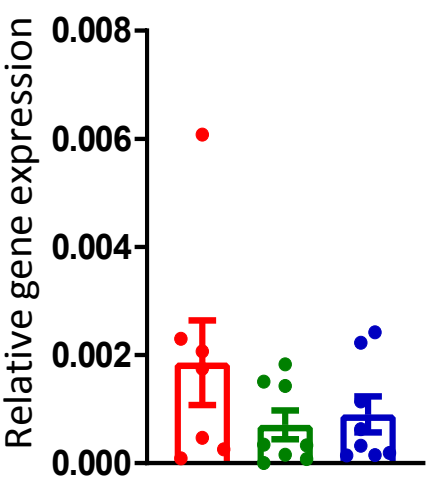

EP300

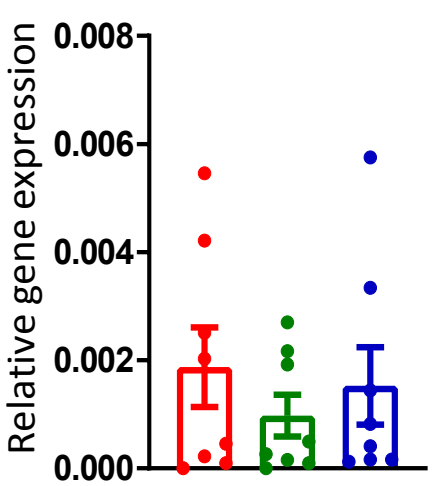

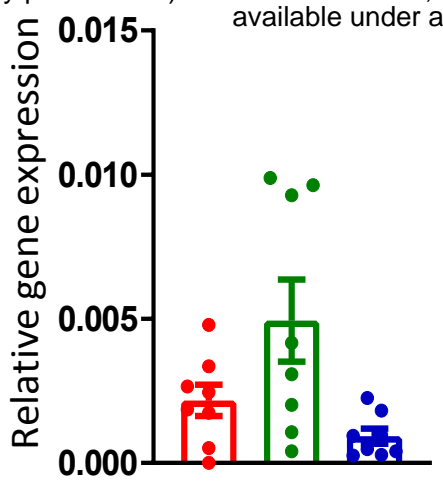

BRD4

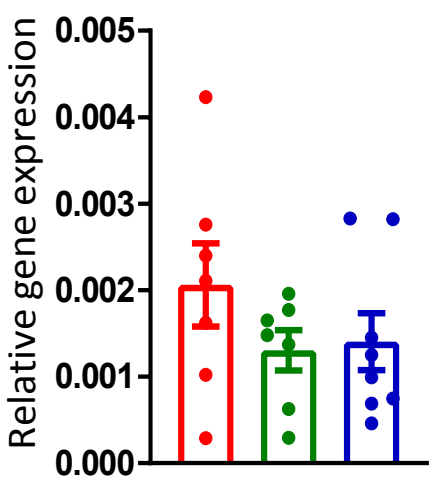

CREBBP

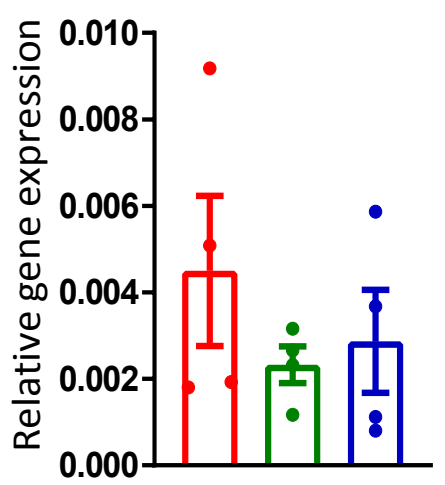

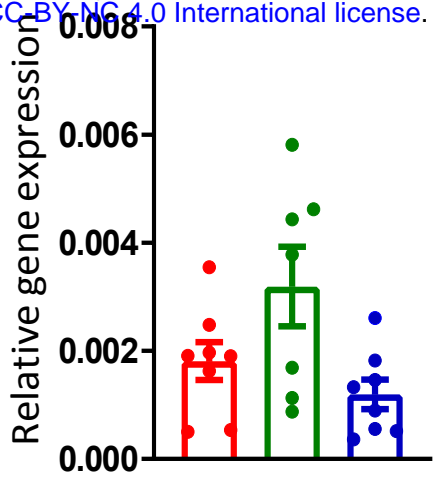

BRD9

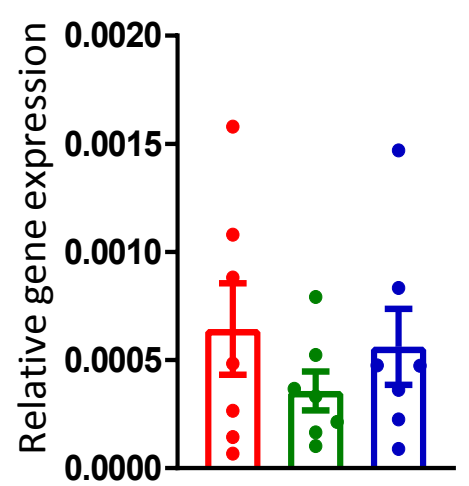

BAZ2A

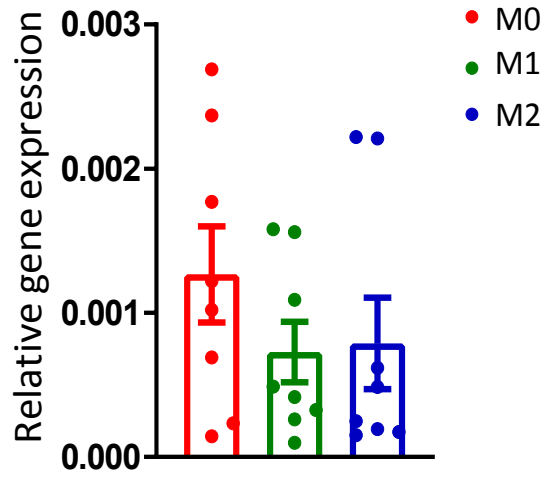

PCAF

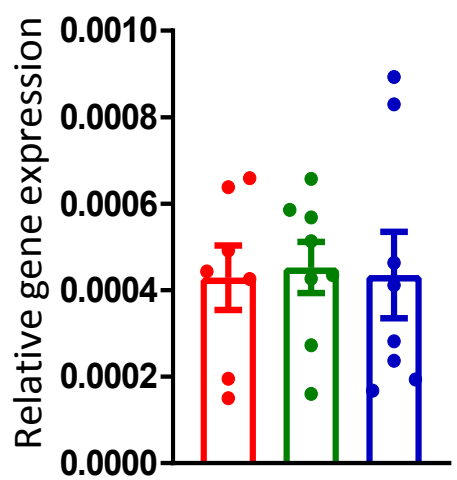

$B A Z 2 B$

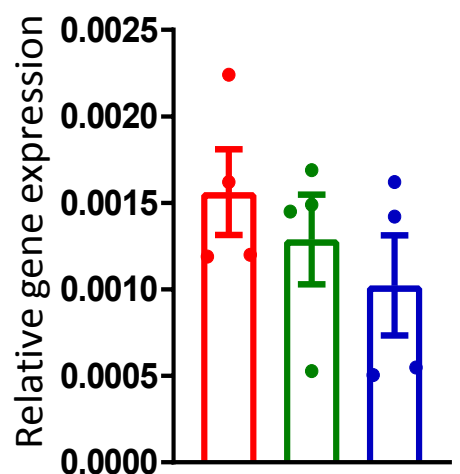

b

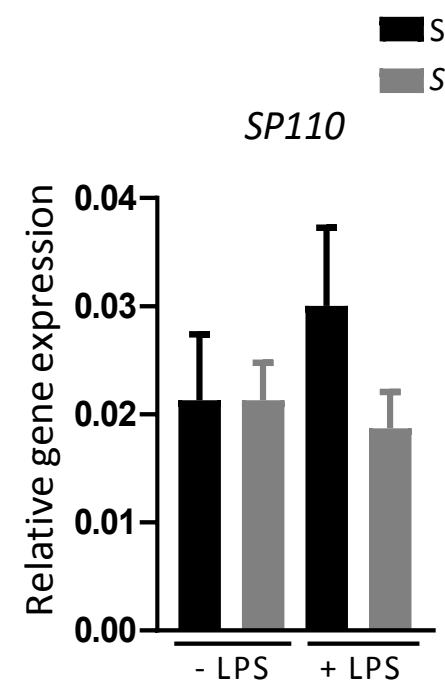

crambled

\begin{abstract}
P140 siRNA
\end{abstract}

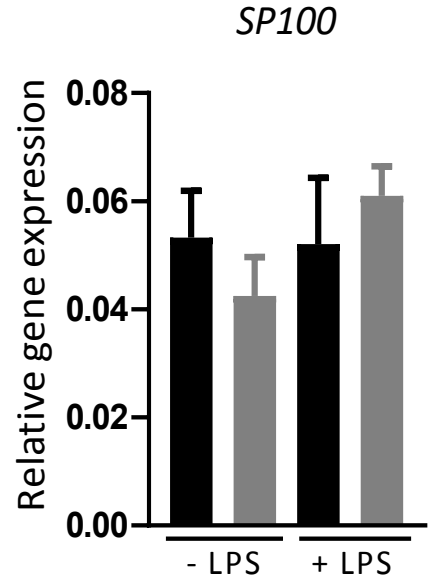

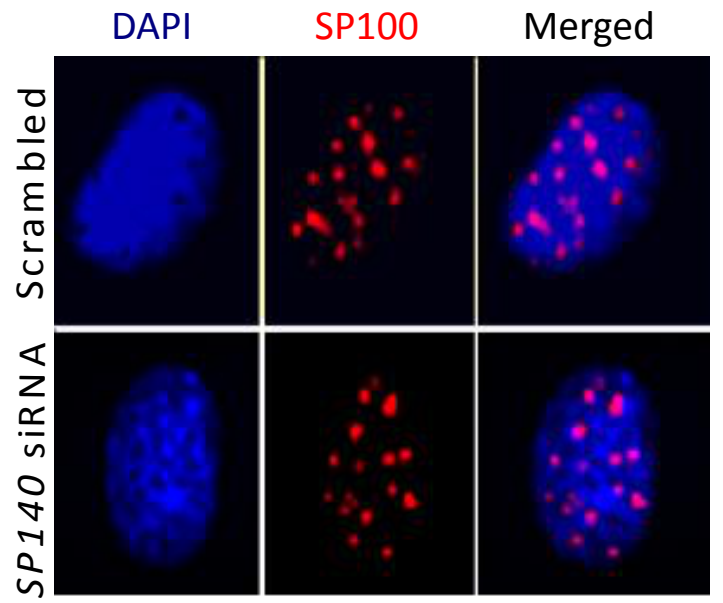

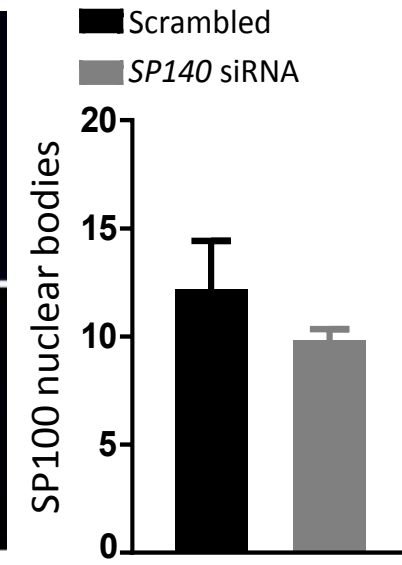




\section{Supplementary figure 5}

a

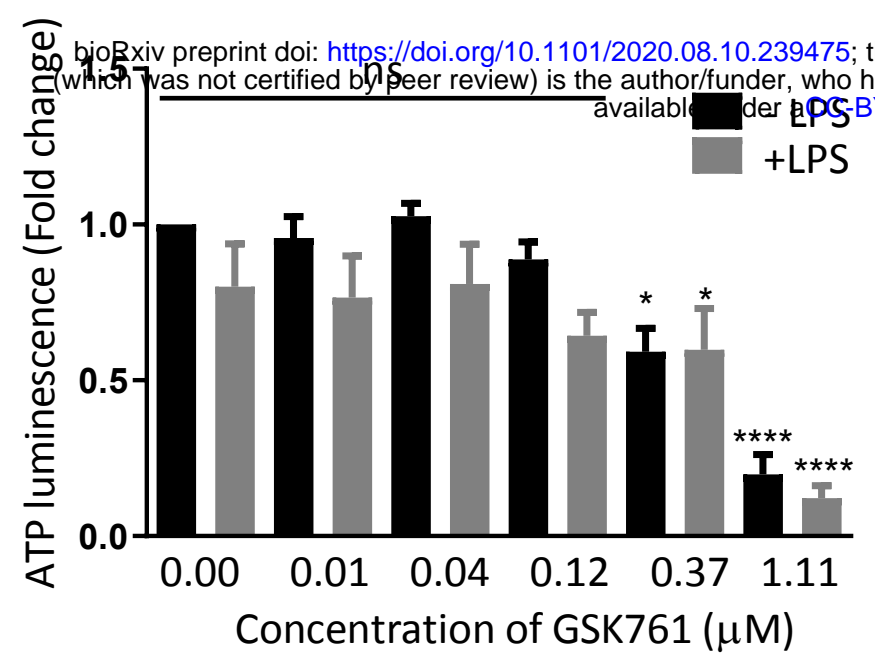

b

DMSO

$0.04 \mu \mathrm{M}$ GSK761 VIABLITY PROFILE

VIABILITY PROFILE

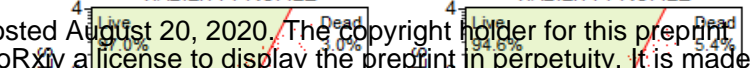

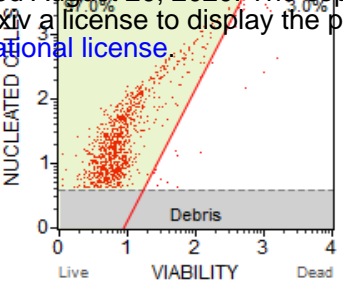
$0.12 \mu \mathrm{M}$ GSK761
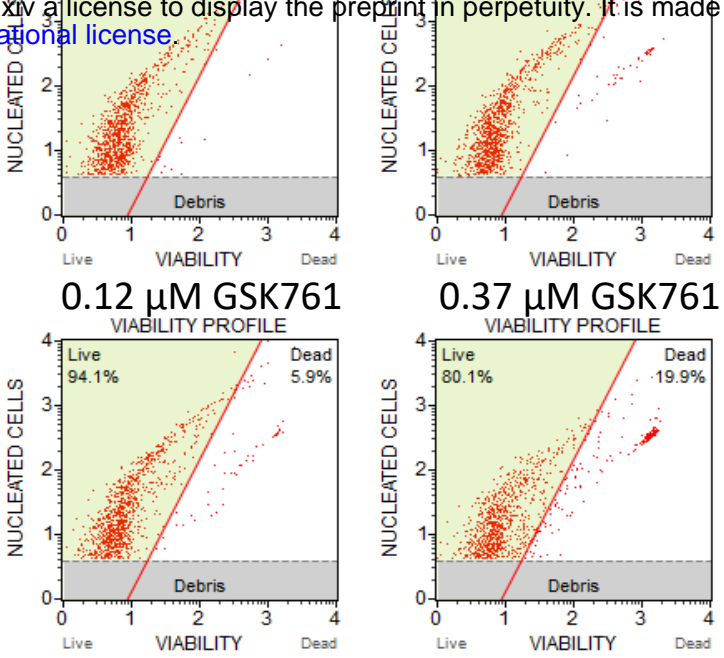

C

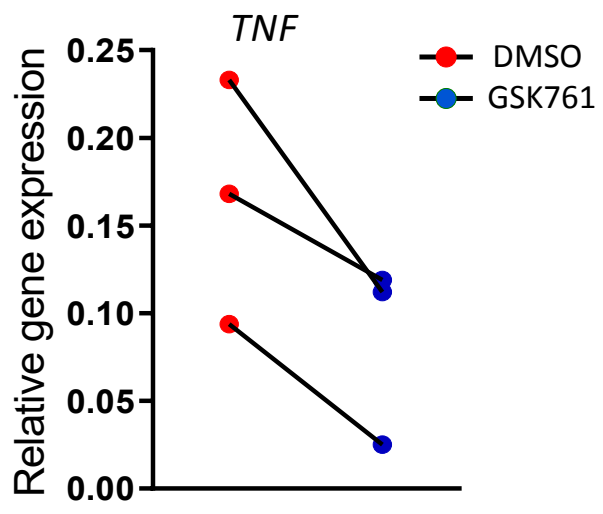




\section{Supplementary figure 6}

a

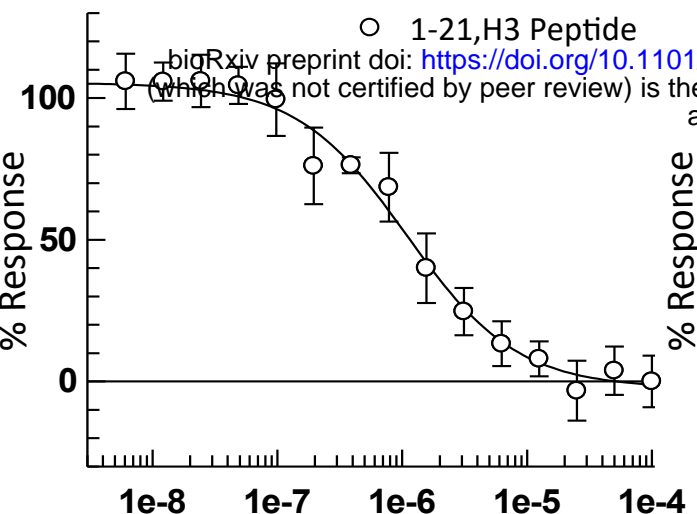

[H3 Peptide] M b

\section{C}

120

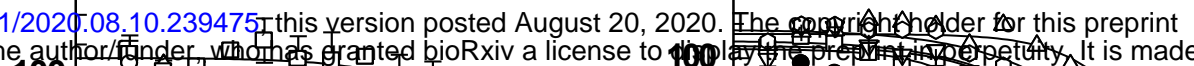

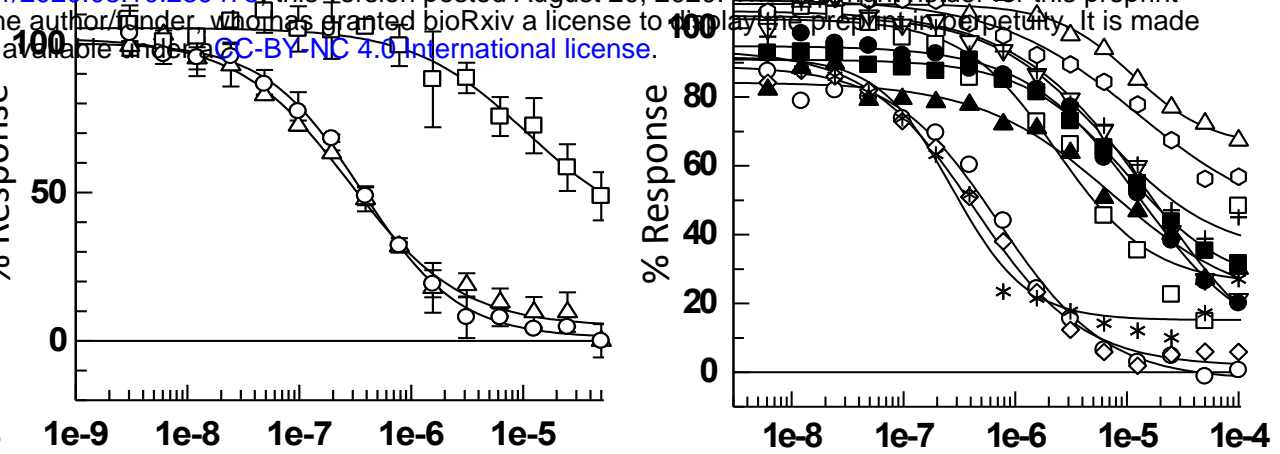

[Peptide] M

e SP140 enrichment at H3K27ac

d

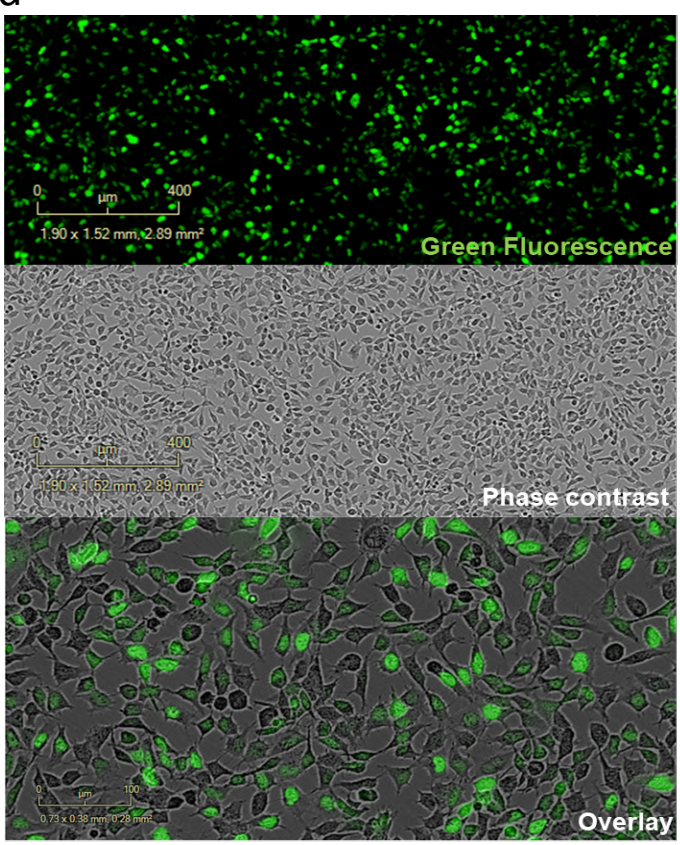

[Peptide] M

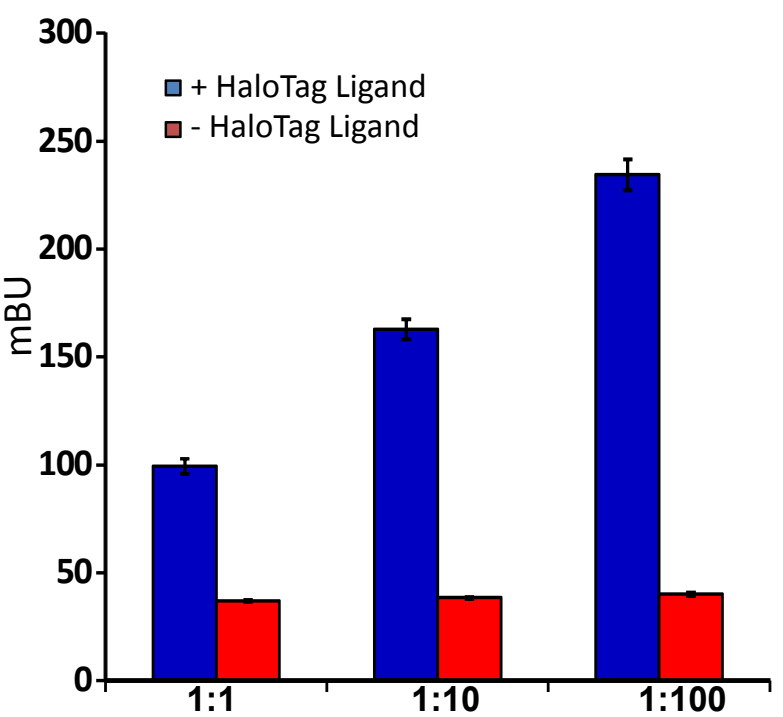

SP140_NanoLuc:Histone_HaloTag f
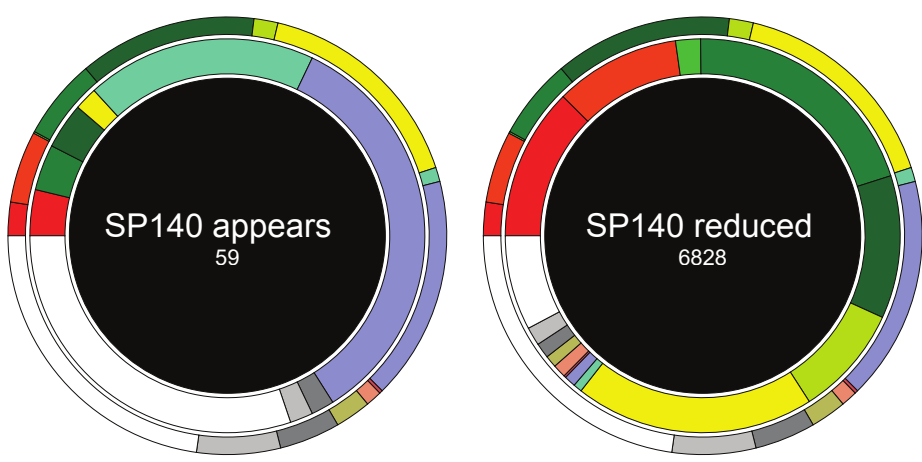

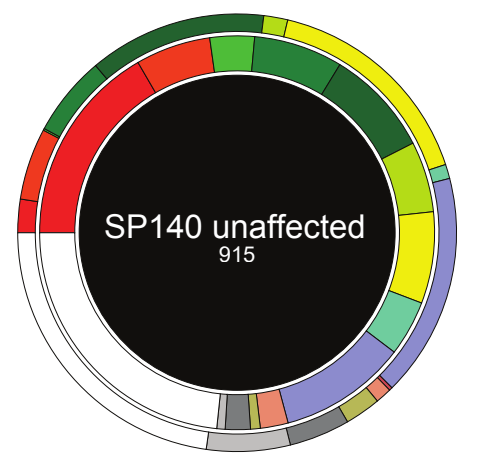

Oh

$1 \mathrm{~h}$

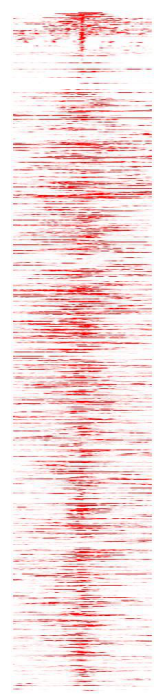

Active TSS

Flanking Active TSS

Transcr. at gene 5 and 3

Strong transcription

Weak transcription

Genic enhancers

Enhancers

ZNF genes \& repeats

Heterochromatin

Bivalent/Poised TSS

Flanking Bivalent TSS/Enh

Bivalent Enhancer

Repressed PolyComb

Weak Repressed PolyComb

Quiescent/Low g

\section{GSK761B vs DMSO_0h LPS_ChIP}

Enrichment FDR Functional Category

7.50E-05 Reactome:R-HSA-168256 Immune System

3.30E-04 Reactome:R-HSA-449147 Signaling by Interleukins

3.90E-04 Reactome:R-HSA-1280215 Cytokine Signaling in Immune system

4.60E-04 Reactome:R-HSA-168928 DDX58/FIH1mediated induction of interferon-alpha/beta

5.20E-03 Reactome:R-HSA-447115 Interleukin-12 family signaling

5.20E-03 Reactome:R-HSA-75893 TNF signaling

8.00E-03 Reactome:R-HSA-5357905 Regulation of TNFR1 signaling

1.80E-02 Reactome:R-HSA-5357956 TNFR1-induced NFkappaB signaling pathway

1.80E-02 Reactome:R-HSA-933542 TRAF6 mediated NF$\mathrm{kB}$ activation

1.90E-02 Reactome:R-HSA-1606322 ZBP1(DAI) mediated induction of type I IFNs

\section{GSK761B vs DMSO_1h LPS_ChIP}

Enrichment FDR Functional Category

1.60E-22 Reactome:R-HSA-1280215 Cytokine Signaling in Immune system

3.10E-20 Reactome:R-HSA-168256 Immune System

5.30E-15 Reactome:R-HSA-449147 Signaling by Interleukins

9.50E-12 Reactome:R-HSA-8953897 Cellular responses to external stimuli

1.10E-10 Reactome:R-HSA-2262752 Cellular responses to stress

6.90E-09 Reactome:R-HSA-913531 Interferon Signaling

2.90E-08 Reactome:R-HSA-6785807 Interleukin-4 and 13 signaling

1.50E-06 Reactome:R-HSA-1280218 Adaptive Immune System

1.50E-06 Reactome:R-HSA-168249 Innate Immune System

1.60E-06 Reactome:R-HSA-1169410 Antiviral mechanism by FN-stimulated genes

\section{GSK761B vs DMSO_4h LPS_ChIP}

.

7.10E-07 Reactome:R-HSA-1280215 Cytokine Signaling in Immune system

7.70E-07 Reactome:R-HSA-449147 Signaling by Interleukins

8.40E-07 Reactome:R-HSA-168256 Immune System

1.70E-05 Reactome:R-HSA-8953897 Cellular responses to external stimuli

1.80E-05 Reactome:R-HSA-8939211 ESR-mediated signaling

2.20E-05 Reactome:R-HSA-9018519 Estrogendependent gene expression

2.20E-05 Reactome:R-HSA-6798695 Neutrophil degranulation

6.30E-05 Reactome:R-HSA-2559583 Cellular Senescence

1.90E-04 Reactome:R-HSA-2262752 Cellular responses to stress

1.90E-04 Reactome:R-HSA-74160 Gene expression (Transcription) 


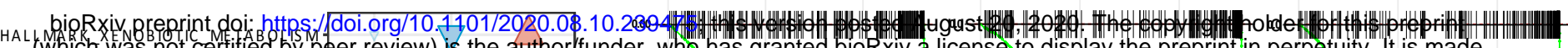
HALLMARK_WNT_BETA_CATENIN_SIGNALING.

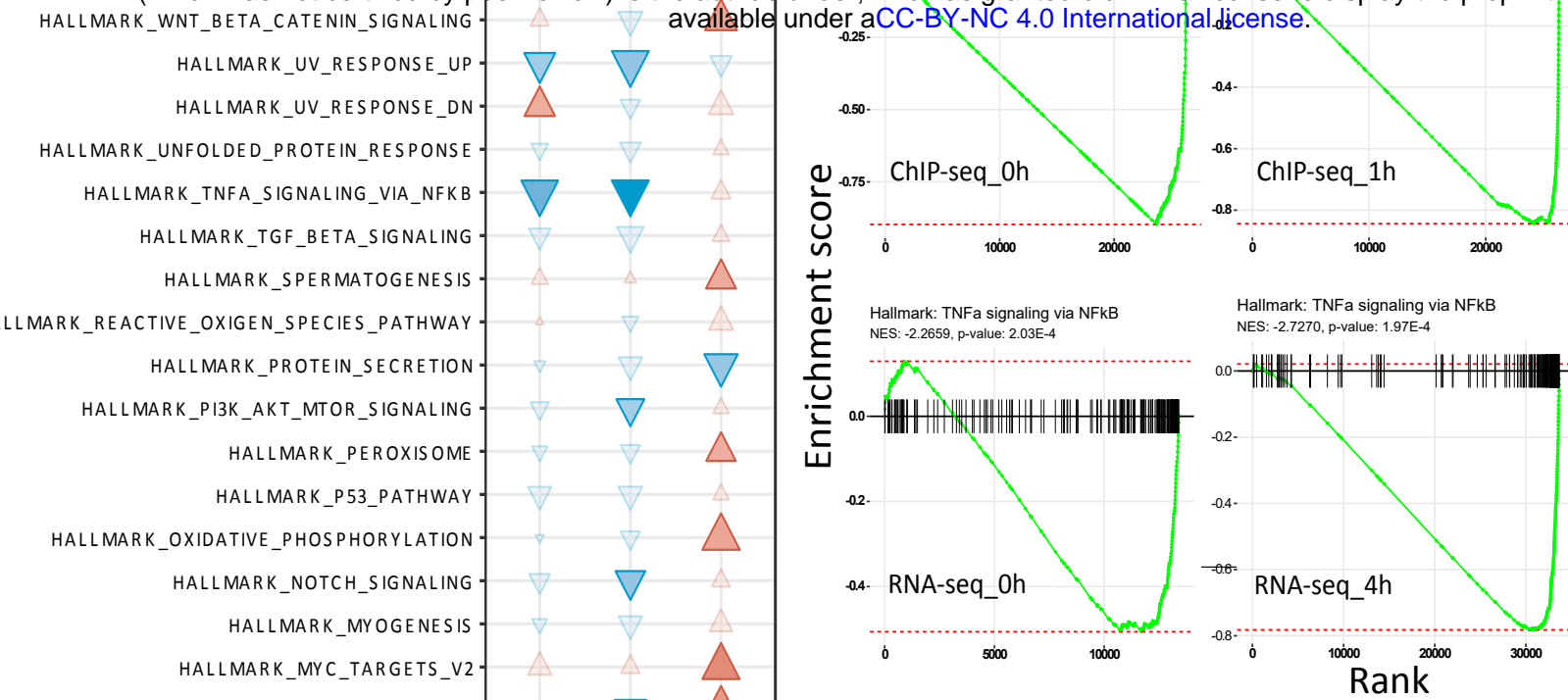

IVE_OXIGEN_SPECIES_PATHWAY HALLMARK_MYC_TARGETS_V1 HALLMARK_MTORC1_SIGNALING HALLMARK_MITOTIC_SPINDLE HALLMARK_KRAS_SIGNALING_UP HALLMARK_KRAS_SIGNALING_DN HALLMARK_INTERFERON_GAMMA_RESPONSE HALLMARK_INTERFERON_ALPHA_RESPONSEHALLMARK_INFLAMMATORY_RESPONSEHALLMARK_IL6_JAK_STAT3_SIGNALING HALLMARK_IL2_STAT5_SIGNALING HALLMARK_HYPOXIA HALLMARK_HEME_METABOLISMHALLMARK_HEDGEHOG_SIGNALING HALLMARK_GLYCOLYSIS HALLMARK_G2M_CHECKPOINT HALLMARK_FATTY_ACID_METABOLISMHALLMARK_ESTROGEN_RESPONSE_LATE HALLMARK_ESTROGEN_RESPONSE_EARLY HALLMARK_EPITHELIAL_MESENCHYMAL_TRANSITION HALLMARK_E2F_TARGETS HALLMARK_DNA_REPAIR HALLMARK_COMPLEMENT HALLMARK_COAGULATION HALLMARK_CHOLESTEROL_HOMEOSTASIS HALLMARK_BILE_ACID_METABOLISMHALLMARK_APOPTOSIS HALLMARK_APICAL_SURFACE HALLMARK_APICAL_JUNCTION HALLMARK_ANGIOGENESIS HALLMARK_ANDROGEN_RESPONSE HALLMARK_ALLOGRAFT_REJECTION HALLMARK_ADIPOGENESIS

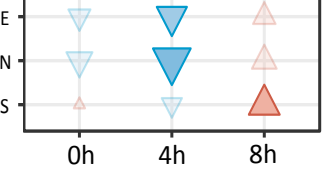

Significant

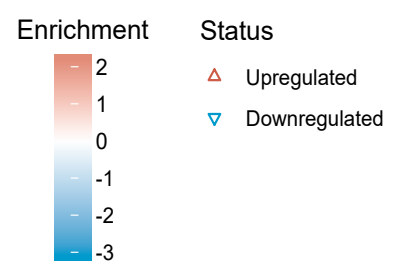

-log10(pval)

$\Delta 1$

$\Delta 2$
C

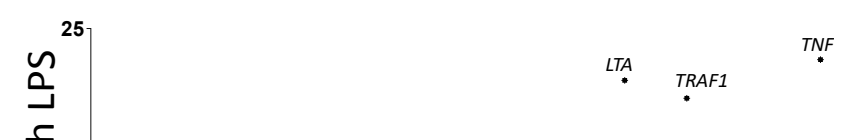

$\sum_{0}^{n}$

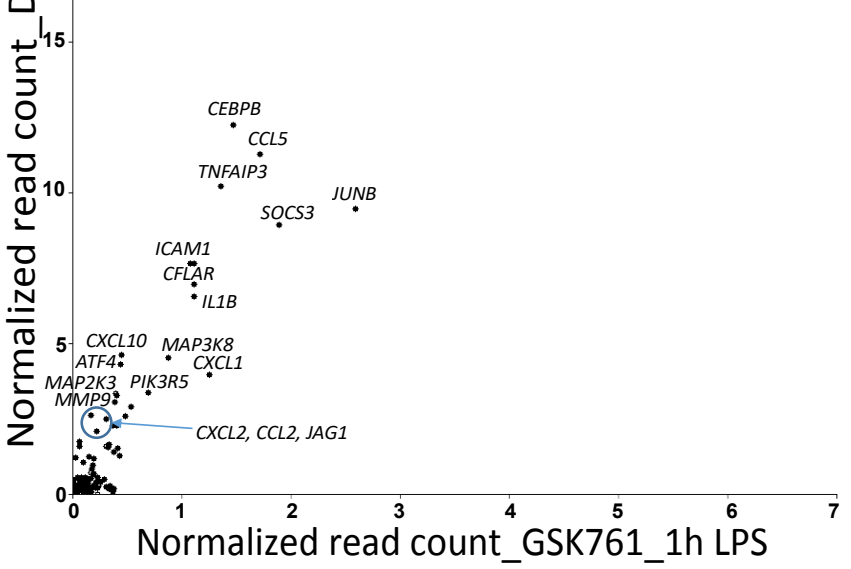

e

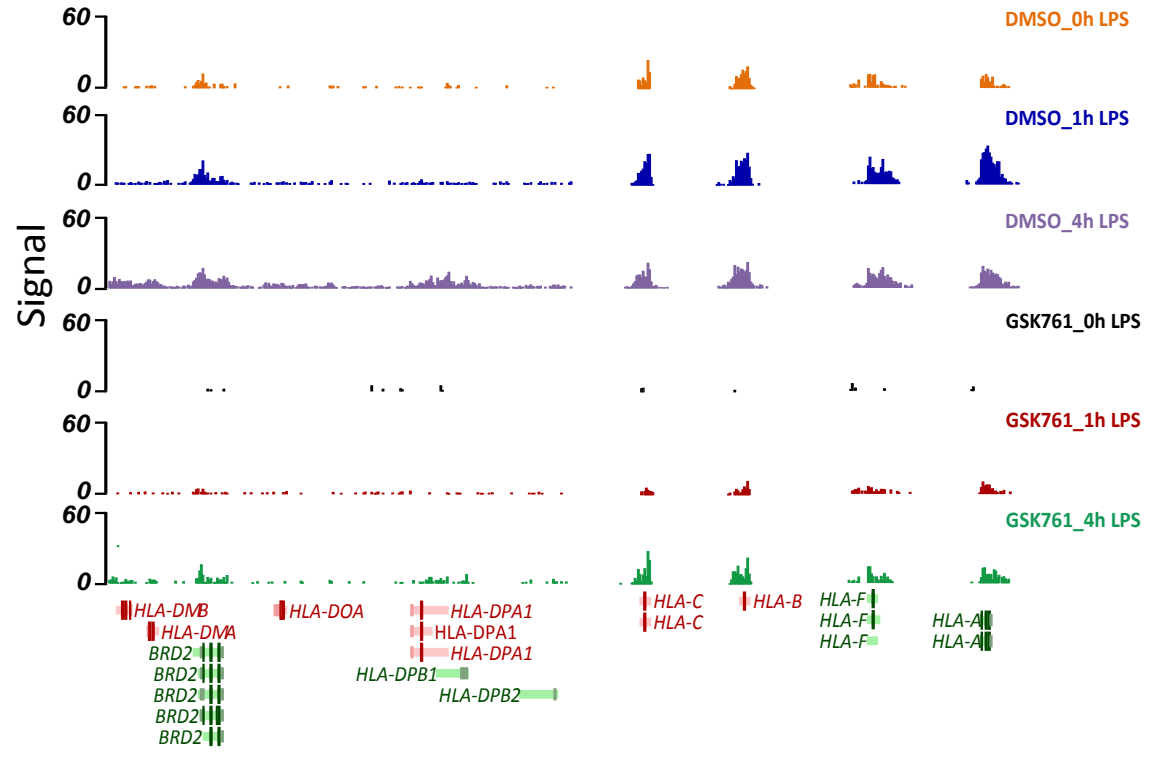


bioRxiv preprint doi: https://doi.org/10.1101/2020.08.10.239475; this version posted August 20, 2020. The copyright holder for this preprint (which was not certified by peer review) is the author/funder, who has granted bioRxiv a license to display the preprint in perpetuity. It is made available under aCC-BY-NC 4.0 International license.

\section{GSK761 vs DMSO}

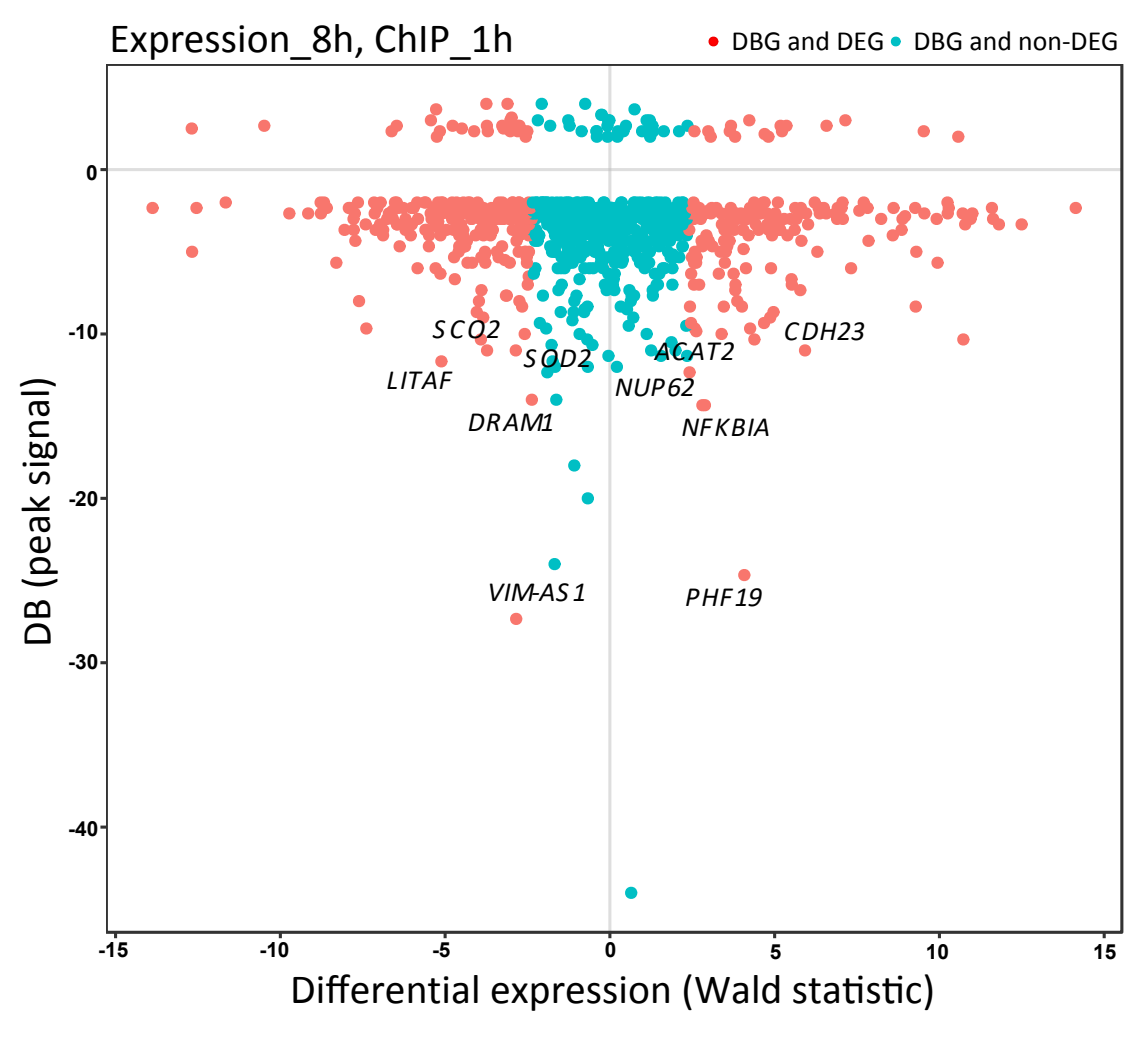

\section{GSK761 vs DMSO}

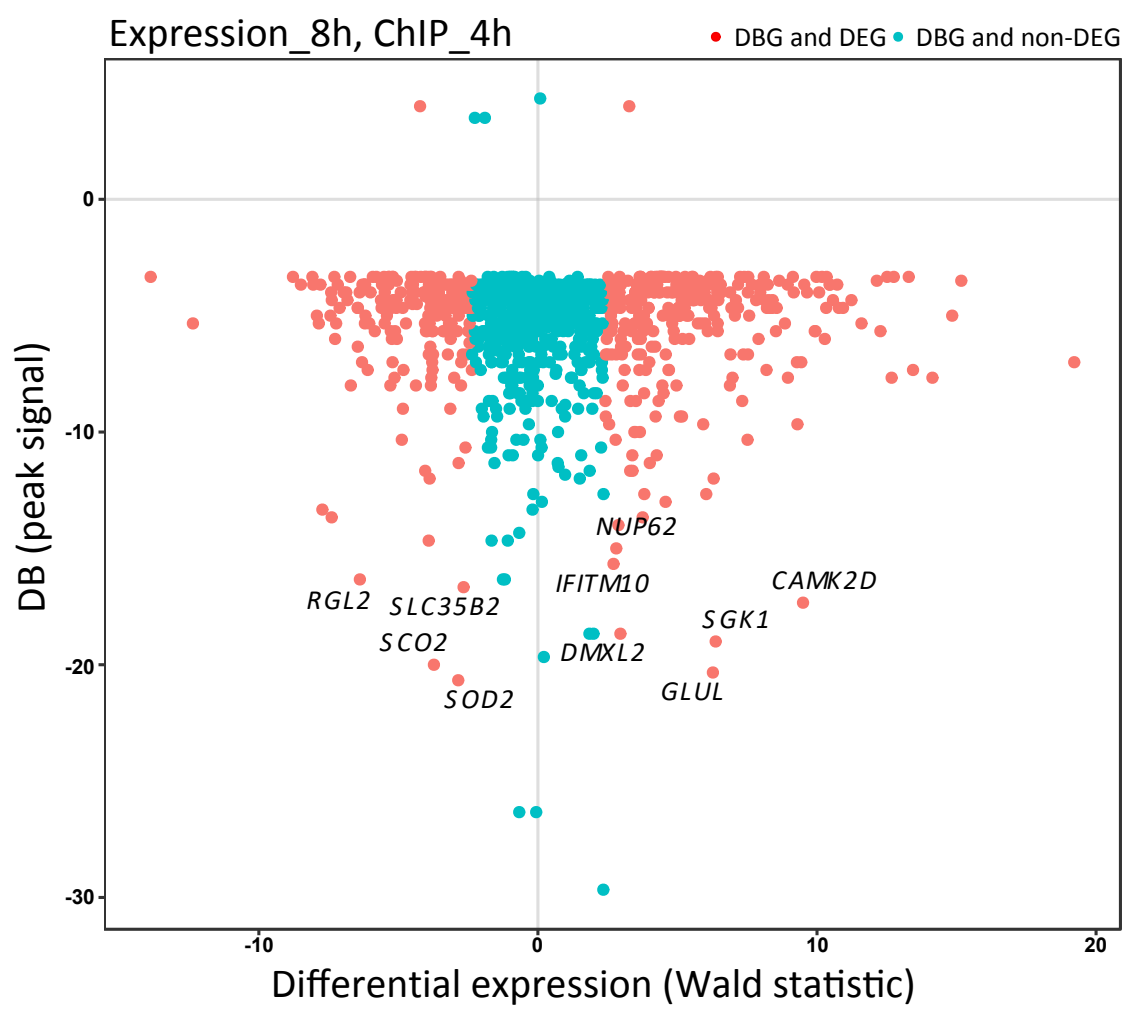




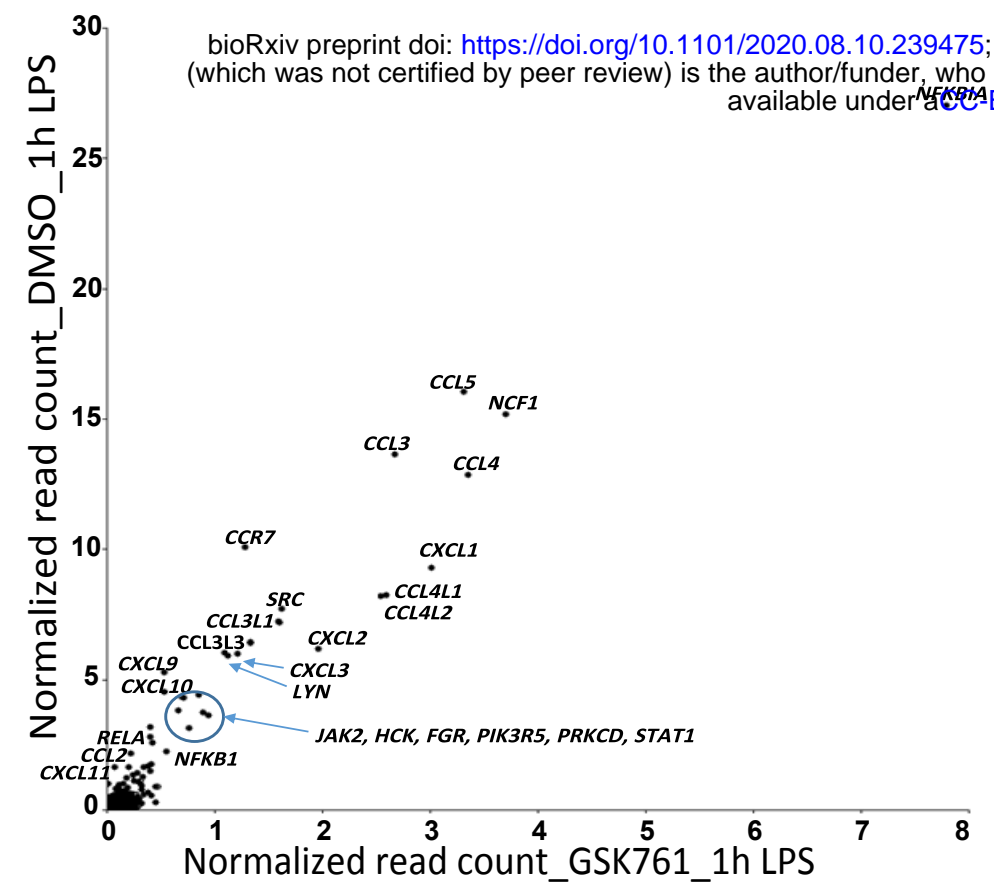

${ }^{80}$ Josted August 20, 2020. The copyright holder for this preprinfe_oh LPS bioRxiv preprint doi: https://doi.org/10.1101/2020.08.10.239475; this version posted August 20, 2020. The copyright holder for this preprint-
(which was not certified by peer review) is the author/funder, who has granted bioRxiv a license to display the preprint in perpetuity. It is made

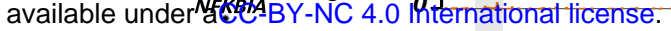
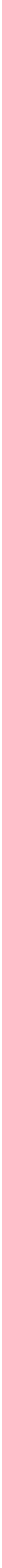

d

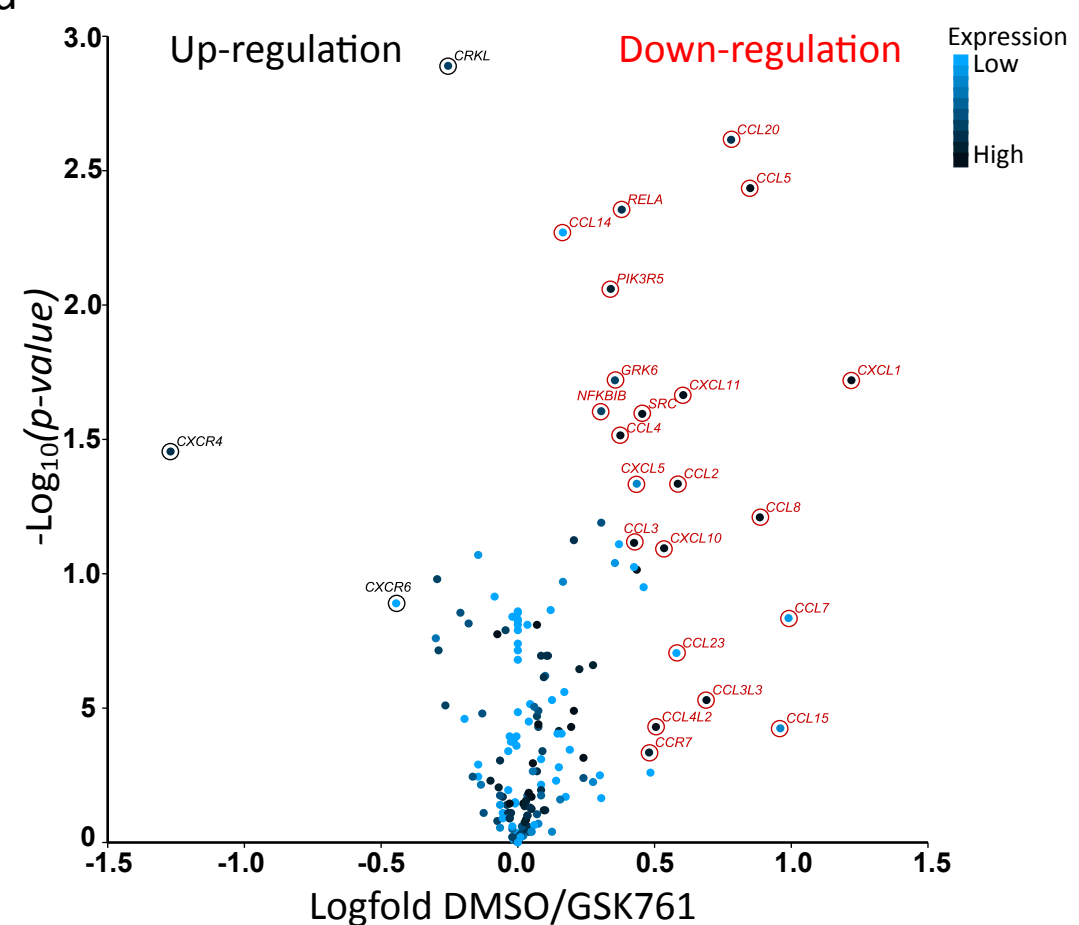


bioRxiv preprint doi: https://doi.org/10.1101/2020.08.10.239475; this version posted August 20, 2020. The copyright holder for this preprint (which was not certified by peer review) is the author/funder, who has granted bioRxiv a license to display the preprint in perpetuity. It is made Supplemental tables. available under aCC-BY-NC 4.0 International license.

Supplemental table 1. Primer sequences used in the quantitative PCR analysis of the genes of interest.

\begin{tabular}{|c|c|c|}
\hline Gene & Forward (5'-3') & Reverse (5'-3') \\
\hline SP140 & AGGATGGTCGCAGAGATCCA & TGGCCTTGTTATTGCACTTGC \\
\hline SP110 & CAGCACACCTTCAGACAAGAA & TCTCTACCGTGGAGTTACAAGTT \\
\hline SP100 & TCCATGACAAATTGCCTCTCC & GAGATGGGGAACCCGAAGG \\
\hline SP140L & GGGCTGAACGGAGGTGTTT & AGTGTCATAGACAAGTCCCTCAT \\
\hline BRD2 & GTGGTTCTCGGCGGTAAG & ACACCCCGGATTACATACCC \\
\hline$B R D 3$ & TTGGCAAACCTCATCTCAAA & GATGTCCGGCTGATGTTCTC \\
\hline BRD4 & GATGGTGCTTCTTCTGCTCC & AGTCCAGCTCCTCTGACAGC \\
\hline$B R D T$ & TCCCTTGAACGTGGTACAGG & GCAGGAGTTGTTGTATCTGCT \\
\hline BRD9 & GCAATGACATACAATAGGCCAGA & GAGCTGCCTGTTTGCTCATCA \\
\hline$B A Z 2 A$ & ATGGAAATGGAGGCAAACGAC & GAGACCCGTTAGTGTAGAGGC \\
\hline$B A Z 2 B$ & ATGGAGTCTGGAGAACGGTTA & AATGTCCACATGGGTTGATTGT \\
\hline EP300 & TCTGGTAAGTCGTGCTCCAA & GCGGCCTAAACTCTCATCTC \\
\hline$P C A F$ & CGAATCGCCGTGAAGAAAGC & CTTGCAGGCGGAGTACACT \\
\hline CREBBP & CAACCCCAAAAGAGCCAAACT & CCTCGTAGAAGCTCCGACAGT \\
\hline CD64 & ACCCCATACAGCTGGAAATC & TTATCCTTCCACGCATGACA \\
\hline CD206 & GGGTTGCTATCACTCTCTATGC & TTTCTTGTCTGTTGCCGTAGTT \\
\hline CCL5 & CCAGCAGTCGTCTTTGTCAC & CTCTGGGTTGGCACACACTT \\
\hline CCL22 & CGCGTGGTGAAACACTTCTA & GGATCGGCACAGATCTCCT \\
\hline$T N F$ & ATGTTGTAGCAAACCCTCAAGC & GGACCTGGGAGTAGATGAGGT \\
\hline IL6 & AGTGAGGAACAAGCCAGAGC & GTCAGGGGTGGTTATTGCAT \\
\hline IL8 & AAATTTGGGGTGGAAAGGTT & TCCTGATTTCTGCAGCTCTGT \\
\hline$A C T B$ & AATGTGGCCGAGGACTTTGA & TGGCTTTTAGGATGGCAAGG \\
\hline RPL37A & CCAAACGTACCAAGAAAGTCGG & GCGTGCTGGCTGATTTCAA \\
\hline$T S S-T N F$ & GGGACATATAAAGGCAGTTGTTGG & TCCCTCTTAGCTGGTCCTCTGC \\
\hline TSS-IL6 & AATGAAACCATCCAGCCATCC & CAGAGACGGTGGTCCTCTGC \\
\hline
\end{tabular}


bioRxiv preprint doi: https://doi.org/10.1101/2020.08.10.239475; this version posted August 20, 2020. The copyright holder for this preprint (which was not certified by peer review) is the author/funder, who has granted bioRxiv a license to display the preprint in perpetuity. It is made

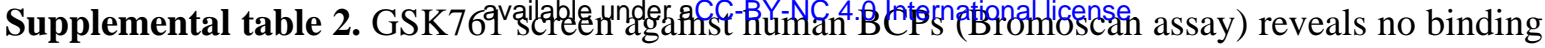

at $K_{d}$ of $\leq 30000 \mathrm{nM}$ (for most of tested BCPs) and at $K_{d}$ of $\leq 21000 \mathrm{nM}$ for PBRM1(5), indicating a high degree of specificity of GSK761 for SP140

\begin{tabular}{|c|c|c|}
\hline Compound Name & DiscoveRx Gene Symbol & $K_{d}(\mathbf{n M})$ \\
\hline GSK761 & ATAD2A & 30000 \\
\hline GSK761 & ATAD2B & 30000 \\
\hline GSK761 & BAZ2A & 30000 \\
\hline GSK761 & BAZ2B & 30000 \\
\hline GSK761 & BRD1 & 30000 \\
\hline GSK761 & BRD2(1) & 30000 \\
\hline GSK761 & $\mathrm{BRD} 2(1,2)$ & 30000 \\
\hline GSK761 & $\mathrm{BRD} 2(2)$ & 30000 \\
\hline GSK761 & BRD3(1) & 30000 \\
\hline GSK761 & $\operatorname{BRD} 3(1,2)$ & 30000 \\
\hline GSK761 & BRD3(2) & 30000 \\
\hline GSK761 & BRD4(1) & 30000 \\
\hline GSK761 & BRD4 $(1,2)$ & 30000 \\
\hline GSK761 & BRD4(2) & 30000 \\
\hline GSK761 & BRD4(full-length,short-iso.) & 30000 \\
\hline GSK761 & BRD7 & 30000 \\
\hline GSK761 & $\mathrm{BRD} 8(1)$ & 30000 \\
\hline GSK761 & BRD8(2) & 30000 \\
\hline GSK761 & BRD9 & 30000 \\
\hline GSK761 & $\operatorname{BRDT}(1)$ & 30000 \\
\hline GSK761 & $\operatorname{BRDT}(1,2)$ & 30000 \\
\hline GSK761 & $\operatorname{BRDT}(2)$ & 30000 \\
\hline GSK761 & BRPF1 & 30000 \\
\hline GSK761 & BRPF3 & 30000 \\
\hline GSK761 & CECR2 & 30000 \\
\hline GSK761 & CREBBP & 30000 \\
\hline GSK761 & EP300 & 30000 \\
\hline GSK761 & FALZ & 30000 \\
\hline GSK761 & GCN5L2 & 30000 \\
\hline GSK761 & PBRM1(2) & 30000 \\
\hline GSK761 & PBRM1(5) & 21000 \\
\hline GSK761 & PCAF & 30000 \\
\hline GSK761 & SMARCA2 & 30000 \\
\hline GSK761 & SMARCA4 & 30000 \\
\hline GSK761 & TAF1(2) & 30000 \\
\hline GSK761 & TAF1L(2) & 30000 \\
\hline GSK761 & TRIM24(Bromo.) & 30000 \\
\hline GSK761 & TRIM24(PHD,Bromo.) & 30000 \\
\hline GSK761 & TRIM33(PHD,Bromo.) & 30000 \\
\hline GSK761 & WDR9(2) & 30000 \\
\hline
\end{tabular}


bioRxiv preprint doi: https://doi.org/10.1101/2020.08.10.239475; this version posted August 20, 2020. The copyright holder for this preprint (which was not certified by peer review) is the author/funder, who has granted bioRxiv a license to display the preprint in perpetuity. It is made

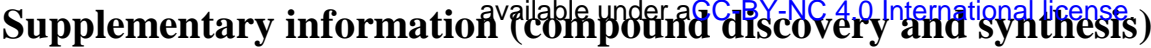

2 Screening of DNA encoded libraries (GSK761 discovery). Affinity screening of DNA Encoded

3 Library (DEL) was done using AntiFlag matrix tips (Phynexus). Before use, the AntiFlag matrix tips were washed four times with 1x selection buffer and stored at $4^{\circ} \mathrm{C}$. The SP140 protein $(24 \mathrm{kDa})$ used for the affinity selection was: 6His-Flag-Tev-SP140 (687-867). During the screening process, each AntiFlag matrix tip was loaded with $5 \mu \mathrm{g}$ of protein and the No target tips was treated with buffer only. The following $1 \mathrm{x}$ selection buffer was used in the affinity selection: $50 \mathrm{mM}$ HEPES (7.5), 150 $\mathrm{mM} \mathrm{NaCl}, 0.1 \%$ Tween 20, $1 \mathrm{mM}$ BME, $1 \mathrm{mg} / \mathrm{mL}$ sheared salmon sperm DNA (sssDNA, Ambion). Three rounds of affinity selection were performed for each screening condition. No target controls (buffer only) were run in parallel as a control.

Selection Round 1: Prior to initiating target selections, $5 \mu \mathrm{g}$ of SP140 (aa 687-867) protein was immobilized on prepared Anti-Flag resin tip (Phynexus), tips were washed four times with $100 \mu \mathrm{L}$ of $1 \mathrm{x}$ selection buffer. For each selection, $5 \mathrm{nM}$ of DEL molecules (pool DEL 34-79) in $60 \mu \mathrm{L}$ of $1 \mathrm{x}$ selection buffer was incubated with the immobilized SP140 (aa 687-867) by pipetting up and down for $1 \mathrm{~h}$ (RT). Tips were then washed eight times with $100 \mu \mathrm{L}$ of $1 \mathrm{x}$ Selection buffer, and another 2 times with $100 \mu \mathrm{L}$ of DNA free 1x Selection buffer. In order to release the bound DEL molecules off the tip, a heat elution was performed by treating the tip in $60 \mu \mathrm{L}$ of $1 \mathrm{x}$ selection buffer (minus sssDNA) for 12 minutes at $80^{\circ} \mathrm{C}$. Eluted samples were post cleared to remove denatured protein by passing over a fresh IMAC resin tip to remove any denatured protein for 10 minutes at RT. This step was repeated once. $1 \mu \mathrm{L}$ of round 1 elution was retained to be used for qPCR. sssDNA and buffer were added to bring the total volume of the eluted material to $60 \mathrm{uL}$ to be used for next round of selection.

Selection Round 2: The $2^{\text {nd }}$ round selection was performed by binding $5 \mu \mathrm{g}$ of fresh SP140 (aa 687867) protein to a fresh prepared Anti-Flag tip. The above selection procedure was repeated using the eluted material from round 1 . At the end of round $2,5 \mu \mathrm{L}$ of the elution was retained. The eluted material was post cleared twice to remove denatured protein, as described above. sssDNA and buffer were added to bring the volume to $60 \mu \mathrm{L}$ in order to begin round 3 of the selection.

Selection Round 3: The above selection procedure was repeated with eluted material from round 2. However, no post-clear step was performed for round 3 selection. At the end of round 3 selection, a quantitative PCR was run to assess yield from each round of selection. Target and No target samples from Round 3 elution were sequenced on an Illumina sequencer. domains (encoding SP140 amino acids 687-867) was prepared in a construct, which was subsequently 
bioRxiv preprint doi: https://doi.org/10.1101/2020.08.10.239475; this version posted August 20, 2020. The copyright holder for this preprint (which was not certified by peer review) is the author/funder, who has granted bioRxiv a license to display the preprint in perpetuity. It is made

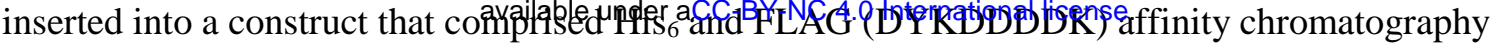
peptides and a TEV protease cleavage site (ENLYFQIS, "I" denotes the cleaved peptide bond). This DNA sequence was then cloned into a ET11c vector (Bioduro) and then subsequently used to transform E. coli BL21 CodonPlus (DE3) RIPL (Stratgene) in media containing $100 \mu \mathrm{g} / \mathrm{mL}$ ampicillin and $34 \mu \mathrm{g} / \mathrm{mL}$ chloramphenicol as selection antibiotics. A culture in Luria Bertani (LB) medium was grown at $30^{\circ} \mathrm{C}, 240 \mathrm{rpm}$, overnight in Erlenmeyer shake flasks to provide a seed for a larger expression culture in auto-inducible Overnight Express medium (supplemented with 1\% Glycerol and $0.1 \mathrm{mM} \mathrm{ZnCl}_{2}$ ), in shake flasks, at $37{ }^{\circ} \mathrm{C}$ and $200 \mathrm{rpm}$. Incubation temperature was reduced to $25^{\circ} \mathrm{C}$ when O.D.600nm was 1.2. The culture was pelleted by centrifugation after a further $20 \mathrm{~h}$ incubation and stored at $-80^{\circ} \mathrm{C}$. For protein purification, a $40 \mathrm{~g}$ cell pellet was processed by mixing with $200 \mathrm{~mL}$ of PBS, $50 \mathrm{mM}$ Imidazole, 10\% Glycerol, PIC III, $1 \mathrm{mg} / \mathrm{mL}$ lysozyme, Benzonase (Merck) pH7.4 and left to stir for 30 minutes at $4^{\circ} \mathrm{C}$. The resulting suspension was lysed by sonication on ice for 15 minutes (10 seconds on /10 seconds off) and then harvested by centrifugation for 90 minutes at 30000 rpm. The lysate supernatant was collected and then passed through a $20 \mathrm{~mL}$ HisTrap HP column (GE Healthcare) and then washed back with buffer A. (Buffer A: PBS, 2 mM DTT, 10\% Glycerol, pH 7.4). Bound SP140 was eluted using stepped protocol with buffer B (PBS, 2 mM DTT, $10 \%$ Glycerol, $500 \mathrm{mM}$ Imidazole, and $\mathrm{pH}$ 7.4) yielding $434.4 \mathrm{mg}$ of total protein. This pool was diluted down to 5 mScm using $20 \mathrm{mM}$ Hepes, $2 \mathrm{mM}$ DTT, 10\% Glycerol, and pH 7.5 and further purified using $100 \mathrm{~mL}$ Source15Q anion exchange. Elution of the SP140 was carried out using a segmented linear $\mathrm{NaCl}$ gradient ( $0-50 \%$ buffer B over 20 column volumes (Cvs), 50-100\% over $1 \mathrm{Cv}$ ). Three peaks were obtained from the post anion exchange material (Peak 1, 2 and 3) and pooled separately. The pooled fractions from absorbance peak 2 were further purified using gel filtration (Superdex $75320 \mathrm{~mL} \mathrm{Cv}$ ), which lead to a final yield of purified SP140 protein of $7.87 \mathrm{mg}$, in a buffer comprising $10 \mathrm{mM}$ Potassium phosphate, $100 \mathrm{mM} \mathrm{NaCl}, 0.5 \mathrm{mM}$ TCEP, 5\% Glycerol , pH7.4.

Compound synthesis. Unless otherwise stated, all reactions were carried using anhydrous solvents. Solvents and reagents were purchased from commercial suppliers and used as received. Reactions were monitored by LCMS. Silica flash chromatography was carried out using SP4 apparatus using RediSep ${ }^{\circledR}$ pre-packed silica cartridges. Ion exchange chromatography was carried out using Biotage Isolute cartridges and extracted organic mixtures were dried using Biotage PTFE hydrophobic phase separator frits unless otherwise stated. NMR spectra were recorded at RT (unless otherwise stated) using standard pulse methods on a Bruker AV-400 spectrometer $\left({ }^{1} \mathrm{H}=400 \mathrm{MHz},{ }^{13} \mathrm{C}=101 \mathrm{MHz}\right)$. Chemical shifts are referenced to trimethylsilane (TMS) or the residual solvent peak, and are reported in ppm. Coupling constants are reported in $\mathrm{Hz}$ and refer to ${ }^{3} \mathrm{~J}_{\mathrm{H}-\mathrm{H}}$ couplings, unless otherwise stated. Coupling constants are quoted to the nearest $0.1 \mathrm{~Hz}$ and multiplicities are given by the following abbreviations and combinations thereof: s (singlet), $d$ (doublet), $\mathrm{t}$ (triplet), q (quartet), m (multiplet), br. (broad). LCMS analysis was carried out on a Waters Acquity UPLC instrument equipped with a 
bioRxiv preprint doi: https://doi.org/10.1101/2020.08.10.239475; this version posted August 20, 2020. The copyright holder for this preprint (which was not certified by peer review) is the author/funder, who has granted bioRxiv a license to display the preprint in perpetuity. It is made

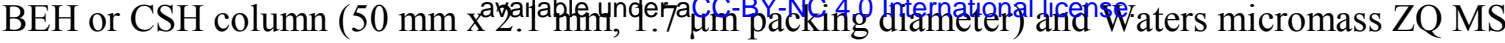
using alternate-scan positive and negative electrospray. Analytes were detected as a summed UV wavelength of $210-350 \mathrm{~nm}$. Two liquid phase methods were used: Formic: $40{ }^{\circ} \mathrm{C}, 1 \mathrm{~mL} / \mathrm{min}$ flow rate. Gradient elution with the mobile phases as (A) water containing $0.1 \%$ volume/volume (v/v) formic acid and (B) acetonitrile containing $0.1 \%$ (v/v) formic acid. Gradient conditions were initially $1 \% \mathrm{~B}$, increasing linearly to $97 \% \mathrm{~B}$ over $1.5 \mathrm{~min}$, remaining at $97 \% \mathrm{~B}$ for $0.4 \mathrm{~min}$ then increasing to $100 \%$ B over $0.1 \mathrm{~min}$. High pH: $40{ }^{\circ} \mathrm{C}, 1 \mathrm{~mL} / \mathrm{min}$ flow rate. Gradient elution with the mobile phases as (A) $10 \mathrm{mM}$ aqueous ammonium bicarbonate solution, adjusted to $\mathrm{pH} 10$ with $0.88 \mathrm{M}$ aqueous ammonia and (B) acetonitrile. Gradient conditions were initially $1 \%$ B, increasing linearly to $97 \%$ B over $1.5 \mathrm{~min}$, remaining at $97 \% \mathrm{~B}$ for $0.4 \mathrm{~min}$ then increasing to $100 \% \mathrm{~B}$ over $0.1 \mathrm{~min}$. Mass directed automatic purification (MDAP): High pH MDAP: The HPLC analysis was conducted on an Xselect CSH C18 column ( $150 \mathrm{~mm} \times 30 \mathrm{~mm}$ i.d. $5 \mu \mathrm{m}$ packing diameter) at ambient temperature, eluting with $10 \mathrm{mM}$ ammonium bicarbonate in water adjusted to $\mathrm{pH} 10$ with ammonia solution (solvent $\mathrm{A}$ ) and acetonitrile (solvent B) using an elution gradient of between 0 and $100 \%$ solvent B over 15 or 25 min. The UV detection was an averaged signal from wavelength of $210 \mathrm{~nm}$ to $350 \mathrm{~nm}$. The mass spectra were recorded on a Waters ZQ Mass Spectrometer using alternate-scan positive and negative electrospray. Ionisation data was rounded to the nearest integer.

\section{GSK761}

\section{N-(3-(2-(tert-Butoxy)ethyl)phenyl)-4-formylbenzamide}

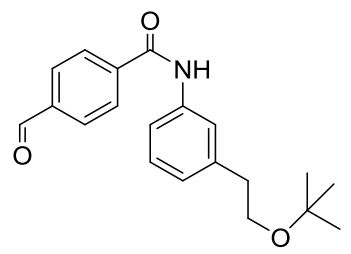

4-Carboxybenzaldehyde (2.3g, $15.32 \mathrm{mmol})$ was dissolved in Dichloromethane (DCM) (25 mL), then oxalyl chloride (5.83 g, $46.0 \mathrm{mmol})$ and $\mathrm{N}, \mathrm{N}^{\prime}$-dimethylformamide (DMF) (0.024 mL, $\left.0.306 \mathrm{mmol}\right)$ were added and the mixture stirred till a colorless solution was obtained. This was evaporated in vacuo and the residue redissolved in DCM $(25 \mathrm{~mL})$ and cooled in an ice bath. Pyridine $(3.72 \mathrm{~mL}$, $46.0 \mathrm{mmol})$ was added, followed by 3-(2-tertbutoxyethyl)aniline $(2.96 \mathrm{~g}, 15.32 \mathrm{mmol})$ and the resulting suspension stirred at $0^{\circ} \mathrm{C}$ to room temperature for $1 \mathrm{~h}$.

The reaction mixture was diluted with DCM $(50 \mathrm{~mL})$, then washed with water $(50 \mathrm{~mL})$ and brine $(50$ $\mathrm{mL})$, dried and evaporated in vacuo to a dark brown gum. This was dissolved in DCM (10 mL) and loaded onto a $100 \mathrm{~g}$ silica column, then eluted with 0-50\% EtOAc/cyclohexane to give $\mathrm{N}$-(3-(2-(tertbutoxy)ethyl)phenyl)-4-formylbenzamide (2.75 g, $8.45 \mathrm{mmol}, 55.2 \%$ yield) as an amber gum. 
bioRxiv preprint doi: https://doi.org/10.1101/2020.08.10.239475; this version posted August 20, 2020. The copyright holder for this preprint (which was not certified by peer review) is the author/funder, who has granted bioRxiv a license to display the preprint in perpetuity. It is made

\section{Methyl 2-(4-((3-(2-(tert-butoxy)ethyl)phenyl)carbamoyl)phenyl)-1-methyl-1H-}

benzo $[d]$ imidazole-5-carboxylate

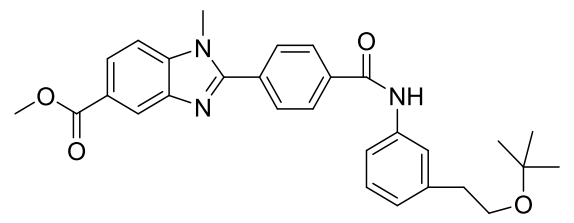

$N$-(3-(2-(tert-butoxy)ethyl)phenyl)-4-formylbenzamide (2.6 g, $7.99 \mathrm{mmol})$ and methyl 4(methylamino)-3-nitrobenzoate $(1.679 \mathrm{~g}, 7.99 \mathrm{mmol})$ were combined in ethanol $(50 \mathrm{~mL})$, then sodium dithionite $(2.78 \mathrm{~g}, 15.98 \mathrm{mmol})$ in water $(20 \mathrm{~mL})$ was added and the mixture was stirred at $70^{\circ} \mathrm{C}$ overnight. The mixture was cooled and evaporated in vacuo to half volume, then extracted with EtOAc $(2 \times 50 \mathrm{~mL})$ and the organic layer dried and evaporated in vacuo to give a pale yellow solid. The solid was dissolved in DCM $(10 \mathrm{~mL})$ and loaded onto a $100 \mathrm{~g}$ silica column, then eluted with 0$80 \%$ EtOAc/cyclohexane and product-containing fractions evaporated in vacuo to give methyl 2-(4((3-(2-(tert-butoxy)ethyl)phenyl)carbamoyl)phenyl)-1-methyl-1H-benzo[ $d]$ imidazole-5-carboxylate (2.35 g, $4.84 \mathrm{mmol}, 60.6 \%$ yield)

${ }^{1} \mathrm{H}$ NMR (CHLOROFORM-d, $\left.400 \mathrm{MHz}\right) \delta 8.55(\mathrm{~s}, 1 \mathrm{H}), 8.18(\mathrm{~s}, 1 \mathrm{H}), 8.11$ (dd, 1H, J=1.0, 8.6 Hz), $8.04(\mathrm{~d}, 2 \mathrm{H}, J=8.1 \mathrm{~Hz}), 7.89$ (d, 2H, J=8.1 Hz), 7.5-7.6 (m, 2H), $7.46(\mathrm{~d}, 1 \mathrm{H}, J=8.6 \mathrm{~Hz}), 7.33$ (t, 1H, $J=7.6 \mathrm{~Hz}$ ), 7.09 (d, 1H, J=7.6 Hz), 3.98 (s, 3H), 3.93 (s, 3H), 3.60 (t, 2H, J=7.6 Hz), 2.87 (t, 2H, $J=7.3 \mathrm{~Hz}), 1.20(\mathrm{~s}, 9 \mathrm{H})$

LCMS (2 min Formic): Rt $=1.14 \mathrm{~min},[\mathrm{MH}]^{+}=486$

\section{2-(4-((3-(2-(tert-Butoxy)ethyl)phenyl)carbamoyl)phenyl)-1-methyl-1H-benzo[d]imidazole-5-} carboxylic acid

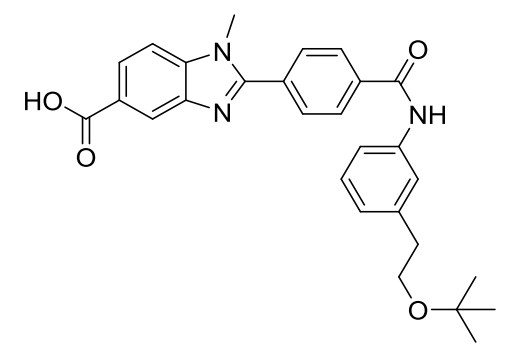

Methyl 2-(4-((3-(2-(tert-butoxy)ethyl)phenyl)carbamoyl)phenyl)-1-methyl-1H-benzo[d]imidazole-5carboxylate (2.3 g, $4.74 \mathrm{mmol})$ was dissolved in THF $(10 \mathrm{~mL})$, then $\mathrm{LiOH}(0.340 \mathrm{~g}, 14.21 \mathrm{mmol})$ in 
bioRxiv preprint doi: https://doi.org/10.1101/2020.08.10.239475; this version posted August 20, 2020. The copyright holder for this preprint (which was not certified by peer review) is the author/funder, who has granted bioRxiv a license to display the preprint in perpetuity. It is made

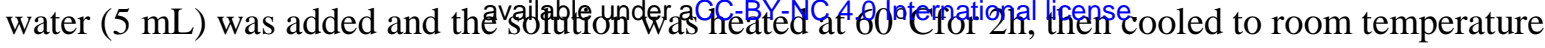
and evaporated in vacuo. The residue was dissolved in water $(20 \mathrm{~mL})$ and acidified with $2 \mathrm{M} \mathrm{HCl}$ to $\mathrm{pH} 4$, then the resulting beige solid collected by filtration and the solid dried in the vacuum oven overnight at $60^{\circ} \mathrm{C}$ to give 2-(4-((3-(2-(tert-butoxy)ethyl)phenyl)carbamoyl)phenyl)-1-methyl-1Hbenzo[ $d$ ]imidazole-5-carboxylic acid (2.2 g, $4.67 \mathrm{mmol}, 98 \%$ yield).

${ }^{1} \mathrm{H}$ NMR (DMSO-d $\left.6,400 \mathrm{MHz}\right) \delta 10.40$ (s, 1H), 8.33 (d, 1H, J=1.0 Hz), 8.20 (d, 2H, J=8.6 Hz), 8.08 $(\mathrm{d}, 2 \mathrm{H}, J=8.6 \mathrm{~Hz}), 8.02(\mathrm{dd}, 1 \mathrm{H}, J=1.0,8.6 \mathrm{~Hz}), 7.86(\mathrm{~d}, 1 \mathrm{H}, J=8.6 \mathrm{~Hz}), 7.6-7.7(\mathrm{~m}, 2 \mathrm{H}), 7.28(\mathrm{t}, 1 \mathrm{H}$, $J=7.8 \mathrm{~Hz}), 7.02(\mathrm{~d}, 1 \mathrm{H}, J=7.6 \mathrm{~Hz}), 4.01(\mathrm{~s}, 4 \mathrm{H}), 3.54$ (t, 2H, J=7.3 Hz), 2.75 (t, 2H, J=7.1 Hz), 1.14 (s, 9H)

LCMS (2 min Formic): Rt $=1.02 \mathrm{~min},[\mathrm{MH}]^{+}=472$

\section{$N$-(3-(2-(tert-Butoxy)ethyl)phenyl)-2-(4-((3-(2-(tert-butoxy)ethyl)phenyl)carbamoyl)phenyl)-1-} methyl-1H-benzo $[d]$ imidazole-5-carboxamide

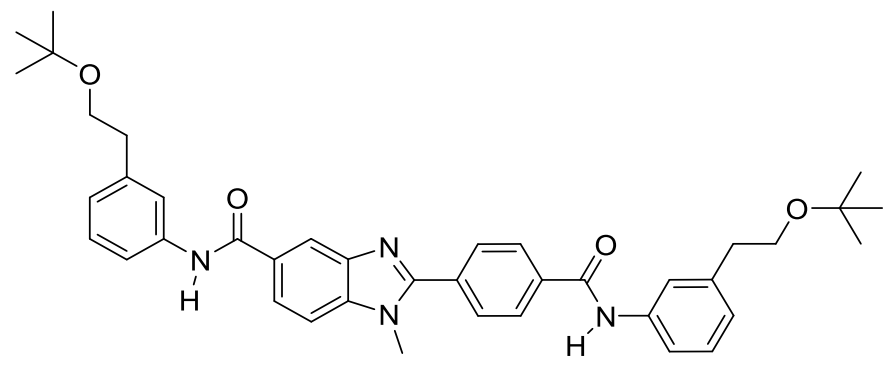

To a mixture of 2-(4-((3-(2-(tert-butoxy)ethyl)phenyl)carbamoyl)phenyl)-1-methyl-1Hbenzo[ $d]$ imidazole-5-carboxylic acid (100 mg, $0.212 \mathrm{mmol}$ ) and 3-(2-(tert-butoxy)ethyl)aniline (62 $\mathrm{mg}, 0.321 \mathrm{mmol})$ in DMF (1 mL) were added HATU $(121 \mathrm{mg}, 0.318 \mathrm{mmol})$ and DIPEA $(0.056 \mathrm{~mL}$, $0.318 \mathrm{mmol}$ ) and the reaction mixture was stirred at room temperature for 3 hours. LCMS showed complete consumption of starting material. The solution was then partitioned between EtOAc and water. The organic layer was washed with water $(3 \times 10 \mathrm{~mL})$, dried over magnesium sulphate and evaporated under vacuum. The sample was loaded in DCM and purified on a $10 \mathrm{~g}$ silica cartridge eluting with 0-100\% EtOAc-cyclohexane. The appropriate fractions were combined and evaporated in vacuo to give the required product $N$-(3-(2-(tert-butoxy)ethyl)phenyl)-2-(4-((3-(2-(tertbutoxy)ethyl)phenyl)carbamoyl)phenyl)-1-methyl-1H-benzo[d]imidazole-5-carboxamide (118 mg, $0.182 \mathrm{mmol}, 86 \%$ yield), as a colorless glass.

${ }^{1} \mathrm{HNMR}$ (CHLOROFORM-d ,400MHz): $\delta$ (ppm) 8.28 (d, J=1.3 Hz, 1H), 8.01 - 8.06 (m, 3H), 7.94 7.99 (m, 2H), 7.89 (d, J=8.3 Hz, 2H), 7.56 (s, 2H), 7.52 - 7.56 (m, 2H), 7.50 (d, J=8.6 Hz, 1H), 7.27 $7.36(\mathrm{~m}, 2 \mathrm{H}), 7.01-7.10(\mathrm{~m}, 2 \mathrm{H}), 3.94(\mathrm{~s}, 3 \mathrm{H}), 3.58$ (t, J=7.5 Hz, 4H), 2.86 (t, J=7.5 Hz, 4H), 1.19 (s, $18 \mathrm{H})$ 
bioRxiv preprint doi: https://doi.org/10.1101/2020.08.10.239475; this version posted August 20, 2020. The copyright holder for this preprint (which was not certified by peer review) is the author/funder, who has granted bioRxiv a license to display the preprint in perpetuity. It is made

GSK064<smiles>CC(C)(C)OC(=O)NCCOCCOCCNc1ccc(C(=O)O)cc1[N+](=O)[O-]</smiles>

$N$-Boc-2,2'-(ethylenedioxy)diethylamine $(1.300 \mathrm{~mL}, 5.48 \mathrm{mmol})$ and diisopropylethylamine (2.781 $\mathrm{mL}, 16.25 \mathrm{mmol})$ were added to a stirred solution of 4-fluoro-3-nitrobenzoic acid (1.0033 g, 5.42 $\mathrm{mmol})$ in ethanol $(15 \mathrm{~mL})$ at ambient temperature. The resulting mixture was stirred under $\mathrm{N}_{2}$ atmosphere at $80^{\circ} \mathrm{C}$ for $3.5 \mathrm{hr}$. The solvent was evaporated and dried in vacuo to give the crude product, 4-((2,2-dimethyl-4-oxo-3,8,11-trioxa-5-azatridecan-13-yl)amino)-3-nitrobenzoic acid (3.5849 $\mathrm{g}, 8.67 \mathrm{mmol}, 160 \%$ yield) as an orange/yellow oil.

${ }^{1} \mathrm{H}$ NMR (CHLOROFORM-d, $\left.400 \mathrm{MHz}\right) \delta 8.92$ (d, 1H, $J=2.0 \mathrm{~Hz}$ ), 8.43 (br t, $1 \mathrm{H}, J=4.8 \mathrm{~Hz}$ ), 8.16 (dd, 1H, J=1.8, 8.8 Hz), 6.84 (d, 1H, J=8.6 Hz), 5.1 (br s, 1H), 3.81 (t, 2H, J=5.3 Hz), 3.6-3.7 (m, $4 \mathrm{H}), 3.5-3.6(\mathrm{~m}, 4 \mathrm{H}), 3.3-3.4(\mathrm{~m}, 2 \mathrm{H}), 1.40(\mathrm{~s}, 9 \mathrm{H})$<smiles>CC(C)(C)OC(=O)NCCOCCOCCNc1ccc(C(=O)O)cc1N</smiles>

Under $\mathrm{N}_{2}$ atmosphere ethanol $(10 \mathrm{~mL})$ was to added palladium, $10 \mathrm{wt} . \%$ (dry basis) on activated carbon, wet, Degussa type E101 NE/W (0.3776 g, $3.55 \mathrm{mmol})$ in a hydrogenation flask. A solution of the crude starting material 4-((2,2-dimethyl-4-oxo-3,8,11-trioxa-5-azatridecan-13-yl)amino)-3nitrobenzoic acid ( $3.548 \mathrm{~g}$ equivalent to $2.241 \mathrm{~g}, 5.42 \mathrm{mmol}$ ) dissolved in ethanol ( $15 \mathrm{~mL})$ was then added to the catalyst mixture under vacuum. The resulting mixture was placed under an atmosphere of hydrogen gas at room temperature and pressure and stirred vigorously. Once hydrogen uptake had 
bioRxiv preprint doi: https://doi.org/10.1101/2020.08.10.239475; this version posted August 20, 2020. The copyright holder for this preprint (which was not certified by peer review) is the author/funder, who has granted bioRxiv a license to display the preprint in perpetuity. It is made

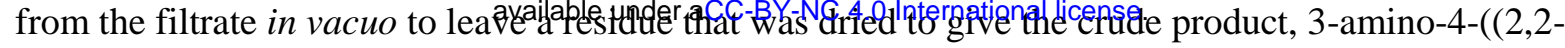
dimethyl-4-oxo-3,8,11-trioxa-5-azatridecan-13-yl)amino)benzoic acid (3.141 g, 8.19 mmol, $151 \%$ yield), as a brown oil, which was used without purification in the next step.

LCMS (2 min Formic): Rt $=0.73 \mathrm{~min},[\mathrm{MH}+]=384$.

\section{2-(4-Carboxyphenyl)-1-(2,2-dimethyl-4-oxo-3,8,11-trioxa-5-azatridecan-13-yl)-1H-} benzo[I]imidazole-5-carboxylic acid

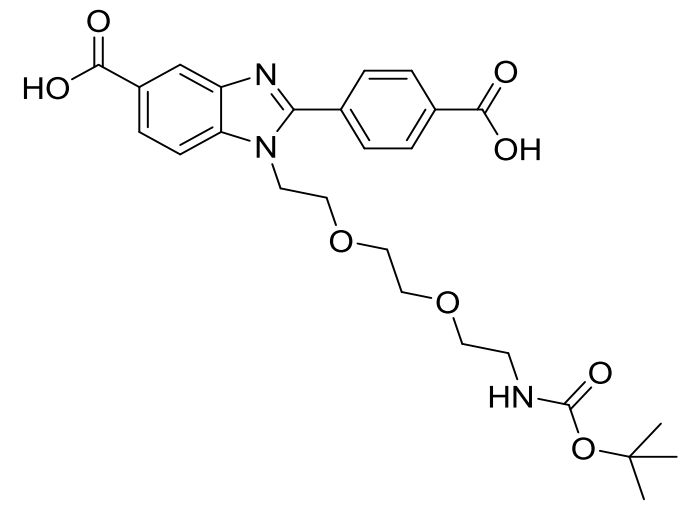

Acetic acid (14 mL) was added to the crude 3-amino-4-((2,2-dimethyl-4-oxo-3,8,11-trioxa-5azatridecan-13-yl)amino)benzoic acid (2.350 g crude, equivalent to $1.557 \mathrm{~g}, 4.06 \mathrm{mmol}$ ) and 4carboxybenzaldehyde $(0.6122 \mathrm{~g}, 4.08 \mathrm{mmol})$. The resulting mixture was stirred under nitrogen at room temperature for $66 \mathrm{hr}$. The solvent was evaporated in vacuo to give a dark reddish-brown oil. The oil was loaded onto a $100 \mathrm{~g}$ silica cartridge as a partial suspension in dichloromethane and then purified by silica flash chromatography, eluting with $0-100 \%$ of $(1: 10: 89$ acetic acid:MeOH:DCM)/DCM. The required fractions were combined and the solvent evaporated in vacuo to give the final product, 2-(4-carboxyphenyl)-1-(2,2-dimethyl-4-oxo-3,8,11-trioxa-5-azatridecan-13yl)-1H-benzo[I]imidazole-5-carboxylic acid (799.2 $\mathrm{mg}, 1.323 \mathrm{mmol}, 32.6 \%$ yield), as a brown crunchy foam.

${ }^{1} \mathrm{H}$ NMR (400 MHz, METHANOL-d 4$) \delta 8.62(\mathrm{~s}, 1 \mathrm{H}), 8.43-8.37(\mathrm{~m}, 2 \mathrm{H}), 8.26(\mathrm{dd}, J=8.6,1.5 \mathrm{~Hz}$, $1 \mathrm{H}), 8.18-8.14(\mathrm{~m}, 2 \mathrm{H}), 7.96-7.92(\mathrm{~m}, 1 \mathrm{H}), 4.76-4.71(\mathrm{~m}, 2 \mathrm{H}), 4.07-4.02(\mathrm{~m}, 2 \mathrm{H}), 3.70-3.56$ $(\mathrm{m}, 2 \mathrm{H}), 3.53-3.46(\mathrm{~m}, 4 \mathrm{H}), 3.28-3.25(\mathrm{~m}, 2 \mathrm{H}), 1.59(\mathrm{~s}, 9 \mathrm{H})$

LCMS (2 min Formic): Rt $=0.78 \mathrm{~min},[\mathrm{MH}+]=514$

tert-Butyl (2-(2-(2-(5-((3-(2-(tert-butoxy)ethyl)phenyl)carbamoyl)-2-(4-((3-(2-(tert-

butoxy)ethyl)phenyl)carbamoyl)phenyl)-1H-benzo[d]imidazol-1-

yl)ethoxy)ethoxy)ethyl)carbamate 
bioRxiv preprint doi: https://doi.org/10.1101/2020.08.10.239475; this version posted August 20, 2020. The copyright holder for this preprint (which was not certified by peer review) is the author/funder, who has granted bioRxiv a license to display the preprint in perpetuity. It is made

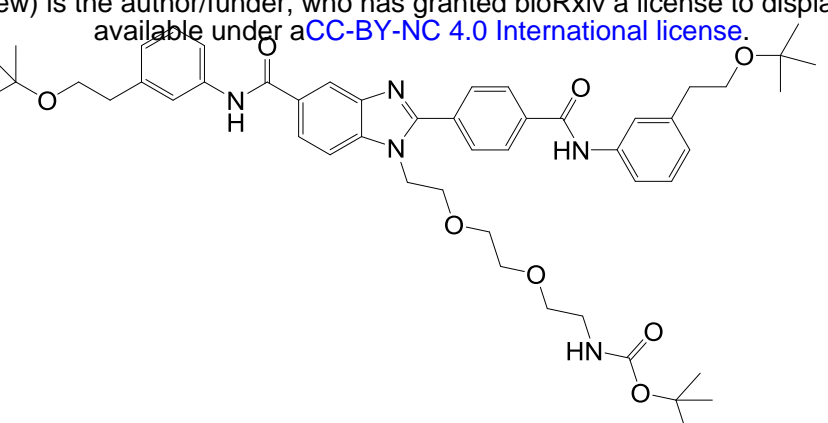

213 Diisopropylethylamine $(0.400 \mathrm{~mL}, 2.337 \mathrm{mmol})$ was added to a solution of 3-(2-(tert-

214 butoxy)ethyl)aniline (181.3 mg, $0.938 \mathrm{mmol}), 2$-(4-carboxyphenyl)-1-(2,2-dimethyl-4-oxo-3,8,11-

215 trioxa-5-azatridecan-13-yl)-1H-benzo[ $d]$ imidazole-5-carboxylic acid (399.4 mg, $0.778 \mathrm{mmol}$ ) and

216 HATU (356.7 mg, $0.938 \mathrm{mmol}$ ) in DMF (5 mL) and the resulting mixture stirred at room temperature

217 under nitrogen for $150 \mathrm{~min}$. The solvent was evaporated under a stream of nitrogen, citric acid (10\%

218 aq) $(50 \mathrm{~mL})$ was added and the aqueous phase extracted with EtOAc $(3 \times 50 \mathrm{~mL})$. The combined

219 organic phases were filtered through a hydrophobic frit and the solvent evaporated in vacuo to give a

220 brown residue. The residue was dissolved in $\mathrm{MeOH}$ and loaded onto a $50 \mathrm{~g}$ silica cartridge, which was

221 then dried in vacuo and eluted with 30-100\% (1\% acetic acid in ethyl acetate)/cyclohexane. The

222 desired product and mono-coupled by-products co-eluted and fractions containing the desired

223 products were combined and the solvent evaporated in vacuo to give a pale yellow residue.

224 The resulting residue was dissolved in dichloromethane and loaded on to a 50g silica cartridge, then

225 eluted with 0-10\% MeOH/DCM to give tert-butyl (2-(2-(2-(5-)(3-(2-(tert-

226 butoxy)ethyl)phenyl)carbamoyl)-2-(4-((3-(2-(tert-butoxy)ethyl)phenyl)carbamoyl)phenyl)-1H-

227 benzo[ $d]$ imidazol-1-yl)ethoxy)ethoxy)ethyl)carbamate $(125.7 \mathrm{mg}, 0.131 \mathrm{mmol}, 16.83 \%$ yield as a

228 pale yellow solid.

$229{ }^{1} \mathrm{H}$ NMR (CHLOROFORM-d, $\left.400 \mathrm{MHz}\right) \delta$ 8.3-8.4 (m, 1H), 7.9-8.2 (m, 6H), 7.6-7.7 (m, 5H), 7.3-7.4

230 (m, 2H), $7.07(\mathrm{t}, 2 \mathrm{H}, J=7.1 \mathrm{~Hz}), 4.8-5.0(\mathrm{~m}, 1 \mathrm{H}), 4.4-4.6(\mathrm{~m}, 2 \mathrm{H}), 3.92$ (br s, 2H), 3.60 (t, $4 \mathrm{H}, J=7.6$

$231 \mathrm{~Hz}), 3.49$ (br s, 4H), 3.3-3.4 (m, 2H), 3.1-3.2 (m, 2H), 2.8-2.9 (m, 4H), $1.43(\mathrm{~s}, 9 \mathrm{H}), 1.21(\mathrm{~s}, 18 \mathrm{H})$

232

LCMS (2 min Formic): Rt = $1.40 \mathrm{~min},[\mathrm{MH}+]=864$.

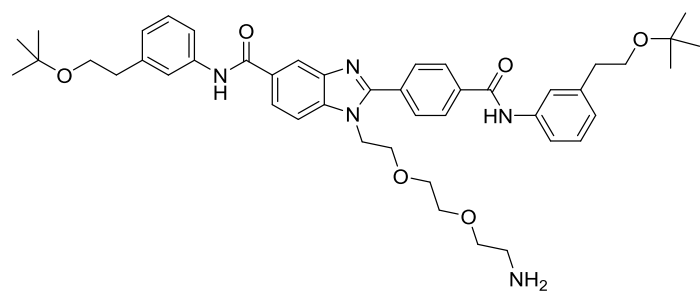


bioRxiv preprint doi: https://doi.org/10.1101/2020.08.10.239475; this version posted August 20, 2020. The copyright holder for this preprint (which was not certified by peer review) is the author/funder, who has granted bioRxiv a license to display the preprint in perpetuity. It is made

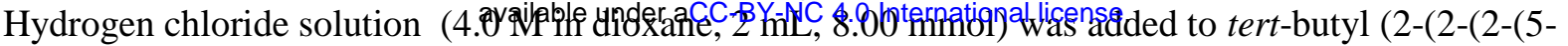
((3-(2-(tert-butoxy)ethyl)phenyl)carbamoyl)-2-(4-((3-(2-(tertbutoxy)ethyl)phenyl)carbamoyl)phenyl)-1H-benzo[d]imidazol-1-yl)ethoxy)ethoxy)ethyl)carbamate (112.1 $\mathrm{mg}, 0.130 \mathrm{mmol}$ ) and the resulting mixture stirred for $2 \mathrm{~min}$ at room temperature. The reaction was quenched with saturated sodium carbonate solution $(2 \mathrm{~mL})$, then water $(3 \mathrm{~mL})$ and EtOAc $(5 \mathrm{~mL})$ were added and the phases separated. The aqueous phase was extracted with further ethyl acetate $(2 \mathrm{x}$ $5 \mathrm{~mL}$ ) and the combined organic phases were filtered through a hydrophobic frit and the solvent evaporated. The resulting residue was dissolved in methanol $(1 \mathrm{~mL})$ and purified by high $\mathrm{pH}$ MDAP to give

1-(2-(2-(2-aminoethoxy)ethoxy)ethyl)-N-(3-(2-(tert-butoxy)ethyl)phenyl)-2-(4-((3-(2-(tertbutoxy)ethyl)phenyl)carbamoyl)phenyl)-1H-benzo[ $d]$ imidazole-5-carboxamide (46.1 mg, 0.057 mmol, $44.2 \%$ yield), was obtained as a very pale yellow glass.

${ }^{1} \mathrm{H}$ NMR (CHLOROFORM-d, $\left.400 \mathrm{MHz}\right) \delta 8.72(\mathrm{~s}, 1 \mathrm{H}), 8.3-8.4(\mathrm{~m}, 2 \mathrm{H}), 8.0-8.1$ (m, 4H), 7.95 (dd, $1 \mathrm{H}, J=1.8,8.3 \mathrm{~Hz}), 7.5-7.6(\mathrm{~m}, 4 \mathrm{H}), 7.32(\mathrm{dt}, 2 \mathrm{H}, J=3.5,7.8 \mathrm{~Hz}), 7.07(\mathrm{t}, 2 \mathrm{H}, J=7.8 \mathrm{~Hz}), 4.51(\mathrm{t}, 2 \mathrm{H}$, $J=5.3 \mathrm{~Hz}), 3.91(\mathrm{t}, 3 \mathrm{H}, J=5.1 \mathrm{~Hz}), 3.60(\mathrm{t}, 6 \mathrm{H}, J=7.3 \mathrm{~Hz}), 3.5-3.6(\mathrm{~m}, 4 \mathrm{H}), 3.39(\mathrm{t}, 2 \mathrm{H}, J=5.3 \mathrm{~Hz}), 2.88$ (t, 4H, J=7.6 Hz), $2.80(\mathrm{t}, 2 \mathrm{H}, J=5.3 \mathrm{~Hz}), 1.21(\mathrm{~s}, 18 \mathrm{H})$

LCMS (2 min high pH): Rt $=1.27 \mathrm{~min},[\mathrm{MH}+]=764$

3-(2-((1E,3E,5Z)-5-(3-(6-((2-(2-(2-(5-)(3-(2-(tert-Butoxy)ethyl)phenyl)carbamoyl)-2-(4-((3-(2)tertbutoxy)ethyl)phenyl)carbamoyl)phenyl)-1H-benzo[d]imidazol-1yl)ethoxy)ethoxy)ethyl)amino)6oxohexyl)-3-methyl-5-sulfo-1-(3-sulfopropyl)indolin-2-ylidene)penta-1,3-dien-1-yl)-3,3-dimethyl5-sulfo-3H-indol-1-ium-1-yl)propane-1-sulfonate, 3 Ammonia salt

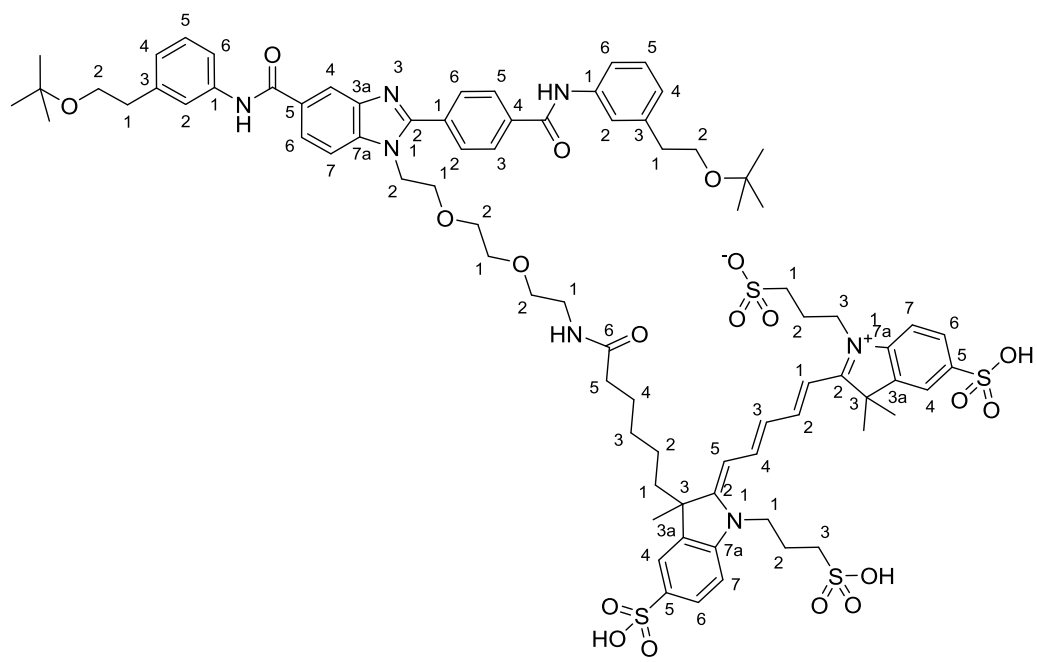

Alexa Fluor 647 carboxylic acid succinimidyl ester (5mg) (Invitrogen) on 15th July 2011; Lot 890799; cat\# A20106; mf not given; Exact Mass: not given; Molecular Weight: not given but cited as " 1250". 
bioRxiv preprint doi: https://doi.org/10.1101/2020.08.10.239475; this version posted August 20, 2020. The copyright holder for this preprint (which was not certified by peer review) is the author/funder, who has granted bioRxiv a license to display the preprint in perpetuity. It is made

265

266

267

268

269

270

271

272

273

274

275

276

277

278

279

280

281

282

283

284

285

286

287

288

289

290

291

292

293

294

295

296

297

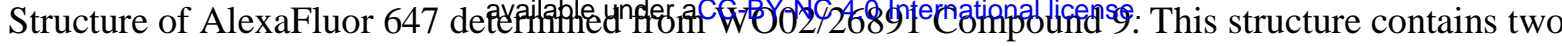

pendant propyl sulfonic acids contrary to some reports suggesting that the molecule contains butyl

sulfonic acids. Salt form from patent example of tris(triethylamine) has MWt. 1259.67 which

approximates to the vendor's citation of " 1250".

3-(2-((1E,3E,5Z)-5-(3-(6-((2,5-dioxopyrrolidin-1-yl)oxy)-6-oxohexyl)-3-methyl-5-sulfo-1-(3-

sulfopropyl)indolin-2-ylidene)penta-1,3-dien-1-yl)-3,3-dimethyl-5-sulfo-3H-indol-1-ium-1-

yl)propane-1-sulfonate, $3 \mathrm{~N}, \mathrm{~N}$-diethylethanamine salt $(5 \mathrm{mg}, 3.97 \mu \mathrm{mol})$ in anhydrous DMF $(200 \mu \mathrm{L})$

was added to 1-(2-(2-(2-aminoethoxy)ethoxy)ethyl)-N-(3-(2-(tert-butoxy)ethyl)phenyl)-2-(4-((3-(2-

(tert-butoxy)ethyl)phenyl)carbamoyl)phenyl)-1H-benzo[d]imidazole-5-carboxamide (5.4 mg, 7.07

$\mu \mathrm{mol})$. Diisopropylethylamine $(1.4 \mu \mathrm{L}, 8.02 \mu \mathrm{mol})$ was added and the resulting mixture stirred at

room temperature in a vial wrapped in foil for $16 \mathrm{hr}$. Acetonitrile was added to increase the sample

volume to $1 \mathrm{~mL}$. The sample was then purified by high $\mathrm{pH}$ MDAP to give 3-(2-((1E,3E,5Z)-5-(3-(6-

((2-(2-(2-(5-((3-(2-(tert-butoxy)ethyl)phenyl)carbamoyl)-2-(4-((3-(2-(tert-

butoxy)ethyl)phenyl)(arbamoyl)phenyl)-1H-benzo[d]imidazol-1-yl)ethoxy)ethoxy)ethyl)amino)-6-

oxohexyl)-3-methyl-5-sulfo-1-(3-sulfopropyl)indolin-2-ylidene)penta-1,3-dien-1-yl)-3,3-dimethyl-5-

sulfo-3H-indol-1-ium-1-yl)propane-1-sulfonate, 3 Ammonia salt (6.7 mg, $3.84 \mu \mathrm{mol}$, $97 \%$ yield), as a blue solid.

${ }^{1} \mathrm{H}$ NMR (METHANOL-d 4 , $\left.400 \mathrm{MHz}\right) \delta 8.2-8.5(\mathrm{~m}, 3 \mathrm{H}), 8.17$ (d, 2H, $\left.J=8.6 \mathrm{~Hz}\right), 8.0-8.1(\mathrm{~m}, 3 \mathrm{H})$, 7.9-7.9 (m, 3H), 7.8-7.9 (m, 2H), 7.6-7.7 (m, 4H), 7.43 (dd, 2H, J=8.3, 10.9 Hz), 7.31 (t, 2H, J=7.8

$\mathrm{Hz}), 7.07$ (dd, 2H, J=3.8, 7.3 Hz), 6.6-6.8 (m, 1H), 6.45 (br dd, 2H, J=5.3, $13.4 \mathrm{~Hz}), 4.57$ (t, 2H, $J=4.8 \mathrm{~Hz}), 4.3-4.4(\mathrm{~m}, 4 \mathrm{H}), 3.88(\mathrm{t}, 2 \mathrm{H}, J=5.1 \mathrm{~Hz}), 3.65(\mathrm{dt}, 6 \mathrm{H}, J=2.5,7.1 \mathrm{~Hz}), 3.42(\mathrm{br} \mathrm{d}, 6 \mathrm{H}, J=3.5$ $\mathrm{Hz}), 3.1-3.2(\mathrm{~m}, 2 \mathrm{H}), 2.9-3.1(\mathrm{~m}, 5 \mathrm{H}), 2.8-2.9(\mathrm{~m}, 5 \mathrm{H}), 2.2-2.3(\mathrm{~m}, 5 \mathrm{H}), 1.92(\mathrm{~s}, 2 \mathrm{H}), 1.73(\mathrm{~s}, 4 \mathrm{H})$, 1.70 (s, 7H), 1.4-1.5 (m, 2H), 1.17 (s, 18H), 1.1-1.2 (m, 1H), 0.83 (br d, 1H, J=3.0 Hz), 0.5-0.7 (m, $1 \mathrm{H})$

LCMS $(2 \min$ high $\mathrm{pH}): \mathrm{Rt}=0.88 \min ,[\mathrm{M}+2 \mathrm{H}] 2+=804$

\section{GSK675}

$N$-(3-(2-(tert-Butoxy)ethyl)phenyl)-4-chloro-3-nitrobenzamide<smiles>CC(C)(C)OCCc1cccc(NC(=O)c2ccc(Cl)c([N+](=O)[O-])c2)c1</smiles>

4-Chloro-3-nitrobenzoic acid (4194.8 mg, $20.81 \mathrm{mmol}$ ) was taken up into DCM (100 mL) in an icebath under nitrogen. Oxalyl dichloride $(5.45 \mathrm{~mL}, 62.4 \mathrm{mmol})$ was slowly added to the mixture 
bioRxiv preprint doi: https://doi.org/10.1101/2020.08.10.239475; this version posted August 20, 2020. The copyright holder for this preprint (which was not certified by peer review) is the author/funder, who has granted bioRxiv a license to display the preprint in perpetuity. It is made

298

299

300

301

302

303

304

305

306

307

308

309

310

311

312

313

314

315

316

317

318

319

320

321

322

323

324

325

326

327

328

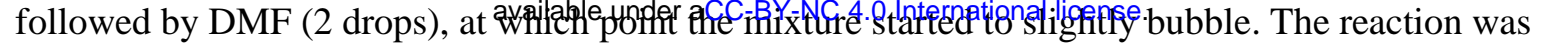

then allowed to stir at RT for $2.5 \mathrm{~h}$ then the volatiles removed in vacuo.

The crude acid chloride was taken up into DCM $(100 \mathrm{~mL})$ in an ice-bath under nitrogen. 3-(2-(tertbutoxy)ethyl)aniline (4023 mg, $20.81 \mathrm{mmol}$ ) was slowly added followed by pyridine (3.36 mL, 41.6 $\mathrm{mmol}$ ). The reaction was allowed to stir at $\mathrm{RT}$ for $2 \mathrm{~h}$, then evaporated in vacuo to give a brown thick oil. The crude was dissolved in DCM (40 mL) and washed with saturated aq sodium bicarbonate solution $(2 \times 40 \mathrm{~mL})$ then with hydrochloric acid $(1 \mathrm{M}$ aq, $40 \mathrm{~mL})$, dried with magnesium sulfate and filtered under vacuum. The solvent was evaporated under vacuum to give $N$-(3-(2-(tertbutoxy)ethyl)phenyl)-4-chloro-3-nitrobenzamide ( $8132.3 \mathrm{mg}, 20.50 \mathrm{mmol}, 99 \%$ yield) as a brown oil.

${ }^{1} \mathrm{H}$ NMR (DMSO-d $\left.6,400 \mathrm{MHz}\right) \delta 10.46$ (s, 1H), 8.64 (d, 1H, J=2.3 Hz), 8.27 (dd, 1H, $J=2.1,8.5 \mathrm{~Hz}$ ), $7.97(\mathrm{~d}, 1 \mathrm{H}, J=8.6 \mathrm{~Hz}), 7.6-7.7$ (m, 2H), 7.2-7.4 (m, 1H), 7.03 (d, 1H, J=7.6 Hz), 3.52 (t, 2H, J=7.1 $\mathrm{Hz}), 2.74(\mathrm{t}, 2 \mathrm{H}, J=7.1 \mathrm{~Hz}), 1.12(\mathrm{~s}, 9 \mathrm{H})$

LCMS (2 min Formic): Rt $=1.28 \mathrm{~min},[\mathrm{M}-\mathrm{H}]^{+}=375,377(1 \mathrm{Cl})$

\section{4-((2-((2-Aminoethyl)(methyl)amino)ethyl)amino)-N-(3-(2-(tert-butoxy)ethyl)phenyl)-3-} nitrobenzamide<smiles>CN(CCN)CCNc1ccc(C(=O)Nc2cccc(CCOC(C)(C)C)c2)cc1[N+](=O)[O-]</smiles>

N-(3-(2-(tert-Butoxy)ethyl)phenyl)-4-chloro-3-nitrobenzamide (1.03g, $2.73 \mathrm{mmol})$ and N1-(2aminoethyl)-N1-methylethane-1,2-diamine (0.480 g, $4.10 \mathrm{mmol})$ were stirred in DMF (10 mL) and triethylamine $(0.381 \mathrm{~mL}, 2.73 \mathrm{mmol})$ for $3 \mathrm{~h}$ at $50^{\circ} \mathrm{C}$, then the solution was cooled and diluted with water $(50 \mathrm{ml})$, extracted with EtOAc $(2 \times 50 \mathrm{~mL})$ and the organic layer washed with water $(2 \times 50$ $\mathrm{mL}$ ), dried and evaporated in vacuo. The residue was loaded onto a $50 \mathrm{~g}$ silica column and eluted with $0-20 \% 2 \mathrm{M}$ methanolic ammonia/DCM to give 4-((2-)((2aminoethyl)(methyl)amino)ethyl)amino)- $N$-(3-(2-(tert-butoxy)ethyl)phenyl)-3-nitrobenzamide $(0.85 \mathrm{~g}$, $1.858 \mathrm{mmol}, 68.0 \%$ yield) as a bright yellow gum

${ }^{1} \mathrm{H}$ NMR (CHLOROFORM-d, $\left.400 \mathrm{MHz}\right) \delta 8.7-8.8(\mathrm{~m}, 1 \mathrm{H}), 8.67$ (d, 1H, J=2.5 Hz), $8.52(\mathrm{~s}, 1 \mathrm{H}), 8.0-$ $8.1(\mathrm{~m}, 1 \mathrm{H}), 7.5-7.6(\mathrm{~m}, 2 \mathrm{H}), 7.2-7.3(\mathrm{~m}, 1 \mathrm{H}), 7.00(\mathrm{~d}, 1 \mathrm{H}, J=7.6 \mathrm{~Hz}), 6.85(\mathrm{~d}, 1 \mathrm{H}, J=9.1 \mathrm{~Hz}), 3.56(\mathrm{t}$, 
bioRxiv preprint doi: https://doi.org/10.1101/2020.08.10.239475; this version posted August 20, 2020. The copyright holder for this preprint (which was not certified by peer review) is the author/funder, who has granted bioRxiv a license to display the preprint in perpetuity. It is made

tert-Butyl (2-((2-((4-((3-(2-(tert-butoxy)ethyl)phenyl)carbamoyl)-2nitrophenyl)amino)ethyl)(methyl)amino)ethyl)carbamate<smiles>CN(CCNC(=O)OC(C)(C)C)CCNc1ccc(C(=O)Nc2cccc(CCOC(C)(C)C)c2)cc1[N+](=O)[O-]</smiles>

4-((2-((2-Aminoethyl)(methyl)amino)ethyl)amino)- $N$-(3-(2-(tert-butoxy)ethyl)phenyl)-3nitrobenzamide $(0.84 \mathrm{~g}, 1.836 \mathrm{mmol})$ and $\mathrm{Boc}_{2} \mathrm{O}(0.426 \mathrm{~mL}, 1.836 \mathrm{mmol})$ were dissolved in DCM $(20 \mathrm{~mL})$ and allowed to stand for $2 \mathrm{~h}$, then the solvent was evaporated in vacuo and the residue was purified by chromatography on a $50 \mathrm{~g}$ silica column eluting with $0-10 \% 2 \mathrm{M}$ methanolic ammonia/DCM to give tert-butyl (2-((2-((4-((3-(2-(tert-butoxy)ethyl)phenyl)carbamoyl)-2nitrophenyl)amino)ethyl)(methyl)amino)ethyl)carbamate $(0.85 \mathrm{~g}, 1.524 \mathrm{mmol}, 83 \%$ yield) as a bright yellow gum.

${ }^{1} \mathrm{H}$ NMR (CHLOROFORM-d, $\left.400 \mathrm{MHz}\right) \delta$ 8.7-8.9 (m, 1H), 8.69 (br s, 1H), 7.9-8.2 (m, 2H), 7.5-7.6 (m, 2H), 7.2-7.4 (m, 1H), 7.03 (d, 1H, J=7.6 Hz), 6.90 (d, 1H, J=9.1 Hz), 5.10 (br s, 1H), 3.58 (t, 2H, $J=7.3 \mathrm{~Hz}$ ), 3.40 (q, 2H, $J=5.6 \mathrm{~Hz}), 3.27$ (q, 2H, $J=5.6 \mathrm{~Hz}), 2.85$ (t, 2H, $J=7.6 \mathrm{~Hz}), 2.77$ (t, 2H, $J=5.8$ $\mathrm{Hz}), 2.58$ (t, 2H, J=5.8 Hz), 2.34 (s, 3H), 1.40 (s, 9H), 1.19 (s, 9H)

LCMS (2 min high $\mathrm{pH}): \mathrm{Rt}=1.41 \mathrm{~min},[\mathrm{MH}]^{+}=558$

1-(2-((2-Aminoethyl)(methyl)amino)ethyl)- $N$-(3-(2-(tert-butoxy)ethyl)phenyl)-2-(4-((3-(2-(tertbutoxy)ethyl)phenyl)carbamoyl)phenyl)-1H-benzo[d]imidazole-5-carboxamide

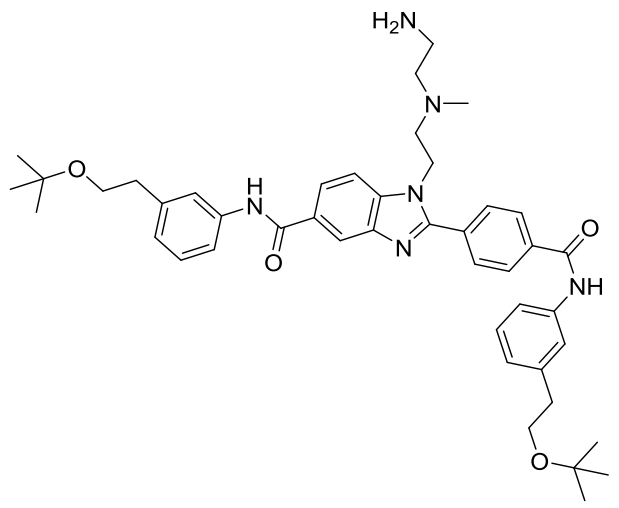


bioRxiv preprint doi: https://doi.org/10.1101/2020.08.10.239475; this version posted August 20, 2020. The copyright holder for this preprint (which was not certified by peer review) is the author/funder, who has granted bioRxiv a license to display the preprint in perpetuity. It is made

351

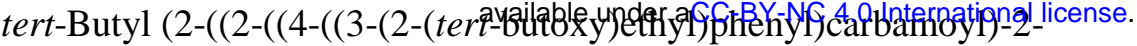

352

353

354

355

356

357

358

359

360

361

362

363

364

365

366

367

368

369

370

371

372

yellow gum. butoxy)ethyl)phenyl)-2-(4-((3-(2-(tert-butoxy)ethyl)phenyl)carbamoyl)phenyl)-1H-

benzo[ $d]$ imidazole-5-carboxamide (10mg, $0.014 \mathrm{mmol}, 3.62 \%$ yield) as a pale yellow gum. butoxy)ethyl)phenyl)-2-(4-((3-(2-(tert-butoxy)ethyl)phenyl)carbamoyl)phenyl)-1Hbenzo[d]imidazole-5-carboxamide ( $85 \mathrm{mg}, 0.116 \mathrm{mmol}, 30.8 \%$ yield) as a colorless foam. $2 \mathrm{H}, J=6.3 \mathrm{~Hz}), 2.4-2.5(\mathrm{~m}, 2 \mathrm{H}), 2.3-2.4(\mathrm{~m}, 2 \mathrm{H}), 2.09$ (s, 3H), $1.20(\mathrm{~s}, 18 \mathrm{H})$

LCMS (2 min high $\mathrm{pH}): \mathrm{Rt}=1.27 \mathrm{~min},[\mathrm{MH}]^{+}=733$ (methyl(2-(6-(5-((3aS,4S,6aR)-2-oxohexahydro-1H-thieno[3,4-d]imidazol-4-

yl)pentanamido)hexanamido)ethyl)amino)ethyl)-1H-benzo[d]imid

azole-5-carboxamide

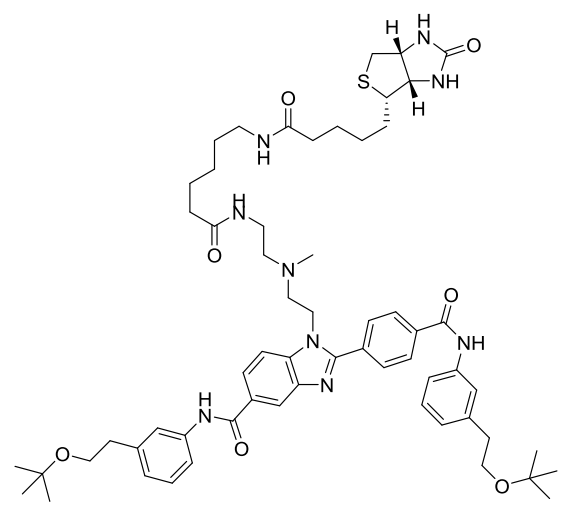

nitrophenyl)amino)ethyl)(methyl)amino)ethyl)carbamate $(0.21 \mathrm{~g}, 0.377 \mathrm{mmol})$ and $N$-(3-(2-(tert-

butoxy)ethyl)phenyl)-4-formylbenzamide $(0.123 \mathrm{~g}, 0.377 \mathrm{mmol})$ were dissolved in ethanol $(10 \mathrm{~mL})$,

then a solution of sodium dithionite $(0.197 \mathrm{~g}, 1.130 \mathrm{mmol})$ in water $(3 \mathrm{~mL})$ was added and the mixture

was heated at reflux for $3 \mathrm{~h}$. The solvent was evaporated in vacuo and the residue was partitioned

between EtOAc $(10 \mathrm{~mL})$ and water $(5 \mathrm{~mL})$, the organic layer dried and evaporated to give a pale

The crude product was dissolved in DCM ( $3 \mathrm{~mL})$ and $\mathrm{HCl}(1 \mathrm{M}$ in ether, $1 \mathrm{~mL}, 1.000 \mathrm{mmol})$ was added, the mixture stirred for $2 \mathrm{~h}$, then evaporated in vacuo. A sample $(20 \mathrm{mg})$ of the crude product was purified by high $\mathrm{pH}$ MDAP to give 1-(2-((2-aminoethyl)(methyl)amino)ethyl)-N-(3-(2-(tert-

The remaining crude amine was purified by chromatography on silica ( $25 \mathrm{~g}$ column) eluting with 0$20 \% 2 \mathrm{M}$ methanolic ammonia/DCM to give 1-(2-((2-aminoethyl)(methyl)amino)ethyl)-N-(3-(2-(tert-

${ }^{1} \mathrm{H}$ NMR (CHLOROFORM-d, $\left.400 \mathrm{MHz}\right) \delta 8.48(\mathrm{~s}, 1 \mathrm{H}), 8.27$ (s, 1H), $8.14(\mathrm{~s}, 1 \mathrm{H}), 8.03(\mathrm{~d}, 3 \mathrm{H}, \mathrm{J}=8.1$ Hz), 7.96 (dd, 1H, J=1.5, 8.6 Hz), 7.87 (d, 3H, J=8.6 Hz), 7.5-7.6 (m, 7H), 7.3-7.4 (m, 3H), 7.07 (t, $2 \mathrm{H}, J=8.8 \mathrm{~Hz}$ ), 4.40 (br t, 2H, J=6.6 Hz), 3.60 (dt, 5H, J=1.8, $7.5 \mathrm{~Hz}$ ), 2.87 (t, 5H, J=7.3 Hz), 2.71 (t,

$N$-(3-(2-(tert-Butoxy)ethyl)phenyl)-2-(4-((3-(2-(tert-butoxy)ethyl)phenyl)carbamoyl)phenyl)-1-(2- 
bioRxiv preprint doi: https://doi.org/10.1101/2020.08.10.239475; this version posted August 20, 2020. The copyright holder for this preprint (which was not certified by peer review) is the author/funder, who has granted bioRxiv a license to display the preprint in perpetuity. It is made

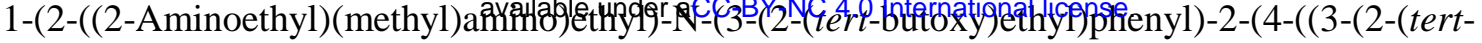
butoxy)ethyl)phenyl)carbamoyl)phenyl)-1H-benzo[d]imidazole-5-carboxamide (15 mg, $0.020 \mathrm{mmol}$ ) and 2,5-dioxopyrrolidin-1-yl 6-(5-((3aS,4S,6aR)-2-oxohexahydro-1H-thieno[3,4-d]imidazol-4yl)pentanamido)hexanoate $(9.30 \mathrm{mg}, 0.020 \mathrm{mmol})$ were dissolved in DMF $(0.9 \mathrm{~mL})$ and triethylamine $(8.56 \mu \mathrm{l}, 0.061 \mathrm{mmol})$ and the solution was allowed to stand overnight. LCMS (2 min high $\mathrm{pH})$ : Rt $=1.21 \mathrm{~min},[\mathrm{MH}]^{+}=1072$. The solution was purified by high $\mathrm{pH}$ MDAP to give $N-(3-(2-($ tert butoxy)ethyl)phenyl)-2-(4-((3-(2-(tert-butoxy)ethyl)phenyl)carbamoyl)phenyl)-1-(2-(methyl(2-(6-(5((3aS,4S,6aR)-2-oxohexahydro-1H-thieno[3,4-d]imidazol-4yl)pentanamido)hexanamido)ethyl)amino)ethyl)-1H-benzo[ $d]$ imidazole-5-carboxamide ( $8.5 \mathrm{mg}, 7.93$ $\mu \mathrm{mol}, 38.7 \%$ yield) as a colorless solid.

${ }^{1} \mathrm{H}$ NMR (METHANOL-d 4 , $\left.400 \mathrm{MHz}\right) \delta 8.39(\mathrm{~d}, 1 \mathrm{H}, J=1.5 \mathrm{~Hz}), 8.19(\mathrm{~d}, 2 \mathrm{H}, J=8.6 \mathrm{~Hz}), 8.04(\mathrm{dd}, 1 \mathrm{H}$, $J=1.5,8.6 \mathrm{~Hz}), 8.0-8.0(\mathrm{~m}, 2 \mathrm{H}), 7.83(\mathrm{~d}, 1 \mathrm{H}, J=8.6 \mathrm{~Hz}), 7.5-7.7(\mathrm{~m}, 4 \mathrm{H}), 7.32(\mathrm{dt}, 2 \mathrm{H}, J=3.0,7.8 \mathrm{~Hz})$, $7.08(\mathrm{t}, 2 \mathrm{H}, J=6.8 \mathrm{~Hz}), 4.54(\mathrm{t}, 2 \mathrm{H}, J=6.1 \mathrm{~Hz}), 4.47$ (dd, 1H, J=5.1, 8.1 Hz), 4.2-4.3 (m, 1H), 3.66 (t, $5 \mathrm{H}, J=7.3 \mathrm{~Hz}), 3.1-3.2(\mathrm{~m}, 1 \mathrm{H}), 3.00(\mathrm{t}, 2 \mathrm{H}, J=6.6 \mathrm{~Hz}), 2.8-2.9(\mathrm{~m}, 5 \mathrm{H}), 2.8-2.8(\mathrm{~m}, 2 \mathrm{H}), 2.6-2.7(\mathrm{~m}$, 1H), 2.37 (t, 2H, J=6.3 Hz), 2.17 (t, 2H, $J=7.3 \mathrm{~Hz}), 2.06(\mathrm{t}, 2 \mathrm{H}, J=7.6 \mathrm{~Hz}), 1.4-1.8(\mathrm{~m}, 11 \mathrm{H}), 1.3-1.3$ $(\mathrm{m}, 3 \mathrm{H}), 1.21(\mathrm{~s}, 18 \mathrm{H})$

LCMS (2 min high pH ): Rt = $1.04 \mathrm{~min}, \mathrm{M} / 2+\mathrm{H}$ observed 536

\section{GSK306}

$N$-(3-(2-(tert-Butoxy)ethyl)phenyl)-2-(4-((3-(2-(tert-butoxy)ethyl)phenyl)carbamoyl)phenyl)-1-(2(2-(2-(3',6'-dihydroxy-3-oxo-3H-spiro[isobenzofuran-1,9'-xanthen]-5ylcarboxamido)ethoxy)ethoxy)ethyl)-1H-benzo[ $d]$ imidazole-5-carboxamide

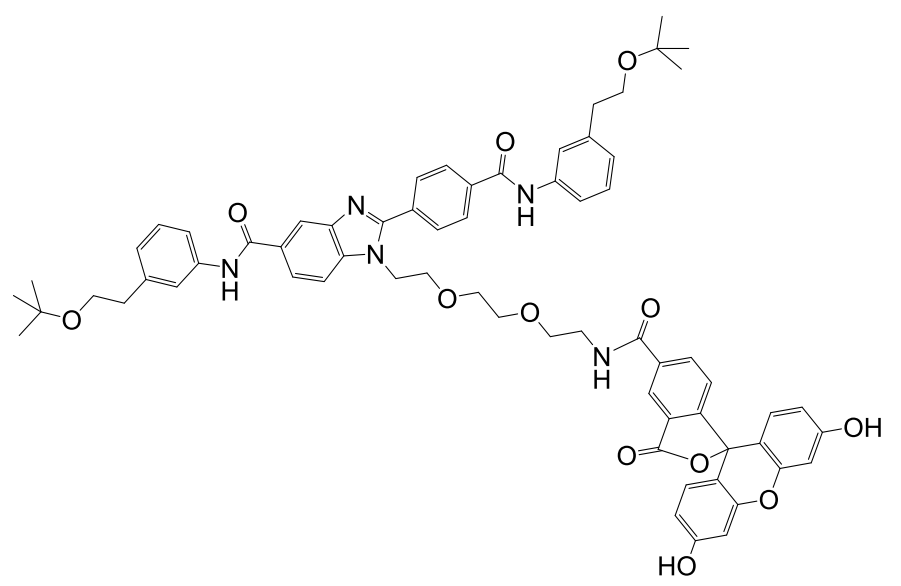

DMF $(0.4 \mathrm{~mL})$ and triethylamine $(4.42 \mu \mathrm{L}, 0.032 \mathrm{mmol})$ were added to 5-carboxyfluorescein $\mathrm{N}$ succinimidyl ester $(5.1 \mathrm{mg}, 10.77 \mu \mathrm{mol})$ and 1-(2-(2-(2-aminoethoxy)ethoxy)ethyl)-N-(3-(2-(tertbutoxy)ethyl)phenyl)-2-(4-((3-(2-(tert-butoxy)ethyl)phenyl)carbamoyl)phenyl)-1H- 
bioRxiv preprint doi: https://doi.org/10.1101/2020.08.10.239475; this version posted August 20, 2020. The copyright holder for this preprint (which was not certified by peer review) is the author/funder, who has granted bioRxiv a license to display the preprint in perpetuity. It is made

404

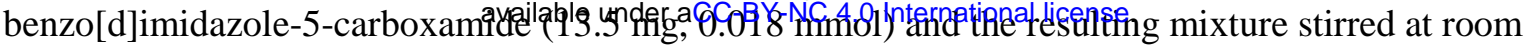

405 temperature in a vial wrapped in foil for $17.5 \mathrm{hr}$. The mixture was left to stand overnight, then diluted

406 with methanol to $1 \mathrm{~mL}$ and then the sample purified by MDAP (high $\mathrm{pH})$ to give $N$-(3-(2-(tert-

407 butoxy)ethyl)phenyl)-2-(4-((3-(2-(tert-butoxy)ethyl)phenyl)carbamoyl)phenyl)-1-(2-(2-(2-(3',6'-

408 dihydroxy-3-oxo-3H-spiro[isobenzofuran-1,9'-xanthen]-5-ylcarboxamido)ethoxy)ethoxy)ethyl)-1H-

409 benzo[ $[d]$ imidazole-5-carboxamide $(6.8 \mathrm{mg}, 5.76 \mu \mathrm{mol}, 53.4 \%$ yield $)$, as an orange solid.

$410{ }^{1} \mathrm{H}$ NMR (METHANOL-d $\left.4,400 \mathrm{MHz}\right) \delta 8.37(\mathrm{dd}, 2 \mathrm{H}, J=1.3,11.9 \mathrm{~Hz}), 8.1-8.2(\mathrm{~m}, 2 \mathrm{H}), 8.0-8.1(\mathrm{~m}$,

$4113 \mathrm{H}), 7.98(\mathrm{dd}, 1 \mathrm{H}, J=1.5,8.6 \mathrm{~Hz}), 7.80(\mathrm{~d}, 1 \mathrm{H}, J=8.6 \mathrm{~Hz}), 7.6-7.7(\mathrm{~m}, 2 \mathrm{H}), 7.58(\mathrm{br} \mathrm{d}, 2 \mathrm{H}, J=7.6 \mathrm{~Hz})$,

$4127.2-7.3(\mathrm{~m}, 2 \mathrm{H}), 7.21(\mathrm{~d}, 1 \mathrm{H}, J=8.1 \mathrm{~Hz}), 7.0-7.1(\mathrm{~m}, 2 \mathrm{H}), 6.6-6.8(\mathrm{~m}, 4 \mathrm{H}), 6.5-6.6(\mathrm{~m}, 2 \mathrm{H}), 4.57$ (br t,

$4132 \mathrm{H}, J=4.8 \mathrm{~Hz}), 3.94(\mathrm{br} \mathrm{t}, 2 \mathrm{H}, J=5.1 \mathrm{~Hz}), 3.63(\mathrm{dt}, 4 \mathrm{H}, J=2.0,7.1 \mathrm{~Hz}), 3.5-3.6(\mathrm{~m}, 8 \mathrm{H}), 2.81(\mathrm{br} \mathrm{t}, 4 \mathrm{H}$,

$414 J=6.6 \mathrm{~Hz}), 1.18(\mathrm{~m}, 18 \mathrm{H})(5$ exchangeable protons not seen).

415 LCMS (2 min high $\mathrm{pH}): \mathrm{Rt}=0.98 \mathrm{~min},[\mathrm{MH}+]=1122$ 